DOI: https://doi.org/10.36691/RJA1474

\title{
Атопический дерматит
}

А.А. Кубанов ${ }^{1}$, Л.С. Намазова-Баранова ${ }^{2,3}$, Р.М. Хаитов ${ }^{4}$ Н.И. Ильина ${ }^{4}$, Е.А. Алексеева ${ }^{2}$, Э.Т. Амбарчян ${ }^{2,5}$, С.И. Артемьева ${ }^{6}$, М.И. Аршинский ${ }^{7}$, Н.Г. Астафьева ${ }^{8}$, Е.А. Вишнева ${ }^{2}$, В.А. Волнухин ${ }^{6}$, И.В. Данилычева ${ }^{4}$, О.Г. Елисютина ${ }^{4}$, Р.В. Епишев ${ }^{2,5}$, А.В. Жестков ${ }^{9}$, М.Б. Жилова ${ }^{1}$, О.В. Жукова ${ }^{6}$, Д.В. Заславский ${ }^{10}$, Л.Ф. Знаменская ${ }^{1}$, А.Э. Карамова ${ }^{1}$, Н.Г. Короткий ${ }^{3}$, М.М. Кохан ${ }^{11}$, Л.С. Круглова ${ }^{12}$, Н.В. Кунгуров ${ }^{11}$, Ю.Г. Левина ${ }^{2}$, А.Н. Львов ${ }^{12,13}$, А.И. Материкин ${ }^{2,5}$, О.С. Мишина ${ }^{6}$, К.Н. Монахов ${ }^{14}$, Н.Н. Мурашкин ${ }^{2,5}$, Н.М. Ненашева ${ }^{15}$, А.Н. Пампура ${ }^{16}$, К.И. Плахова ${ }^{1}$, Н.Н. Потекаев ${ }^{6}$, О.А. Притуло ${ }^{17}$, К.И. Разнатовский ${ }^{18}$, С.Г. Сапунцова ${ }^{19}$, Л.Р. Селимзянова ${ }^{2}$, О.В. Скороходкина ${ }^{20}$, Е.С. Феденко ${ }^{4}$, Д.С. Фомина ${ }^{21,22}$, Н.В. Фриго ${ }^{6}$, 3.В. Фролова ${ }^{7}$, М.Р. Хаитов ${ }^{3,4}$, В.В. Чикин ${ }^{1}$

1 Государственный научный центр дерматовенерологии и косметологии, Москва, Российская Федерация

2 Научно-исследовательский институт педиатрии и охраны здоровья детей ЦКБ РАН, Москва, Российская Федерация

3 Российский национальный исследовательский медицинский университет имени Н.И. Пирогова, Москва, Российская Федерация

4 Государственный научный центр «Институт иммунологии» Федерального медико-биологического агентства, Москва, Российская Федерация

5 Национальный медицинский исследовательский центр здоровья детей, Москва, Российская Федерация

6 Московский научно-практический центр дерматовенерологии и косметологии, Москва, Российская Федерация

7 Краевой кожно-венерологический диспансер, Хабаровск, Российская Федерация

8 Саратовский государственный медицинский университет имени В.И. Разумовского, Саратов, Российская Федерация

9 Самарский государственный медицинский университет, Самара, Российская Федерация

${ }^{10}$ Санкт-Петербургский государственный педиатрический медицинский университет, Санкт-Петербург, Российская Федерация

11 Уральский научно-исследовательский институт дерматовенерологии и иммунопатологии, Екатеринбург, Российская Федерация

12 Центральная государственная медицинская академия Управления делами Президента Российской Федерации, Москва, Российская Федерация

${ }^{13}$ Медицинский научно-образовательный центр Московского государственного университета имени М.В. Ломоносова, Москва, Российская Федерация

${ }^{14}$ Первый Санкт-Петербургский государственный медицинский университет имени академика И.П. Павлова, Санкт-петербург, Российская Федерация

15 Российская медицинская академия непрерывного профессионального образования, Москва, Российская Федерация

${ }^{16}$ Научно-исследовательский клинический институт педиатрии имени академика Ю.Е. Вельтищева ФГАОУ ВО «Российский национальный исследовательский медицинский университет имени Н.И. Пирогова», Москва, Российская Федерация

${ }^{17}$ Медицинская академия имени С.И. Георгиевского ФГАОУ ВО «Крымский федеральный университет имени В.И. Вернадского», Симферополь, Российская Федерация

${ }^{18}$ Северо-Западный государственный медицинский университет имени И.И. Мечникова, Санкт Петербург, Российская Федерация

19 Дальневосточный государственный медицинский университет, Хабаровск, Российская Федерация

${ }^{20}$ Казанский государственный медицинский университет, Казань, Российская Федерация

${ }^{21}$ Городская больница № 52, Москва, Российская Федерация

22 Первый Московский государственный медицинский университет имени И.М. Сеченова (Сеченовский Университет), Москва, Российская Федерация

$44 \quad$ Copyright (C) 2020 Pharmarus Print Media License: CC BY-NC-ND https://creativecommons.org/licenses/by-nc-nd/4.0/
Российский аллергологический журнал. 2021. T. 18. № 3. С. 44-92 Russian Journal of Allergy 2021;18(3):44-92 
Клинические рекомендации разработаны экспертами Общероссийской общественной организации «Российское общество дерматовенерологов и косметологов», Общероссийской общественной организации «Российская ассоциация аллергологов и клинических иммунологов», Общероссийской общественной организации «Союз педиатров России» при участии Союза «Национальный альянс дерматовенерологов и косметологов».

Код по Международной статистической классификации болезней и проблем, связанных со здоровьем, L20 Атопический дерматит, L20.0 Почесуха Бенье, L20.8 Другие атопические дерматиты: экзема: сгибательная, детская (острая), (хроническая), эндогенная (аллергическая); нейродерматит: атопический (локализованный), (диффузный), L20.9 Атопический дерматит неуточнённый.

В июне 2021 года проект клинических рекомендаций был одобрен на заседании научно-практического совета Министерства здравоохранения Российской Федерации (протокол № 13/2-3-4 от 16.07.2021).

\section{АННОТАЦИЯ}

Атопический дерматит - одно из наиболее распространённых заболеваний (от 20 до $40 \%$ в структуре кожных заболеваний), встречающееся во всех странах у лиц обоего пола и в разных возрастных группах. Актуальность проблемы обусловлена ростом заболеваемости, хроническим рецидивирующим течением, нередко приводящим к снижению качества жизни и инвалидизации, низкой эффективностью традиционных методов лечения и ограничением доступности к современной эффективной таргетной терапии. Представленные клинические рекомендации, целью которых является оптимизация помощи больным атопическим дерматитом, содержат актуальную информацию об эпидемиологии, этиологических факторах, механизмах развития и патогенезе, особенностях клинической картины и течения заболевания, современных методах диагностики, включая аллергологические методы обследования, а также подходы к лечению, в том числе традиционные методы и современную таргетную терапию. Определены показания к аллергенспецифической иммунотерапии и описаны особенности её проведения. Изложен порядок оказания медицинской помощи, профилактики и диспансерного наблюдения. Клинические рекомендации по атопическому дерматиту предназначены для практикующих врачей всех специальностей, студентов, преподавателей медицинских вузов, ординаторов, аспирантов и научных работников.

Ключевые слова: атопический дерматит; эпидемиология; патогенез; клиническая картина; диагностика; терапия; наружная терапия; системная терапия; аллергенспецифическая иммунотерапия; биологическая терапия

Для цитирования: Кубанов А.А., Намазова-Баранова Л.С., Хаитов Р.М., Ильина Н.И., Алексеева Е.А., Амбарчян Э.Т., Артемьева С.И., Аршинский М.И., Астафьева Н.Г., Вишнева Е.А., Волнухин В.А., Данилычева И.В., Елисютина О.Г., Епишев Р.В., Жестков А.В., Жилова М.Б., Жукова О.В., Заславский Д.В., Знаменская Л.Ф., Карамова А.Э., Короткий Н.Г., Кохан М.М., Круглова Л.С., Кунгуров Н.В., Левина Ю.Г., Львов А.Н., Материкин А.И., Мишина О.С., Монахов К.Н., Мурашкин Н.Н., Ненашева Н.М., Пампура А.Н., Плахова К.И., Потекаев Н.Н., Притуло О.А., Разнатовский К.И., Сапунцова С.Г., Селимзянова Л.Р., Скороходкина О.В., Феденко Е.С., Фомина Д.С., Фриго Н.В., Фролова З.В., Хаитов М.Р., Чикин В.В. Атопический дерматит. Клинические рекомендации // Российский аллергологический журнал. 2021. Т. 18. № 3. С. 44-92. DOI: https://doi.org/10.36691/RJA1474

\section{Atopic dermatitis}

A.A. Kubanov' ${ }^{1}$ L.S. Namazova-Baranova ${ }^{2,3}$, R.M. Khaitov ${ }^{4}$, N.I. Ilina ${ }^{4}$, E.A. Alekseeva ${ }^{2}$, E.T. Ambarchian ${ }^{2,5}$, S.I. Artemieva ${ }^{6}$, M.I. Arshinskiy ${ }^{7}$, N.G. Astafieva ${ }^{8}$, E.A. Vishneva ${ }^{2}$, V.A. Volnukchin ${ }^{6}$, I.V. Danilicheva ${ }^{4}$, O.G. Elisutina ${ }^{4}$, R.V. Epishev ${ }^{2,5}$, A.V. Zhestkov', M.B. Zhilova ${ }^{1}$, O.V. Zhukova ${ }^{6}$, D.V. Zaslavsky ${ }^{1}$, L.F. Znamenskaya ${ }^{1}$, A.E. Karamova ${ }^{1}$, N.G. Korotky ${ }^{3}$, M.M. Kokchan ${ }^{11}$, L.S. Kruglova ${ }^{12}$, N.V. Kungurov ${ }^{11}$, J.G. Levina ${ }^{2}$, A.N. Lvov ${ }^{12,13}$, A.I. Materikin ${ }^{2,5}$, O.S. Mishina ${ }^{6}$, K.N. Monakhov ${ }^{14}$, N.N. Murashkin ${ }^{2,5}$, N.M. Nenasheva ${ }^{15}$, A.N. Pampura ${ }^{16}$, X.I. Plakhova ${ }^{1}$, N.N. Potekaev ${ }^{6}$, O.A. Prytulo ${ }^{17}$, K.I. Raznatovskiy ${ }^{18}$, S.G. Sapuntsova ${ }^{19}$, L.R. Selimzianova ${ }^{2}$, O.V. Skorokhodkina ${ }^{20}$, E.S. Fedenko ${ }^{4}$, D.S. Fomina ${ }^{21,22}$, N.V. Frigo ${ }^{6}$, Z.V. Frolova ${ }^{7}$, M.R. Khaitov ${ }^{3,4}$, V.V. Chikin ${ }^{1}$

${ }^{1}$ State Research Center of Dermatovenerology and Cosmetology, Moscow, Russian Federation

${ }^{2}$ Research Institute of Pediatrics and Children's Health of Central Clinical Hospital of the Russian Academy of Sciences, Moscow, Russian Federation

${ }^{3}$ Pirogov Russian National Research Medical University, Moscow, Russian Federation

${ }^{4}$ National Research Center - Institute of Immunology Federal Medical-Biological Agency of Russia, Moscow, Russian Federation 


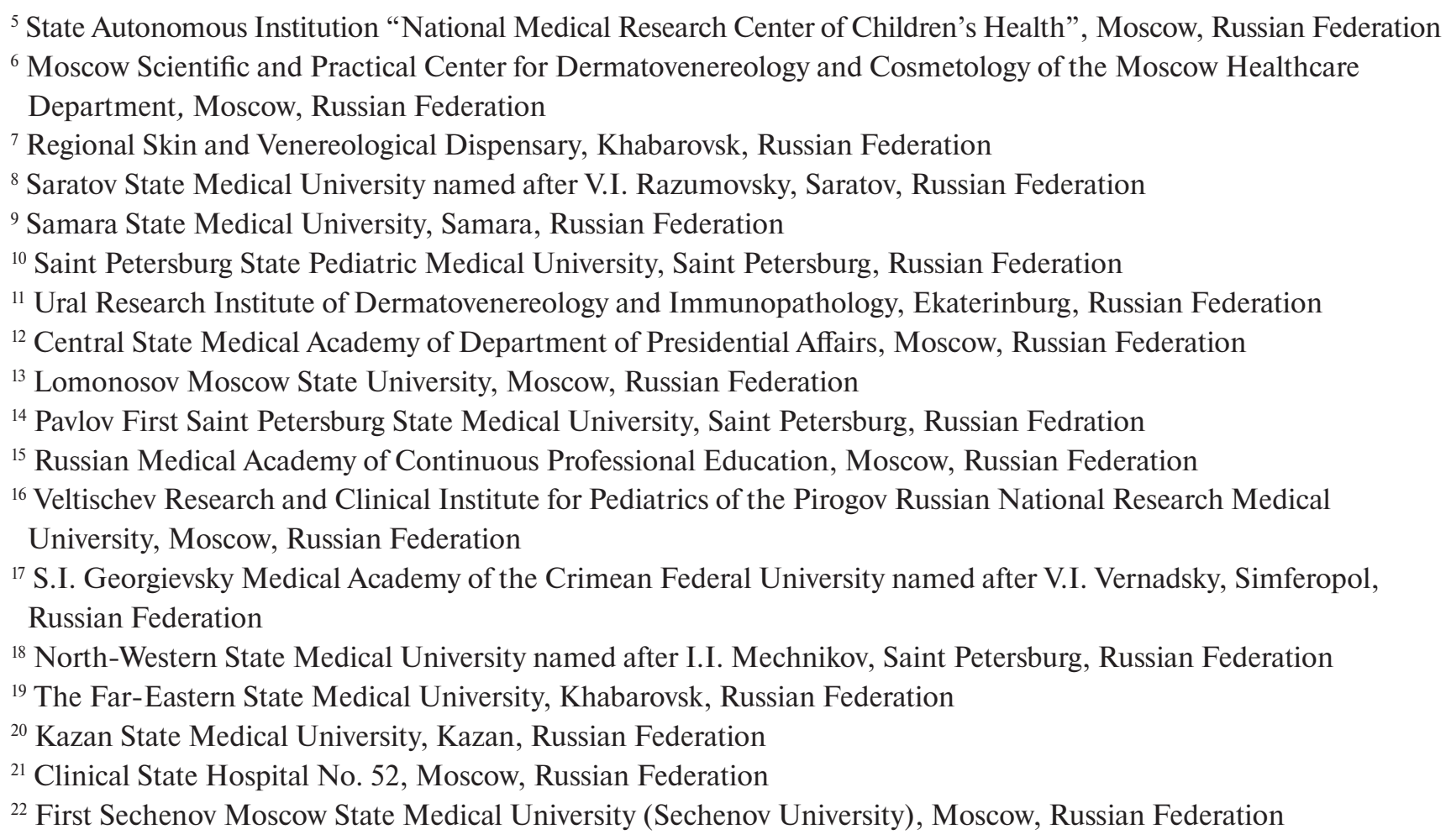

\section{ABSTRACT}

Atopic dermatitis is one of the most common diseases (20-40\% among skin diseases) that occur in both genders worldwide and in different age groups. The problem urgency is caused by an increase in morbidity, a chronic relapsing course that often leads to a decrease in the quality of life and disability, low efficiency of traditional treatment methods, and limited access to contemporary effective targeted therapy. The clinical guidelines, which aimed to optimize care for patients with atopic dermatitis, contain up-to-date information on epidemiology, etiological factors, mechanisms of development and pathogenesis, aspects of the clinical presentation and disease course, current diagnostic methods (including allergological examination methods), as well as approaches to treatment (including traditional methods and modern targeted therapy). The indications for allergen-specific immunotherapy are determined, and the aspects of its implementation are described. The procedure for the provision of medical care, prevention, and follow-up monitoring is outlined. Clinical practice guidelines for atopic dermatitis are intended for practitioners of all specialties, students, teachers of medical schools, residents, graduate students, and researchers.

Keywords: atopic dermatitis; epidemiology; pathogenesis; clinical presentation; diagnostics; therapy; external therapy; systemic therapy; allergen-specific immunotherapy; biological therapy

For citation: Kubanov AA, Namazova-Baranova LS, Khaitov RM, Ilina NI, Alekseeva EA, Ambarchian ET, Artemieva SI, Arshinskiy MI, Astafieva NG, Vishneva EA, Volnukchin VA, Danilicheva IV, Elisutina OG, Epishev RV, Zhestkov AV, Zhilova MB, Zhukova OV, Zaslavsky DV, Znamenskaya LF, Karamova AE, Korotky NG, Kokchan MM, Kruglova LS, Kungurov NV, Levina JG, Lvov AN, Materikin AI, Mishina OS, Monakhov KN, Murashkin NN, Nenasheva NM, Pampura AN, Plakhova XI, Potekaev NN, Prytulo OA, Raznatovskiy KI, Sapuntsova SG, Selimzianova LR, Skorokhodkina OV, Fedenko ES, Fomina DS, Frigo NV, Frolova ZV, Khaitov MR, Chikin VV. Atopic dermatitis. Russian Journal of Allergy. 2021;18(3):44-92. DOI: https://doi.org/10.36691/RJA1474 


\section{Список сокращений:}

ИЛ - интерлейкин

ИФН - интерферон

МКБ - Международная классификация болезней

ПУВА - разновидность фототерапии с облучени-

ем кожного покрова пациента ультрафиолетовым

излучением типа А

УФА-1 - ультрафиолетовая терапия дальнего длинноволнового диапазона
УФВ - узкополосная средневолновая ультрафиолетовая терапия

EASI (Eczema Area and Severity Index) - индекс распространённости и тяжести экземы IgE (immunoglobulin E) - иммуноглобулин E IGA (Investigator Global Assessment) - общая оценка тяжести дерматита исследователем

SCORAD (Scoring of Atopic Dermatitis) - оценка тяжести течения атопического дерматита

\section{Термины и определения}

Атопический дерматит - мультифакторное генетически детерминированное воспалительное заболевание кожи, характеризующееся зудом, хроническим рецидивирующим течением, возрастными особенностями локализации и морфологии очагов поражения.

\section{1. Краткая информация по заболеванию или состоянию (группы заболеваний или состояний)}

\section{1. Определение заболевания или состояния (группы заболеваний или состояний)}

Атопический дерматит - мультифакторное генетически детерминированное воспалительное заболевание кожи, характеризующееся зудом, хроническим рецидивирующим течением, возрастными особенностями локализации и морфологии очагов поражения.

\section{2. Этиология и патогенез заболевания или состояния (группы заболеваний или состояний)}

К генетическим факторам развития атопического дерматита относят наличие мутации гена филаггрина в нарушении функции эпидермального барьера при атопическом дерматите, а также семейный анамнез аллергических заболеваний [1].

С дефектами иммунной системы связано развитие воспалительной реакции в коже с участием Т-лимфоцитов. В острую фазу заболевания преобладает Th2-ответ, когда происходит стимуляция Th2-клеток с последующей гиперпродукцией IgE; в хроническую происходит переключение с Th2на Th1-иммунный ответ [2]. Ключевыми цитокинами, вовлечёнными в патофизиологические механизмы атопического дерматита, являются ИЛ-4, ИЛ-5, ИЛ-13, ИЛ-31 и ИФН- $\gamma$, которым для передачи сигнала требуется участие сигнальной системы JAK/STAT, в том числе Янус-киназы 1 (JAK-1) [3]. Во многих исследованиях описана патогенетическая роль ИЛ-4 в развитии аллергенспецифических $\mathrm{IgE-опосредованных} \mathrm{реакций} \mathrm{при} \mathrm{атопическом}$ дерматите, которая заключается в переключении синтеза антител на IgЕ. ИЛ-4 связывается не только с рецептором ИЛ-4, но и с рецептором ИЛ-13, данные цитокины имеют схожие биологические функции. ИЛ-13 также играет важную роль в развитии Th2-типа иммунного ответа при атопическом дерматите [4].

Доказана роль аллергии к клещам домашней пыли, энтеротоксинам золотистого стафилококка, плесневым грибам, а также IgE-аутореактивности в механизмах развития заболевания [5].

\section{3. Эпидемиология заболевания или состояния (группы заболеваний или состояний)}

Атопический дерматит - одно из наиболее распространённых заболеваний (от 20 до 40\% в структуре кожных заболеваний), встречающееся во всех странах, у лиц обоего пола и в разных возрастных группах. Распространённость атопического дерматита среди детского населения составляет до 20\%, среди взрослого населения - 2-8\% [6]. Согласно данным Федерального статистического наблюдения, в 2018 году в Российской Федерации заболеваемость атопическим дерматитом составила 188,2 случая на 100000 населения, а распространённость 426,3 случая на 100000 всего населения. Среди детей в возрасте от 0 до 14 лет заболеваемость атопическим дерматитом составила 774,4 случая на 100000 соответствующего населения, а распространённость 1589,4 случая на 100000 всего населения. Заболеваемость атопическим дерматитом среди детей в возрасте от 15 до 17 лет в Российской Федерации составила 374,1 случая на 100000 соответствующего населения, распространённость - 1134, 0 случая на 100000 соответствующего населения [7].

Атопический дерматит может быть ассоциирован с респираторной аллергией - аллергическим ринитом и бронхиальной астмой. Риск развития респираторной аллергии у пациентов, страдающих атопическим дерматитом, по разным данным, составляет 30-80\%; 60\% пациентов с атопическим дерматитом имеют латентную склонность к развитию бронхиальной астмы, а 30-40\% пациентов заболевают бронхиальной астмой $[8,9]$. По данным 
систематического обзора, у 29,5\% детей с атопическим дерматитом в возрасте 6 лет или старше диагностирована бронхиальная астма [10]. Поллиноз был выявлен у 48,4\% пациентов с атопическим дерматитом по сравнению с 24,4\% человек, не страдающих атопическим дерматитом; бронхиальная астма была диагностирована у 24,1\% пациентов с атопическим дерматитом по сравнению с 8,9\% человек, не страдающих атопическим дерматитом [11].

Риск развития аллергической реакции и бронхиальной астмы существенно выше у детей с пищевой аллергией и атопическим дерматитом; пищевая сенсибилизация, развившаяся в возрасте до 2 лет независимо от наличия сопутствующей сенсибилизации к ингаляционным аллергенам, была ассоциирована с развитием бронхиальной астмы к школьному возрасту, хотя сенсибилизация только к ингаляционным аллергенам в возрасте до 2 лет не влияла на риск развития бронхиальной астмы [12].

Согласно концепции «атопического марша», у пациентов с атопическим дерматитом и пищевой аллергией может произойти последовательное развитие других атопических заболеваний - аллергического ринита и бронхиальной астмы на протяжении жизни $[13,14]$. Взаимосвязь между этими заболеваниями тогда зависит от степени тяжести атопического дерматита: у $20 \%$ детей со среднетяжёлым течением и у $60 \%$ с тяжёлым течением могут присоединяться симптомы бронхиальной астмы и аллергического ринита [15]. Предполагается, что существует группа пациентов с атопическим дерматитом, у которых бронхиальная обструкция развивается также рано, как и поражение кожи, или даже предшествует ему, в связи с чем в данном случае нельзя говорить о развитии бронхиальной астмы как итога «атопического марша» [16, 17].

\section{4. Особенности кодирования заболевания или состояния (группы заболеваний или состояний) по Международной статической классификации болезней и проблем, связанных со здоровьем}

L20 Атопический дерматит.

L20.0 Почесуха Бенье.

L20.8 Другие атопические дерматиты: экзема: сгибательная, детская (острая), (хроническая), эндогенная (аллергическая), нейродерматит: атопический (локализованный), (диффузный).

L20.9 Атопический дерматит неуточнённый.

\section{5. Классификация заболевания или состояния (группы заболеваний или состояний)}

Общепринятой клинической классификации не существует.

\section{6. Клиническая картина заболевания или} состояния (группы заболеваний или состояний)

В большинстве случаев атопический дерматит начинается в раннем детском возрасте (до 2 лет).
Для заболевания характерны возрастные особенности клинических проявлений и хроническое рецидивирующее течение с периодическими обострениями и ремиссиями, которые могут продолжаться на протяжении нескольких лет. В анамнезе у пациента могут быть другие атопические заболевания (аллергический ринит, бронхиальная астма). Характерен семейный анамнез аллергических заболеваний (бронхиальная астма, аллергический ринит, атопический дерматит). Для заболевания характерна сезонность обострений с ухудшением состояния в холодное время года и улучшением летом. Обострение процесса может развиться также под влиянием ряда провоцирующих факторов (аллергены, раздражающие вещества, пищевые продукты, эмоциональный стресс и т.д.). При повышенном потоотделении может увеличиться интенсивность зуда.

Клинические проявления атопического дерматита отличаются в разные возрастные периоды. Основные различия заключаются в локализации очагов поражения и соотношении экссудативных и лихеноидных компонентов высыпаний.

Младенческий период атопического дерматита обычно начинается с 2-3 месяцев жизни ребёнка. В этот период преобладает экссудативная форма заболевания, при которой воспаление носит острый или подострый характер. Отмечаются симметричные эритематозные, папуло-везикулёзные высыпания на коже лица и волосистой части головы, экссудация с образованием чешуйко-корок. В дальнейшем высыпания распространяются на кожу наружной поверхности голеней, предплечий, туловища и ягодиц, а также могут появляться в естественных складках кожи. Дермографизм обычно красный или смешанный. Субъективно отмечается зуд кожных покровов различной интенсивности. К концу этого периода очаги сохраняются преимущественно в локтевых и подколенных сгибах, а также в области запястий и шеи. Обострения заболевания в значительной степени связаны с алиментарными факторами. Младенческий период атопического дерматита обычно заканчивается ко второму году жизни ребёнка клиническим выздоровлением (у 60\% пациентов) или переходит в следующий период (детский).

Детский период атопического дерматита характеризуется высыпаниями, которые носят менее экссудативный характер, чем в младенческом периоде, и представлены воспалительными милиарными и/или лентикулярными папулами, папуло-везикулами и эритематозно-сквамозными элементами, локализующимися на коже верхних и нижних конечностей, в области запястий, предплечий, локтевых и подколенных сгибов, голеностопных суставов и стоп. Характерно наличие зудящих узелков, эрозий и экскориаций, а также незначительная эритема и инфильтрация в области высыпаний на коже 
туловища, верхних и нижних конечностей, реже на коже лица. Дермографизм становится розовым, белым или смешанным. Появляются пигментация век, дисхромии, нередко - ангулярный хейлит.

Подростковый и взрослый период атопического дерматита характеризуется высыпаниями преимущественно на сгибательной поверхности конечностей (в области локтевых и коленных сгибов, сгибательных поверхностей голеностопных и лучезапястных суставов), на задней поверхности шеи, в заушных областях. Высыпания представлены эритемой, папулами, шелушением, инфильтрацией, лихенификацией, множественными экскориациями и трещинами. В местах разрешения высыпаний в очагах поражения остаются участки гипо- или гиперпигментации. Со временем у большинства пациентов кожа очищается от высыпаний, поражёнными остаются лишь подколенные и локтевые сгибы.

Возможны гиперлинеарность ладоней и подошв, фолликулярный гиперкератоз («роговые» папулы на боковых поверхностях плеч, предплечий, локтей), хейлит, экзема сосков, складки на передней поверхности шеи. Наблюдается гиперпигментация кожи периорбитальной области, появление складки под нижним веком (линии Денни-Моргана). Отмечается повышенная сухость кожи. Дермографизм белый стойкий или смешанный. Зуд выраженный, постоянный, реже - приступообразный. Нередко у подростков и взрослых преобладает лихеноидная форма заболевания, которая характеризуется сухостью, выраженным рисунком, отечностью и инфильтрацией кожных покровов, крупными, сливающимися очагами лихенизации кожи и упорным стойким зудом. Относительно редко наблюдается пруригинозная форма заболевания, для которой характерны высыпания в виде множественных изолированных плотных отечных папул, на вершине которых могут появляться мелкие пузырьки. Очаги поражения могут иметь распространенный характер с преимущественной локализацией на коже конечностей.

Наиболее тяжёлым проявлением атопического дерматита является эритродермия, которая характеризуется универсальным поражением кожных покровов в виде эритемы, инфильтрации, лихенификации, шелушения и сопровождается симптомами интоксикации и нарушением терморегуляции (гипертермия, озноб, лимфоаденопатия).

При лабораторном обследовании пациентов с атопическим дерматитом могут быть выявлены эозинофилия периферической крови, повышение содержания общего и аллергенспецифических IgE в сыворотке крови.

Стадии болезни. Стадия обострения или выраженных клинических проявлений характеризуется наличием эритемы, папул, микровезикул, мокнутия, множественных экскориаций, корок, шелушения; зуда разной степени интенсивности.

\section{Стадии ремиссии:}

- при неполной ремиссии отмечается значительное уменьшение симптомов заболевания с сохранением инфильтрации, лихенификации, сухости и шелушения кожи, гипер- или гипопигментации в очагах поражения;

- полная ремиссия характеризуется отсутствием всех клинических симптомов заболевания [18].

Распространённость кожного процесса. При ограниченно-локализованном процессе площадь поражения не превышает 10\% кожного покрова.

При распространённом процессе площадь поражения составляет от 10 до 50\% кожного покрова.

При диффузном процессе площадь поражения составляет более $50 \%$ кожного покрова.

Степень тяжести атопического дерматита. Лёгкое течение заболевания характеризуется преимущественно ограниченно-локализованными проявлениями кожного процесса, незначительным кожным зудом, редкими обострениями (реже 1-2 раз в год), продолжительностью рецидива до 1 месяца, преимущественно в холодное время года. Длительность ремиссии составляет 8-10 месяцев и более. Отмечается хороший эффект от проводимой терапии.

При среднетяжёлом течении отмечается распространённый характер поражения. Частота обострений - 3-4 раза в год с увеличением их продолжительности. Длительность ремиссий составляет 2-3 месяца. Процесс приобретает упорное течение с незначительным эффектом от проводимой терапии.

При тяжёлом течении заболевания кожный процесс носит распространённый или диффузный характер с длительными обострениями, редкими и непродолжительными ремиссиями (частота обострений - 5 раз в год и более, длительность ремиссии $1-1,5$ месяца). Лечение приносит кратковременное и незначительное улучшение. Отмечается выраженный зуд, приводящий к нарушению сна [18].

Осложнённые формы атопического дерматита. Течение атопического дерматита часто осложняется присоединением вторичной инфекции (бактериальной, микотической или вирусной). Эта особенность, свойственная пациентам с атопическим дерматитом, отражает нарушение противоинфекционной защиты, обусловленное нарушением синтеза антимикробных пептидов и эпидермального барьера.

1. Наиболее частое инфекционное осложнение атопического дерматита - присоединение вторичной бактериальной инфекции. Оно протекает в виде стрепто- и/или стафилодермии с характерными кожными проявлениями на фоне обострения атопического дерматита. Пиококковые осложнения проявляются в виде различных форм пиодермии - остиофолликулитов, фолликулитов, вуль- 
гарного, реже стрептококкового импетиго, иногда фурункулов.

2. Разнообразная микотическая инфекция (дерматофиты, дрожжеподобные, плесневые и другие виды грибов) также часто осложняет течение атопического дерматита, приводит к более продолжительным обострениям, отсутствию улучшения или к ухудшению состояния. Заболевание приобретает персистирующий характер. Наличие микотической инфекции может изменить клиническую картину атопического дерматита: появляются очаги с чёткими фестончатыми, несколько приподнятыми краями, часто рецидивируют заеды (хейлит), отмечаются поражения заушных, паховых складок, ногтевого ложа, гениталий.

3. Пациенты с атопическим дерматитом, независимо от остроты процесса, склонны к поражению вирусной инфекцией (чаще вирусом простого герпеса, вирусом папилломы человека, вирусом контагиозного моллюска). Герпетическая суперинфекция может привести к редкому, но тяжёлому осложнению - герпетической экземе Капоши. Заболевание характеризуется распространёнными пузырьковыми высыпаниями, сильным зудом, повышением температуры, быстрым присоединением пиококковой инфекции. Возможно поражение центральной нервной системы, глаз, развитие сепсиса.

4. Доброкачественная лимфаденопатия, как правило, связана с обострениями атопического дерматита и проявляется увеличением лимфатических узлов в шейной, подмышечной, паховой и бедренной областях. Величина узлов может варьировать, они подвижны, эластичной консистенции, безболезненны. Доброкачественная лимфаденопатия проходит самостоятельно при улучшении состояния либо на фоне проводимого лечения. Сохраняющееся, несмотря на уменьшение активности заболевания, выраженное увеличение лимфатических узлов требует проведения диагностической биопсии для исключения лимфопролиферативного заболевания.

5. Осложнения атопического дерматита со стороны глаз проявляются в виде рецидивирующих кератоконъюнктивитов, сопровождающихся зудом. В тяжёлых случаях хронический конъюнктивит может прогрессировать в эктропион и вызывать постоянное слезотечение. Возможно формирование ранней катаракты, как правило, связанное с частым использованием топических стероидов в периорбитальной зоне.

\section{2. Диагностика заболевания или состояния (группы заболеваний или состояний); медицинские показания и противопоказания к применению методов диагностики}

Рекомендуется для диагностики атопического дерматита пациентам всем возрастных групп ис- пользовать диагностические критерии J.M. Hanifin и G. Rajka [19].

Уровень убедительности рекомендаций С (уровень достоверности доказательств 5).

Комментарий. Для постановки диагноза атопического дерматита необходимо сочетание трёх основных и не менее трёх дополнительных критериев.

Выделяют основные и дополнительные диагностические критерии J.M. Hanifin и G. Rajka.

Основные диагностические критерии (3 или более):

- кожный зуд;

- типичная морфология и локализация поражения кожи: у детей первых лет жсизни - покраснение и высыпания на лице и разгибательных поверхностях конечностей, у детей более старшего возраста и взрослых лии - лихенификация и расчёсы в области сгибов конечностей;

- хроническое рецидивирующее течение;

- наличие атопических заболеваний у пациента или его родственников.

Дополнительные диагностические критерии (3 или более):

- сухость кожи (ксероз);

- гиперлинеарность ладоней («складчатые») и подошв или фолликулярный гиперкератоз;

- повышение содержания общего и специфических IgE в сыворотке крови;

- начало заболевания в раннем детском возрасте (до 2 лет);

- склонность к кожным инфекциям (S. aureus, H. simplex);

- локализация кожного процесса на кистях и стопах,

- экзема сосков;

- хейлит;

- рецидивирующие конбюнктивиты;

- симптом Денни-Моргана (дополнительная складка нижнего века);

- кератоконус,

- передняя субкапсулярная катаракта;

- гиперпигментация кожи периорбитальной области;

- бледность/эритема лииа;

- себорейная экзема;

- складки на передней поверхности шеи;

- зуд при повышенном потоотделении;

- обострение процесса и усиление зуда под влиянием провоцирующих факторов (шерстяная одежда, мыло, аллергены, ирританты, пищевые продукты, эмоциональный стресс и т.д.);

- перифолликулярная акцентуация;

- непереносимость пищи;

- сезонность обострений (ухудшение в холодное время года и улучшение летом);

- бельй дермографизм.

Дифференциальный диагноз атопического дерматита проводят с Т-клеточной лимфомой кожи, хронической экземой, аллергическим и ир- 
ритантным контактным дерматитом, себорейным дерматитом, нуммулярной экземой, чесоткой, псориазом, ихтиозом, питириазом красным волосяным отрубевидным, дерматофитией, иммунодефицитными состояниями (X-сцепленный синдром Вискотта-Олдрича, синдром гипериммуноглобулинемии Е) и др.

У детей атопический дерматит следует дифференцировать со всеми вышеперечисленными заболеваниями, а также с пелёночным дерматитом.

\section{1. Жалобы и анамнез}

Зуд является постоянным симптомом заболевания во всех возрастных периодах [20]. Зуд, по J.M. Hanifin и G. Rajka, относится к основным диагностическим критериями атопического дерматита.

Рекомендуется оценивать характер течения заболевания; сроки начала заболевания; наличие атопических заболеваний как у пациента, так и его родственников; сезонность обострений; факторы, провоцирующие обострения дерматита, а также обращать внимание на склонность пациента к развитию бактериальных, вирусных и грибковых инфекций кожи [20].

Уровень убедительности рекомендаций С (уровень достоверности доказательств 5).

Комментарий. Оценивается соответствие данных анамнеза основным и дополнительным диагностическим критериям атопического дерматита no J.M. Hanifin u G. Rajka.

\section{2. Физикальное обследование}

Для постановки диагноза основным является проведение визуального осмотра кожных покровов пациента. (Проявления заболевания подробно описаны в разделе «Клиническая картина»).

\section{3. Лабораторные диагностические исследования}

Рекомендуется всем пациентам общий (клинический) анализ крови развёрнутый для диагностики заболеваний и состояний, являющихся противопоказаниями к проведению системной терапии атопического дерматита и для контроля безопасности проводимой системной терапии циклоспорином**1 [21].

Уровень убедительности рекомендаций С (уровень достоверности доказательств 5).

Комментарий. Контроль показателей общего (клинического) анализа крови необходим во время терапии ииклоспорином**, так как ииклоспорин** может вызвать развитие нежелательных явлений - лейкопении, анемии, тромбоцитопении [21].

Рекомендуется анализ крови биохимический общетерапевтический пациентам для диагностики заболеваний и состояний, являющихся противо-

\footnotetext{
** Препараты для медицинского применения, внесённые в перечень жизненно необходимых и важнейших лекарственных препаратов для медицинского применения.
}

показанием к проведению системной терапии атопического дерматита и для контроля безопасности проводимой системной терапии циклоспорином** [21].

Уровень убедительности рекомендаций С (уровень достоверности доказательств 5).

Комментарий. Контроль показателей анализа крови биохимического общетерапевтического необходим во время терапии циклоспорином **, так как циклоспорин $^{* *}$ может вызвать развитие нежелательных явлений - увеличение концентрации креатинина и мочевины в плазме крови, гиперлипидемию, гиперурикемию, гиперкалиемию, гипомагниемию, гипергликемию. Циклоспорин** может также вызывать дозозависимое обратимое увеличение концентрации билирубина в плазме крови и активности ферментов печени. Возможно гепатотоксическое действие циклоспорина** с развитием холестаза, желтухи, гепатита и печёночной недостаточности [21].

Рекомендуется общий (клинический) анализ мочи пациентам для диагностики заболеваний и состояний, являющихся противопоказаниями к проведению системной терапии атопического дерматита и для контроля безопасности проводимой системной терапии циклоспорином** [21].

Уровень убедительности рекомендаций С (уровень достоверности доказательств 5).

Комментарий. Контроль показателей общего (клинического) анализа мочи необходим во время терапии циклоспорином **, так как ииклоспорин ** может вызвать токсическое поражение почек, и, кроме того, обладая иммуносупрессивным действием, он может способствовать развитию инфекционных поражений почек и мочевыводящих путей [21].

Рекомендуется пациентам в случае отсутствия достаточного для установления диагноза атопического дерматита числа диагностических критериев исследование уровня общего иммуноглобулина Е в крови [20].

Уровень убедительности рекомендаций С (уровень достоверности доказательств 5).

Комментарий. Повышение содержсания общего $\operatorname{IgE}$ в сыворотке крови является дополнительным диагностическим критерием атопического дерматита [20] и коррелирует с тяжестью заболевания.

\section{4. Инструментальные диагностические исследования}

Не применяются.

\section{5. Иные диагностические исследования}

Рекомендуется патологоанатомическое исследование биопсийного (операционного) материала кожи для дифференциальной диагностики в случае наличия у пациента клинических признаков общих с другими заболеваниями кожи [23].

Уровень убедительности рекомендаций С (уровень достоверности доказательств 5). 
Комментарий. В случае диагностики атопического дерматита у взрослых пациентов проводится дифференциальная диагностика с Т-клеточными лимфомами кожи или другими дерматозами. При атопическом дерматите наблюдается различной степени выраженности акантоз с удлинением эпидермальных выростов и их разветвлением. Могут обнаруживаться участки паракератоза, экзоцитоз. В дерме обнаруживается периваскулярный или сливающийся лимфогистиоцитарный инфильтрат; при хроническом течении инфильтрация незначительная, преобладает фиброз.

Рекомендуется проведение аллергологического обследования пациентам с атопическим дерматитом с семейным и/или личным анамнезом аллергических заболеваний - пищевой аллергии, аллергического ринита, бронхиальной астмы, а также с указанием на обострение заболевания при контакте с аллергенами [245-251, 258-260].

Уровень убедительности рекомендаций С (уровень достоверности доказательств 5).

Комментарий. Проведение аллергологического обследования необходимо для подтверждения аллергической природы атопического дерматита, выявления причинно-значимых аллергенов с целью выработки рекомендаций по образужизни, питанию и определения целесообразности проведения аллергенспецифической иммунотерапии. Аллергологическое обследование может проводиться методом кожного тестирования с небактериальными аллергенами (накожные исследования реакции на аллергены; определение уровня аллергенспецифических IgE-антител в сыворотке крови, проведение провокационных тестов). Выбор метода аллергологического обследования определяется достуиностью и оснащённостью аллергологического кабинета и наличием/отсутствием противопоказаний к проведению кожного тестирования (обострение заболевания, необходимость приёма антигистаминных препаратов).

Рекомендуется проведение накожных исследований реакции на аллергены с бытовыми, пыльцевыми, эпидермальными, грибковыми и пищевыми аллергенами для диагностики [22, 253, 255-257].

Уровень убедительности рекомендаций А (уровень достоверности доказательств 2).

Комментарий. Объём обследования определяет врач аллерголог-иммунолог. Кожные пробы проводят в условиях аллергологического кабинета специально обученная медицинская сестра и врач аллергологиммунолог. Наиболее часто применяют prick-тесты (тесты уколом) или скарификационные тесты. Pезультаты тестирования с аллергенами соотносят с результатами отрицательного и положительного тест-контроля.

Рекомендуется пациентам с атопическим дерматитом при наличии противопоказаний или иных причин, препятствующих проведению кожного тестирования, при сомнительных результатах кож- ного тестирования, расхождении данных, полученных при сборе анамнеза, с результатами кожного тестирования исследование уровня аллергенспецифических IgE-антител к пыльцевым, бытовым, эпидермальным, грибковым и пищевым аллергенам [245-250].

Уровень убедительности рекомендаций С (уровень достоверности доказательств 5).

Комментарий. Определение уровня аллергенспецифических IgE-антител в сыворотке особенно важно при неубедительных результатах кожных проб либо при невозможности их постановки (например, в период обострения аллергического заболевания или наличии иных противопоказаний). На достоверность результата влияет используемая тест-система, которая может иметь невысокие чувствительность и специфичность, что в свою очередь отражается как в ложноположительном, так и в ложноотрицательном результате. Компонентная (молекулярная) диагностика используется для картирования аллергенной сенсибилизации пациента на молекулярном уровне с применением очищенных натуральных или рекомбинантных аллергенных молекул вместо экстрактов аллергенов. Этот метод может быть использован при расхождении данных анамнеза, результатов накожных исследований реакций на аллергены и результатов определения специфических IgE-антител к экстрактам аллергенов, а также при наличии указаний на пищевую анафилаксию, перекрёстную пищевую аллергию и при неэффективности аллергенспецифической иммунотерапии.

Рекомендуется при необходимости дополнительной количественной оценки степени тяжести атопического дерматита определять обшую оценку заболевания исследователем (IGA) (Приложение Г1) [24].

Уровень убедительности рекомендаций А (уровень достоверности доказательств 2).

Рекомендуется при необходимости дополнительной количественной оценки степени тяжести атопического дерматита использовать индекс SCORAD (Приложение Г2) [6, 25, 26].

Уровень убедительности рекомендаций В (уровень достоверности доказательств 3).

Комментарий. SCORAD является интегральным показателем, включающим балльную оценку шести объективных симптомов (эритема, отёк/папулёзные элементы, корки/мокнутие, экскориации, лихенификация/шелушение, сухость кожи) и двух субъективных показателей (интенсивность зуда и выраженность нарушений сна).

\section{3. Лечение, включая медикаментозную} и немедикаментозную терапию, диетотерапию, обезболивание, медицинские показания и противопоказания к применению методов лечения 


\section{1. Консервативное лечение}

Рекомендуются всем пациентам с атопическим дерматитом, независимо от степени тяжести, увлажняющие и смягчающие средства (эмоленты) наружно [27-37].

Уровень убедительности рекомендаций В (уровень достоверности доказательств 2).

Комментарий. Эмоленты могут использоваться в форме лосьонов, кремов, мазей, моющих средств, средств для ванн. Выбор препарата и его формы осуществляется индивидуально с учётом предпочтений пациента, индивидуальных особенностей кожи, сезона, климатических условий.

Пациентам с атопическим дерматитом необходимо постоянно, часто и в больших количествах использовать увлажсняющие и смягчающие средства (не менее 3-4 раз в день) как самостоятельно, так и после водных процедур [38-40]. Однако есть указания, что нанесение эмолентов без принятия ванны имеет более продолжительное действие [40].

Наиболее выраженный эффект увлажняющих и смягчающих препаратов наблюдается при их постоянном использовании в виде крема, мази, масла для ванны и заменителей мыла. Выбор препарата и его формы осуществляется индивидуально с учётом предпочтений пациента, индивидуальных особенностей кожи, сезона, времени года, климата. Они не должны иметь запаха, ивета и содержать консерванты. Средства на мазевой основе (более жирные) можно использовать в холодное время года, а летом следует применять кремы и гели с высоким содержанием воды. Лосьоны отличаются более высоким содержанием воды, которая может испаряться, поэтому их не следует применять у пациентов с выраженным ксерозом.

Для достижения клинического эффекта необходимо использовать достаточный объём смягчающих препаратов (у взрослого с распространённым поражением кожи расходуется до 600 граммов в неделю, у ребенка - до 250 граммов в неделю) [28].

\section{Наружная терапия}

Пациентам при атопическом дерматите лёгкой, средней и тяжёлой степени тяжести рекомендуется наружная терапия глюкокортикоидами, применяемыми в дерматологии, препаратами для лечения дерматита, кроме глюкокортикоидов [41, 42].

Уровень убедительности рекомендаций С (уровень достоверности доказательств 4).

Комментарий. При лёгком течении атопического дерматита предпочтительно применение низкои умеренно активных глюкокортикоидов, применяемых в дерматологии, а при среднетяжёлом и тяяёлом течении атопического дерматита иелесообразно применение активных и высокоактивных глюкокортикоидов, применяемых в дерматологии, в минимальных эффективных дозах (Приложсение ГЗ). Для быстрого лечения обострения атопического дерматита воз- можно использование средств для наружной терапии и эмолентов с применением влажных повязок. Сначала на поражённые участки кожи наносят наружные средства (глюкокортикоиды, применяемые в дерматологии и/или эмоленты), затем накладывают влажную хлопчатобумажную или марлевую салфетку, а затем сухую наружную повязку [43-45]. Следует соблюдать осторожнность при использовании глюкокортикоидов средней и высокой силы действия, применяемых в дерматологии, с использованием влажных повязок в связи с риском угнетения функции надпочечников [45, 46].

Рекомендуются для наружной терапии пациентов с атопическим дерматитом глюкокортикоиды, применяемые в дерматологии:

- клобетазол $0,05 \%$ крем для наружного применения, 0,05\% мазь для наружного применения (наносить тонким слоем на поражённые участки кожи 1-2 раза в сутки в течение $3-4$ недель) [47-51].

Уровень убедительности рекомендаций В (уровень достоверности доказательств 2).

Комментарий. Противопоказанием к назначению препарата клобетазол является детский возраст до 12 лет;

- или бетаметазон ${ }^{* *} 0,05 \%$ мазь для наружного применения наносить на поражённый участок кожи тонким слоем 1-2 раза в сутки, слегка втирая, в течение 2-4 недель [52, 53].

Уровень убедительности рекомендаций С (уровень достоверности доказательств 5).

Комментарий. Противопоказанием к назначению препарата бетаметазон ${ }^{* *} 0,05 \%$ мазь для наружного применения является детский возраст до 1 года;

- или бетаметазон** $0,05 \%$ крем для наружного применения 1 раз в сутки (наносить взрослым пациентам с атопическим дерматитом на поражённый участок кожи тонким слоем 1-2 раза в сутки, слегка втирая, в течение 2-4 недель) $[54,55]$.

Уровень убедительности рекомендаций В (уровень достоверности доказательств 3).

Комментарий. Противопоказанием к назначению препарата бетаметазон ** 0,05\% крем для наружного применения является детский возраст до 1 года;

- или триамцинолон $0,1 \%$ мазь для наружного применения наносить тонким слоем на поражённые участки кожи 2-3 раза в сутки в течение $2-4$ недель. Возможно использование окклюзионной повязки [56-58].

Уровень убедительности рекомендаций В (уровень достоверности доказательств 2).

Комментарий. Противопоказанием к назначению препарата триамцинолон 0,1\% мазь для наружного применения является детский возраст до 2 лет;

- или флутиказон 0,05\% крем для наружного применения, 0,005\% мазь для наружного применения наносить 1 или 2 раза в сутки тонким слоем 
в количестве, не большем чем необходимо для покрытия всего поражённого участка, и осторожно втирать в течение 2-4 недель [59-61]. Уровень убедительности рекомендаций С (уровень достоверности доказательств 5).

Комментарий. Противопоказанием к назначению мази флутиказон является детский возраст до бмесяцев, крема флутиказон - детский возраст до 1 года; - или мометазон** крем $0,1 \%$, мазь $0,1 \%$ тонким слоем наносить на поражённые участки кожи 1 раз в сутки в течение 2-4 недель [51, 62-69].

Уровень убедительности рекомендаций С (уровень достоверности доказательств 5).

Комментарий. Противопоказанием к назначению препарата мометазон ** является детский возраст до 2 лет;

- или метилпреднизолона ацепонат 0,1\% крем, мазь, эмульсия для наружного применения (наносить 1 раз в сутки тонким слоем на поражённые участки кожи в течение 2-4 недель) [70-74].

Уровень убедительности рекомендаций С (уровень достоверности доказательств 5).

Комментарий. Противопоказанием к назначению крема, мази, эмульсии для наружного применения метилпреднизолона ацепоната является детский возраст до 4 месяцев;

- или алклометазон крем 0,05\%, мазь 0,05\% наносить пациентам с атопическим дерматитом детского возраста на поражённые участки кожи равномерным слоем 2-3 раза в сутки в течение 2-4 недель. У детей и в период долечивания возможно использовать препарат 1 раз в сутки [75-79].

Уровень убедительности рекомендаций В (уровень достоверности доказательств 2).

Комментарий. Противопоказанием к назначению алклометазона 0,05\% крема, 0,05\% мази для наружного применения является детский возраст до 6 месяиев;

- или гидрокортизон** $0,1 \%$ крем для наружного применения, 0,1\% мазь для наружного применения, 0,1\% эмульсия для наружного применения наносить на поражённые участки кожи тонким слоем не чаще 2 раз в сутки в течение 2-4 недель [80-87].

Уровень убедительности рекомендаций В (уровень достоверности доказательств 2).

Комментарий. Возможно применение 0,1\% крема, мази и эмульсии гидрокортизона с 6-месячного возраста;

- или гидрокортизон** $1 \%$ мазь для наружного применения пациентам с атопическим дерматитом детского возраста наносить на поражённые участки кожи тонким слоем $1-3$ раза в сутки в течение 2-4 недель [88-90].

Уровень убедительности рекомендаций В (уровень достоверности доказательств 2).
Комментарий. Противопоказанием к назначению мази 1\% является детский возраст до 2 лет;

- или преднизолон ${ }^{* *} 0,5 \%$ мазь для наружного применения наносить тонким слоем на поражённые участки кожи 1-3 раза в сутки [91].

Уровень убедительности рекомендаций С (уровень достоверности доказательств 5).

Комментарий. Противопоказанием к назначению преднизолона** 0,5\% мази для наружного применения является детский возраст до 1 года. Длительность применения не должнна превышать 14 дней.

Рекомендуются пациентам со средней тяжестью течения и тяжёлой формой атопического дерматита препараты для лечения дерматита, кроме глюкокортикоидов:

- такролимус** взрослым 0,03\% мазь для наружного применения или 0,1\% мазь для наружного применения, детям старше 2 лет - 0,03\% мазь для наружного применения (наносить 2 раза в сутки тонким слоем на поражённые участки кожи) [85, 92-110].

Уровень убедительности рекомендаций А (уровень достоверности доказательств 1).

Комментарий. Продолжительность лечения по данной схеме не должна превышать трёх недель. В дальнейшем частота применения уменьшается до одного раза в сутки, лечение продолжается до полного регресса очагов поражения. При отсутствии положительной динамики в течение 14 дней необходима повторная консультация врача для уточнения дальнейшей тактики терапии. Через 12 месяцев поддерживающей терапии (при использовании такролимуса** 2 раза в неделю) следует временно отменить препарат и затем рассмотреть вопрос о необходимости продолжения поддерживающей терапии.

Такролимус** применяется для лечения атопического дерматита (средней степени тяжести и тяжёлых форм) в случае его резистентности к иным средствам наружной терапии или наличия противопоказаний к таковым. Применение 0,1\% мази такролимус ** противопоказано детям до 16лет. Противопоказанием к назначению 0,03\% мази такролимус** является детский возраст до 2 лет.

Во время применения такролимуса** следует избегать попадания на кожу солнечных лучей, посещения солярия, ультрафиолетового облучения кожи УФлучами В или А, ПУВА-терапии;

- или пимекролимус** $1 \%$ крем для наружного применения 2 раза в сутки взрослым и детям старше 3 месяцев (наносить на поражённую поверхность тонким слоем) [92, 111-119].

Уровень убедительности рекомендаций А (уровень достоверности доказательств 1).

Комментарий. Пимекролимус** крем для наружного применения показан как для кратковременного, так и длительного лечения атопического дерматита лёгкой и средней степени тяжести у взрослых, под- 
ростков и детей (от 3 месяцев). Возможно длительное применение по интермиттирующей схеме (1 раз в неделю или реже). Противопоказанием к назначению пимекролимуса ** является детский возраст до 3 месяцев.

Препарат назначают 2 раза в сутки на поражённые участки кожи любых частей тела, включая голову, лищо, шею, области опрелостей. Особенно показан для чувствительных участков кожи [119]. При первых признаках рецидива атопического дерматита терапию следует возобновить. Если симптомы заболевания сохраняются в течение 6 недель, следует провести повторную оценку состояния пациента. Не запрещён беременным и кормящим.

Во время применения пимекролимуса** следует избегать попадания на кожу солнечных лучей, посещения солярия, ультрафиолетового облучения кожи УФ-лучами В или А, ПУВА-терапии.

Рекомендуется пиритион цинк для местного применения пациентам с атопическим дерматитом детского возраста:

- крем 0,2\% наносят тонким слоем на поражённые участки кожи 2 раза в сутки детям с 1 года, возможно применение под окклюзионную повязку;

- аэрозоль 0,2\% детям с 1 года в случаях выраженного мокнутия распыляют с расстояния $15 \mathrm{~cm}$ 2-3 раза в сутки [120-122].

Уровень убедительности рекомендаций С (уровень достоверности доказательств 4).

Комментарий. Курс лечения при атопическом дерматите - 3-4 недели.

Рекомендуется в случае наличия у пациентов выраженной инфильтрации высыпания:

- нафталанская нефть линимент 10\% (наносить тонким слоем, не втирая, на поражённые участки кожи 2 раза в сутки) [123].

Уровень убедительности рекомендаций С (уровень достоверности доказательств 5).

Комментарий. Обладает противовоспалительным, противозудным, дезинфицирующим и заживляющим эффектом.

\section{Системная терапия для уменышения интенсивности зуда}

Рекомендуются пациентам для уменьшения интенсивности зуда:

- клемастин 1 мг, перорально взрослым и детям старше 12 лет по 1 таблетке (1 мг) утром и вечером в течение 7-10 дней. В случаях, трудно поддающихся лечению, суточная доза может составлять до 6 таблеток (6 мг); детям в возрасте 6-12 лет - по 1/2-1 таблетке перед завтраком и на ночь [91, 124, 125].

Уровень убедительности рекомендаций С (уровень достоверности доказательств 5).

Комментарий. Клемастин в форме таблеток противопоказан в возрасте до 6 лет;
- или хлоропирамин ${ }^{* *} 25$ мг перорально, детям в возрасте от 1 месяца до 12 месяцев - по 6,25 мг (1/4 таблетки) 2-3 раза в сутки в растёртом до порошка состоянии вместе с детским питанием; детям в возрасте от 1 года до 6 лет - по 8,3 мг (1/3 таблетки) 2-3 раза в сутки; детям в возрасте от 7 до 14 лет - по 12,5 мг (1/2 таблетки) 2-3 раза в сутки; детям в возрасте старше 14 лет и взрослым - по 1 таблетке 3-4 раза в сутки (75-100 мг в сутки) [126-130].

Уровень убедительности рекомендаций С (уровень достоверности доказательств 5).

Комментарий. Хлоропирамин ** в форме таблеток противопоказан в зависимости от производителя лекарственного препарата в возрасте до 6 месяцев или до 14 лет;

- или хифенадин 10 мг, 25 мг, 50 мг, взрослым по 25-50 мг 2-4 раза в сутки; детям в возрасте от 3 до 7 лет - по 10 мг перорально 2 раза в сутки, детям в возрасте от 7 до 12 лет - по 10-15 мг перорально 2-3 раза в сутки, детям в возрасте старше 12 лет и взрослым - по 1 таблетке 25 мг перорально 2-3 раза в сутки в течение 10-15 дней [91].

Уровень убедительности рекомендаций С (уровень достоверности доказательств 5).

Комментарий. Противопоказанием к назначению хифенадина в форме таблеток является детский возраст до 3 лет (для дозировки 10 мг), детский возраст до 18 лет (для дозировки 50 мг);

- или лоратадин** сироп, таблетки 10 мг, детям в возрасте от 2 до 12 лет с массой тела менее 30 кг - 5 мг (5 мл) 1 раз в сутки перорально, при массе тела более 30 кг - 10 мг (10 мл) 1 раз в сутки; детям в возрасте старше 12 лет и взрослым - 10 мг (10 мл) 1 раз в сутки перорально в течение 14-28 дней, в возрасте от 2 до 12 лет 5 мг (5 мл) 1 раз в сутки перорально; детям в возрасте старше 12 лет и взрослым - 10 мг (10 мл) 1 раз в сутки перорально 1 раз в сутки в течение 14-18 дней [131-133].

Уровень убедительности рекомендаций В (уровень достоверности доказательств 2);

- или цетиризин ** капли для приема внутрь 10 мг/мл, таблетки 10 мг - детям в возрасте от 6 до 12 месяцев (только по назначению врача и под строгим медицинским контролем) - 2,5 мг (5 капель) перорально 1 раз в сутки, детям в возрасте от 1 года до 2 лет - 2,5 мг (5 капель) перорально 1-2 раза в сутки, детям в возрасте от 2 до 6 лет - 2,5 мг (5 капель) перорально 2 раза в сутки или 5 мг (10 капель) перорально 1 раз в сутки, детям в возрасте старше 6 лет и взрослым - 5 мг перорально 1 раз в сутки в течение 14-28 дней [134-138].

Уровень убедительности рекомендаций В (уровень достоверности доказательств 2). 
Комментарий. Цетиризин** в форме таблеток противопоказан в возрасте до 6 лет, цетиризин ** в форме капель для приёма внутрь противопоказан в возрасте до 6 месяцев или до 1 года в зависимости от производителя;

- или левоцетиризин 5 мг - детям в возрасте старше 6 лет и взрослым - 5 мг перорально 1 раз в сутки в течение 14-28 дней [139-143].

Уровень убедительности рекомендаций С (уровень достоверности доказательств 4).

Комментарий. Противопоказанием к назначению левоцетиризина является детский возраст до 6 лет. [123]:

Рекомендуется пациентам с выраженным зудом

- клемастин раствор для инъекций внутримышечно взрослым 2 мг (2 мл) 2 раза в сутки (утром и вечером); детям -0,025 мг на кг массы тела в сутки внутримышечно, разделяя на 2 инъекции; в течение 5-7 дней.

Уровень убедительности рекомендаций С (уровень достоверности доказательств 5).

Комментарий. Противопоказанием к назначению клемастина в форме раствора для инбекций является детский возраст до 1 года;

- или хлоропирамин** раствор для инъекций детям в возрасте от 1 месяца до 1 года по 5 мг ( 0,25 мл раствора) внутримышечно 1 раз в сутки; детям в возрасте от 1 года до 6 лет - по 10 мг (0,5 мл раствора) внутримышечно 1 раз в сутки; детям в возрасте от 6 до 14 лет - по 10-20 мг (0,5-1 мл раствора) внутримышечно 1 раз в сутки; детям в возрасте старше 14 лет и взрослым - по 20-40 мг (1-2 мл раствора) внутримышечно 1 раз в сутки в течение 5-7 дней [123]. Уровень убедительности рекомендаций С (уровень достоверности доказательств 5).

Комментарий. Хлоропирамин ** в форме раствора для инбекций противопоказан новорождённым.

Терапия пациентов с атопическим дерматитом средней и тяжёлой степени тяжести

\section{Физиотерапевтическое лечение}

Рекомендуется пациентам с атопическим дерматитом средней и тяжёлой степени тяжести ультрафиолетовое облучение кожи (фототерапия) [144-158]:

Уровень убедительности рекомендаций В (уровень достоверности доказательств 2).

Комментарий. Перед назначением фототерапии пациентам с атопическим дерматитом для выявления противопоказаний рекомендуется комплекс лабораторных исследований, включающий общий (клинический) анализ крови, общий анализ мочи, анализ крови биохимический общетерапевтический, консультация врача-терапевта или врача-педиатра, врача-эндокринолога, врача акушера-гинеколога (для женщин). По показаниям рекомендуют обследование у других специалистов [159-164].
Рекомендуются пациентам с атопическим дерматитом средней и тяжёлой степени тяжести:

- узкополосная средневолновая ультрафиолетовая УФВ-311 терапия с длиной волны 311 нм взрослым пациентам с атопическим дерматитом [144-146].

Уровень убедительности рекомендаций В (уровень достоверности доказательств 2).

- или узкополосная средневолновая ультрафиолетовая УФВ-311 терапия с длиной волны 311 нм детям с атопическим дерматитом [147, 148].

Уровень убедительности рекомендаций С (уровень достоверности доказательств 4).

Комментарий. Данные о применении фототерапии в детском возрасте ограничены, ввиду чего необходимо соблюдать осторожность при использовании. Узкополосная средневолновая ультрафиолетовая терапия назначается детям от 5 лет и старше. При назначении узкополосной средневолновой ультрафиолетовой терапии необходимо учитывать психоэмоциональные особенности ребёнка, общее состояние, способность самостоятельно находиться в кабине и выполнять требований медицинского персонала;

- или ультрафиолетовая терапия дальнего длинноволнового диапазона (УФА-1 терапия, длина волны 340-400 нм) взрослым [149-153].

Уровень убедительности рекомендаций В (уровень достоверности доказательств 2).

Комментарий. Ультрафиолетовая терапия дальнего длинноволнового диапазона противопоказана детям до 18лет;

- или селективная фототерапия (широкополосная средневолновая ультрафиолетовая терапия (УФВ терапия с длиной волны 280-320 нм) взрослым пациентам с атопическим дерматитом [154].

Уровень убедительности рекомендаций С (уровень достоверности доказательств 4).

Комментарий. Данные о применении фототерапии в детском возрасте ограничены.

Рекомендуется при отсутствии эффекта от лечения другими методами фототерапии, а также наличии очагов поражения с выраженной инфильтрацией кожи взрослым:

- фотохимиотерапия с внутренним применением фотосенсибилизаторов (ПУВА) [155-158].

Комментарий. Для выявления противопоказаний $\kappa$ ПУВА-терапии следует провести комплекс лабораторных исследований, включающий общий (клинический) анализ крови, общий (клинический) анализ мочи, анализ крови биохимический общетерапевтический, консультацию врача-терапевта, врача-эндокринолога, врача-офтальмолога, врача акушера-гинеколога (для женнщин).

Многокурсовое применение метода ПУВА-терапии может повышать риск злокачественных новообразо- 
ваний кожи. ПУВА-терапия противопоказана лицам до 18 лет.

\section{Системная терапия}

Рекомендуется пациентам детского возраста в возрасте от 6 лет и старше при атопическом дерматите средней и тяжёлой степени тяжести и при отсутствии противопоказаний:

- дупилумаб** 200 или 300 мг раствор для подкожного введения. Для пациентов с массой тела от 15 до <30 кг начальная доза 600 мг (2 инъекции по 300 мг), далее по 300 мг каждые 4 недели; для пациентов с массой тела от 30 до $<60$ кг начальная доза 400 мг (2 инъекции по 200 мг), далее по 200 мг каждые 2 недели; для пациентов с массой тела 60 кг и более начальная доза 600 мг (2 инъекции по 300 мг), далее по 300 мг каждые 2 недели [165-168].

Уровень убедительности рекомендаций А (уровень достоверности доказательств 2).

Комментарий. Противопоказанием к назначению дупилумаба** больным атопическим дерматитом является детский возраст до 6 лет.

Рекомендуется взрослым пациентам при атопическом дерматите средней и тяжёлой степени тяжести и при отсутствии противопоказаний:

- дупилумаб** 300 мг раствор для подкожного введения в начальной дозе 600 мг (2 инъекции по 300 мг в разные места для инъекций), далее по 300 мг каждые 2 недели. В зависимости от индивидуального терапевтического ответа доза может быть увеличена до 300 мг еженедельно [169-175].

Уровень убедительности рекомендаций А (уровень достоверности доказательств 1).

Комментарий. Дупилумаб** может применяться в монотерапии или одновременно с топическими лекарственными препаратами. Инбекцию препарата может делать себе либо сам пациент, либо лицо, ухаживающее за ним. Необходимо до начала применения дупилумаба ** обучить пациентов и/или ухаживающих за ними лии подготовке и проведению инъекции препарата согласно указаниям в инструкции по медицинскому применению. Дупилумаб ** также может применяться у пациентов с сочетанием среднетяжёлого и тяжёлого атопического дерматита с тяжёлой бронхиальной астмой.

Эффективность дупилумаба** в лечении пациентов с атопическим дерматитом подтверждена результатами клинических исследований SOLO 1, SOLO 2, CHRONOS и CAFÉ [169-171]. Тяжесть атопического дерматита, оцениваемая по индексу EASI (Eczema Area and Severity Index), на фоне терапии дупилумабом** в режиме 1 инбекция каждые 2 недели на 16-й неделе уменьшилась на 75\% и более (EASI75) y 44-51\% пациентов, не получавших наружную терапию. В случае если терапия дупилумабом** в режиме
1 инбекция каждые 2 недели сопровождалась наружной терапией глюкокортикоидами, применяемыми в дерматологии, то эффективностьлечения была еще на 10-20\% выше, чем монотерапия дупилумабом**, и на 16-й неделе лечения тяжесть атопического дерматита по EASI уменьшилась на 75\% и более (EASI75) y $69 \%$ пациентов с атопическим дерматитом, получавшихлечение дупилумабом ** и глюкокортикоидами, применяемыми в дерматологии. Уменьшение зуда у пациентов отмечалось уже на 2-й неделе терапии, и на 16-й неделе терапии отмечено уменьшение зуда в среднем на 53,9\%. К 52-й неделе терапии эффект сохранялся, и уменьшение тяжести атопического дерматита на $75 \%$ и более по сравнению с исходным уровнем (ЕASI75) отмечено у 65\% пациентов с атопическим дерматитом, получавших дупилумаб** 1 инбекцию каждые 2 недели и наружную терапию глюкокортикоидами, применяемыми в дерматологии [169-171].

Рекомендуется при тяжёлом течении атопического дерматита у взрослых и при отсутствии противопоказаний:

- циклоспорин** в начальной дозе 2,5-3 мг на кг массы тела в сутки в 2 приёма с 12-часовым интервалом. При необходимости доза препарата может быть увеличена до максимальной 5 мг на кг массы тела в сутки - в зависимости от индивидуального состояния пациента. При достижении положительного результата дозу необходимо постепенно снижать до полной отмены [176-181].

Уровень убедительности рекомендаций С (уровень достоверности доказательств 4).

Комментарий. В число противопоказаний для назначения циклоспорина ${ }^{* *}$ входит детский возраст до 18 лет для всех показаний, не связанных странсплантацией за исключением нефротического синдрома.

Степень тяжести атопического дерматита уменьшается на 50\% через 6-8 недель непрерывного лечения ииклоспорином**. У пациентов, которые получают более высокую начальную дозу препарата (4-5 мг/кг/сут), наступает более быстрое улучшение - через 2 недели (снижение тяжести на 40\%), чем у пациентов, получавших более низкую начальную дозу (2,5-3мг/кг/сут; снижение тяжести на 22\%). Однако через 6-8недель терапии циклоспорином ** не было разницы в ответе между пациентами, получавшими препарат в более высоких и в более низких дозах, однако те пациенты, кто получал более высокую дозу препарата, сообщали о больщем количестве побочных эффектов, связанных с ииклоспорином** $[181,182]$. Длительность непрерывной терапии циклоспорином ** предлагается ограничить 2 годами [183].

Пациентам с тяжёлым течением атопического дерматита рекомендуются кортикостероиды системного действия перорально по схеме в течение первых 2-3 дней [6, 184]: 
- метилпреднизолон ${ }^{* *} 16-20$ мг 1 раз в сутки после завтрака или преднизолон ${ }^{* *} 20-25$ мг после завтрака и 5 мг после обеда;

далее 1 раз в сутки после завтрака в течение последующих 2-3 дней:

- метилпреднизолон ${ }^{* *} 12$ мг или преднизолон** 15 мг;

далее 1 раз в сутки после завтрака в течение последующих 2-3 дней:

- метилпреднизолон ${ }^{* *} 8$ мг или преднизолон ${ }^{* *}$ 10 мг 1 раз в сутки,

далее 1 раз в сутки после завтрака с последующей отменой препарата:

- метилпреднизолон ${ }^{* *} 4$ мг или преднизолон** 5 мг [91].

Уровень убедительности рекомендаций С (уровень достоверности доказательств 5).

Комментарий. При необходимости прием кортикостероидов системного действия можно продолжить еще в течение 2-3 дней 1 раз в день после завтрака: метилпреднизолон ** 2 мг или преднизолон ** 2,5 мг.

\section{Лечение осложнённого атопического дерматита}

Рекомендуются для лечения атопического дерматита, осложнённого вторичной инфекцией, антибиотики и противомикробные средства, применяемые в дерматологии:

- фузидовая кислота, 2\% крем для наружного применения или 2\% мазь для наружного применения (наносить на инфицированные очаги поражения 3 раза в сутки в течение 7-14 дней) [185-188].

Уровень убедительности рекомендаций С (уровень достоверности доказательств 4);

- или бацитрацин + неомицин $250 \mathrm{ME} / г$ + 5000 ME/мг наружно (наносить на инфицированные очаги поражения 2-3 раза в сутки в течение 7-14 дней) [189, 190].

Уровень убедительности рекомендаций С (уровень достоверности доказательств 5);

- или мупироцин $2 \%$ мазь для наружного применения (наносить на инфицированные очаги поражения 2-3 раза в сутки не более 10 дней) [191, 192]. Уровень убедительности рекомендаций В (уровень достоверности доказательств 2);

- или эритромицин мазь для наружного применения (10000 ЕД/г) наружно (наносить на инфицированные очаги поражения 2-3 раза в сутки 7-14 дней) [193].

Уровень убедительности рекомендаций С (уровень достоверности доказательств 5);

- или сульфатиазол серебра крем для наружного применения 2\% (наносить на инфицированные очаги поражения 2-3 раза в сутки 7-14 дней) [193, 194].

Уровень убедительности рекомендаций С (уровень достоверности доказательств 5).
Комментарий. Антибактериальные препараты используются для наружного применения при локализованных формах вторичной инфекции [195, 196].

Рекомендуется при наличии признаков вторичного инфицирования использовать короткими курсами (обычно в течение 1 недели) глюкокортикоиды в комбинации с антибиотиками или глюкокортикоиды в комбинации с другими препаратами:

- гидрокортизон + окситетрациклин мазь, аэрозоль наружно на инфицированные очаги поражения 1-3 раза в сутки в течение 7 дней [91].

Уровень убедительности рекомендаций С (уровень достоверности доказательств 5);

- или тетрациклин + триамцинолон аэрозоль для наружного применения (орошать струей аэрозоля инфицированные очаги поражения 1-3 раза в сутки, держа баллон в вертикальном положении, на расстоянии 15-20 см от кожи, в течение 7-10 дней) [197, 198].

Уровень убедительности рекомендаций В (уровень достоверности доказательств 3);

- или гидрокортизон + фузидовая кислота крем для наружного применения наружно на инфицированные очаги поражения 3 раза в сутки взрослым и детям в возрасте 2 лет и старше в течение 14 дней [199].

Уровень убедительности рекомендаций В (уровень достоверности доказательств 2);

- или бетаметазон + фузидовая кислота крем для наружного применения взрослым пациентам с атопическим дерматитом наружно на инфицированные очаги поражения 2 раза в сутки в течение 7 дней [200].

Уровень убедительности рекомендаций В (уровень достоверности доказательств 2);

- или бетаметазон+ гентамицин + клотримазол крем для наружного применения, мазь для наружного применения наружно на инфицированные очаги поражения 2 раза в сутки взрослым и детям в возрасте 2 лет и старше в течение 7-14 дней [91, 201-204].

Уровень убедительности рекомендаций С (уровень достоверности доказательств 4).

Комментарий. Для наружного лечения детей предпочтительными являются лекарственные формы в виде крема и монокомпонентные наружные средства: глюкокортикоиды, применяемые в дерматологии, препараты для лечения дерматита, кроме глюкокортикоидов (такролимус** и пимекролимус**). Многокомпонентные наружные лекарственные препараты - глюкокортикоиды в комбинации с антибиотиками или глюкокортикоиды в комбинации с другими препаратами - показаны только при клиническом и/или лабораторном подтвержждении бактериальной и/или грибковой инфекции. Необоснованное применение многокомпонентных наружных препаратов может способствовать развитию у детей дополни- 
тельной сенсибилизации к компонентам топического лекарственного средства.

Рекомендуется пациентам с дефектами кожи (трещины, экскориации) с целью устранения вторичного инфицирования на местах экскориаций и трещин, особенно у детей, антисептики и дезинфицирующие средства или другие лечебные средства (метилтиониния хлорид) 1-2 раза в сутки в течение 5-10 дней [123, 193].

Уровень убедительности рекомендаций С (уровень достоверности доказательств 5).

- борная кислота + резорцин + фенол + фуксин раствор для наружного применения (наносить с помощью тампона или стеклянной палочки на поражённые участки кожи 2-4 раза в сутки. После высыхания жидкости на обработанный участок можно наносить мази и пасты) [123, 193].

Комментарий. Не рекомендуется применять препарат борная кислота + резориин + фенол + фуксин женшинам во время беременности и в период грудного вскармливания;

- или метилтиониния хлорид $1 \%$ раствор для местного и наружного применения, [водный] взрослым и детям с момента рождения (раствор наносят с помощью тампона или стеклянной палочки на поражённые участки 2-3 раза в сутки) [123, 193].

Комментарий. Возможсно применение водного раствора метилтиониния хлорида во время беременности и грудного вскармливания.

Рекомендуется пациентам с дефектами кожи (трещины, экскориации) с целью устранения вторичного инфицирования на местах экскориаций и трещин, особенно у детей, антисептики и дезинфицирующие средства или другие лечебные средства (метилтиониния хлорид) 1-2 раза в сутки в течение 5-10 дней [123, 193].

Уровень убедительности рекомендаций С (уровень достоверности доказательств 5).

- борная кислота + резорцин + фенол + фуксин раствор для наружного применения (наносят с помощью тампона или стеклянной палочки на поражённые участки кожи 2-4 раза в сутки. После высыхания жидкости на обработанный участок можно наносить мази и пасты) [123, 193].

Комментарий. После высыхания жсидкости на обработанный участок можсно наносить мази и пасты. Не следует применять препарат борная кислота + резориин + фенол + фуксин женшинам во время беременности и в период грудного вскармливания;

- или метилтиониния хлорид $1 \%$ раствор для местного и наружного применения, [водный] взрослым и детям с момента рождения (раствор наносят с помощью тампона или стеклянной палочки на поражённые участки 2-3 раза в сутки) [121, 190].
Комментарий. Возможсно применение водного раствора метилтиониния хлорида во время беременности и грудного вскармливания.

Рекомендуются антибактериальные препараты системного действия для лечения рецидивирующей или распространённой бактериальной инфекции:

- амоксициллин + клавулановая кислота** взрослым и детям старше 12 лет (массой 40 кг и более) таблетки, покрытые плёночной оболочкой, 250 мг +125 мг по 1 таблетке 3 раза в сутки или 875 мг + 125 мг по 1 таблетке 2 раза в сутки в течение 5-14 дней, или таблетки диспергируемые взрослым и детям старше 12 лет (массой 40 кг и более) по 500/125 мг 3 раза в сутки в течение 5-14 дней, детям от 2 до 12 лет или с массой тела менее 40 кг - по 125/31,25 мг или по 250/62,5 мг в дозах, не превышающих 2400/600 мг в сутки, в 3 приёма в течение 5-14 дней [205].

Уровень убедительности рекомендаций С (уровень достоверности доказательств 4).

Комментарий. Противопоказанием для назначения таблеток, покрытых плёночной оболочкой, амоксициллин + клавулановая кислота ** является детский возраст до 12 лет. Противопоказанием для назначения диспергируемых таблеток амоксициллин + клавулановая кислота ** является детский возраст до 1 года;

- или цефуроксим** по 250 мг перорально 2 раза в сутки взрослым и детям в возрасте 3 лет и старше в течение 5-10 дней [206-208].

Уровень убедительности рекомендаций С (уровень достоверности доказательств 2).

Комментарий. Противопоказанием для назначения таблеток цефуроксим**, покрытых плёночной оболочкой, является детский возраст до 3 лет;

- или цефтриаксон** по 1-2 г в сутки внутримышечно или внутривенно детям старше 12 лет (желательно в 2 введения через 12 часов), новорождённым до 2 недель - 20-50 мг/кг/сут, детям от 3 недель до 12 лет - 20-80 мг/кг/сут в 2 введения [207].

Уровень убедительности рекомендаций С (уровень достоверности доказательств 4).

Комментарий. Цефтриаксон ** противопоказан недоношенным детям в возрасте до 41 недели включительно. Цефттриаксон ${ }^{* *}$ следует назначать с осторожностью в период грудного вскармливания.

Комментарий. Атопический дерматит часто осложняется развитием бактериальных инфекционных поражений кожи, требующих проведения антибактериальной терапии [209, 210]. До назначения антибактериальных препаратов системного действия следует провести микробиологическое (культуральное) исследование гнойного отделяемого на аэробные и факультативно-анаэробные микроорганизмы и с целью идентификации возбудителя и микробиологическое (культуральное) исследование отделяемого высыпных 
элементов кожи на чувствительность к антибактериальным и противогрибковым препаратам.

До получения результатов микробиологического исследования в большинстве случаев начинают лечение антибактериальными препаратами широкого спектра действия, активными в отношении наиболее часто встречающихся возбудителей, в первую очередь S. aureus. C высокой эффективностью применяются комбинации пенициллинов, включая комбинации с ингибиторами бета-лактамаз, цефалоспорины первого или второго поколения, макролиды, у взрослых лиц фторхинолоны.

Продолжительность терапии антибактериальными препаратами системного действия обычно составляет 7-10 дней.

Рекомендуются противовирусные препараты прямого действия в случае развития у пациентов с атопическим дерматитом герпетической экземы Капоши [211, 212]:

- ацикловир** таблетки 200 мг взрослым и детям от 3 лет внутрь 5 раз в сутки. Курс лечения составляет 5 дней, но может быть продлён при тяжёлых инфекциях.

Уровень убедительности рекомендаций В (уровень достоверности доказательств 2).

Комментарий. В случае диссеминированного процесса, сопровождающегося повышением температуры тела, явлениями тяжёлой интоксикации, необходима госпитализация в стационар с наличием боксированного отделения. В условиях стационара следует проводить внутривенное введение ацикловира. Наружная терапия заключается в использовании антисептиков и дезинфицирующих средств (борная кислота + резорцин + фенол + фуксин, метилтиониния хлорид 1\% раствор для местного и наружного применения, [водный] и др.).

В случае поражения глаз следует применять мазь глазную $3 \%$ ацикловир **, которая закладывается в нижний конбюнктивальный мешок 5 раз в сутки. Лечение продолжают на протяжении не менее 3 дней после купирования симптомов.

Противопоказанием к назначению ацикловира ** в таблетках является детский возраст до 3 лет.

\section{2. Иное лечение}

Пациентам с наличием сенсибилизации к аллергенам клещей домашней пыли и пыльцевым аллергенам, контакт с которыми вызывает обострение атопического дерматита и/или респираторные проявления - аллергический ринит, бронхиальную астму, рекомендуется аллергенспецифическая иммунотерапия аллергенами клещей домашней пыли [6, 213-223]:

- аллергены бытовые раствор для накожного скарификационного нанесения прик-теста и подкожного введения [215-220];

- или аллергены бытовые суспензия для подкожного введения [216];
- или аллергены бытовые капли подъязычные [221-223].

Уровень убедительности рекомендаций В (уровень достоверности доказательств 1).

Комментарий. Показания выбор метода и противопоказания к аллергенспецифической иммунотерапии определяет врач аллерголог-иммунолог. Аллергенспецифическую иммунотерапию назначают только после купирования обострения атопического дерматита с помощью адекватной наружной терапии, а также санации очагов хронической инфекции и лечения сопутствующих заболеваний. Проводится врачом аллергологом-иммунологом в условиях аллергологического кабинета или стационара. Продолжительность и схема аллергенспецифической иммунотерапии определяется индивидуально.

4. Медицинская реабилитация, медицинские показания и противопоказания к применению методов реабилитации

Не применяется.

5. Профилактика и диспансерное наблюдение, медицинские показания и противопоказания к применению методов профилактики

Первичная профилактика атопического дерматита направлена на предупреждение возникновения и воздействия факторов риска развития заболевания и включает в себя комплекс гипоаллергенных мероприятий [252].

Рекомендуется в качестве мероприятий первичной профилактики атопического дерматита беременным женщинам с пищевой аллергией элиминация аллергенного продукта из диеты [224, 254, 255].

Уровень убедительности рекомендаций В (уровень достоверности доказательств 3).

Рекомендуется в качестве мероприятий первичной профилактики атопического дерматита всем детям на протяжении первых 4-6 месяцев жизни грудное вскармливание [225, 226].

Уровень убедительности рекомендаций В (уровень достоверности доказательств 2).

Рекомендуется в качестве мероприятий первичной профилактики атопического дерматита введение прикормов с 4-го месяца жизни ребёнка вне зависимости от наследственной отягощенности [226].

Уровень убедительности рекомендаций С (уровень достоверности доказательств 5).

Рекомендуются в качестве мероприятий первичной профилактики атопического дерматита при необходимости для прикорма детям из группы высокого риска профилактические или лечебные (высокогидролизные) смеси [227, 257].

Уровень убедительности рекомендаций А (уровень достоверности доказательств 1).

Рекомендуются для прикорма здоровым детям без наследственной отягощённости по аллергиче- 
ским заболеваниям адаптированные смеси на основе коровьего молока [227].

Уровень убедительности рекомендаций С (уровень достоверности доказательств 5).

Рекомендуются беременным и новорождённым из групп риска пробиотики, содержащие лактобактерии [227-230].

Уровень убедительности рекомендаций В (уровень достоверности доказательств 1).

Не рекомендуются ограничительные гипоаллергенные диеты в общей популяции [231].

Уровень убедительности рекомендаций С (уровень достоверности доказательств 5).

Комментарий. Убедительных данных об эффективности гипоаллергенных или элиминационных диет в процессе беременности в отношении развития атопического дерматита в общей популяции в настоящее время не получено [225].

Не рекомендуются элиминационные диеты здоровым женщинам во время лактации [224, 254].

Уровень убедительности рекомендаций В (уровень достоверности доказательств 3).

Рекомендуется беременным, детям и взрослым в качестве мероприятий первичной профилактики атопического дерматита с целью контроля за факторами внешней среды исключение воздействия табачного дыма [232].

Уровень убедительности рекомендаций В (уровень достоверности доказательств 2).

Комментарий. Курение недопустимо во время беременности и лактации; пассивное курение исключают с первых дней жизни ребёнка.

Рекомендуется в качестве мероприятий первичной профилактики атопического дерматита у детей с целью контроля за факторами внешней среды поддержание низкой влажности и адекватной вентиляции в помещениях, где находится ребёнок (исключение сырости) [233].

Уровень убедительности рекомендаций С (уровень достоверности доказательств 4).

Рекомендуется беременным, детям и взрослым в качестве мероприятий первичной профилактики атопического дерматита с целью контроля за факторами внешней среды уменьшение воздействия загрязняющих веществ окружающей среды (поллютантов) [234, 235].

Уровень убедительности рекомендаций С (уровень достоверности доказательств 4).

Рекомендуется элиминация или удаление причинно-значимых аллергенов. При установленной сенсибилизации к бытовым, эпидермальным, грибковым аллергенам рекомендованы элиминационные мероприятия с целью уменьшения выраженности симптомов атопического дерматита, снижения фармакологической нагрузки и профилактики обострений. При развитии симптомов пищевой аллергии, включая анафилаксию, что нередко наблюдается у детей и взрослых с сенсибилизацией к белкам пищевых аллергенов, установленной с помощью определения аллергенспецифических IgE-антител в сыворотке крови, рекомендованы элиминационные диеты с исключением причинно-значимых аллергенов $[252,255,256]$.

Уровень убедительности рекомендаций С (уровень достоверности доказательств 5).

Вторичная профилактика атопического дерматита - комплекс мероприятий, направленных на устранение выраженных факторов риска, которые при определённых условиях (стресс, ослабление иммунитета, чрезмерные нагрузки на любые другие функциональные системы организма) могут привести к возникновению, обострению и рецидиву заболевания.

Рекомендуется в качестве мероприятий вторичной профилактики атопического дерматита обучение пациентов с атопическим дерматитом и/или членов их семьи [236-240].

Уровень убедительности рекомендаций А (уровень достоверности доказательств 2).

Рекомендуется в качестве мероприятий вторичной профилактики атопического дерматита профилактическое консультирование по коррекции факторов риска развития неинфекционных заболеваний [236-240].

Уровень убедительности рекомендаций А (уровень достоверности доказательств 2).

Комментарий. Любые профилактические элиминационные мероприятия, назначаемые на длительное время, могут оказывать негативное влияние на членов семьи, ухудшая качество их жизни.

Третичная профилактика - это комплекс мероприятий, направленных на предотвращение обострений или развития осложнений атопического дерматита.

Рекомендуется в качестве мероприятий третичной профилактики атопического дерматита уменьшение влияния провоцирующих факторов: ограничение использования мыла, одежды из грубых тканей; минимализация факторов, влияющих на потливость [241, 242].

Уровень убедительности рекомендаций С (уровень достоверности доказательств 4).

Рекомендуется в качестве мероприятий третичной профилактики атопического дерматита рациональный уход за кожей [243, 244].

Уровень убедительности рекомендаций С (уровень достоверности доказательств 4).

Рекомендуется при проведении плановой вакцинации детей с атопическим дерматитом придерживаться национального календаря профилактических прививок [245-247].

Уровень убедительности рекомендаций С (уровень достоверности доказательств 5). 
Комментарий. Вакцинация не влияет на течение каких-либо аллергических заболеваний, в том числе атопического дерматита. Вакцинация не проводится в период обострения заболевания. При персистирующем течении атопического дерматита следует провести курс терапии глюкокортикоидами, применяемыми в дерматологии, в течение 2 недель до вакцинации. Паииенты, получающие лечение иммунодепрессантами, должны быть проконсультированы врачом перед вакцинацией живыми вакцинами, так как противопоказанием к терапии иммунодепрессантами может быть вакцинация живыми вакцинами. При аллергии на белок куриного яйца перед вакцинацией необходима консультация врача аллерголога-иммунолога.

\section{6. Организация оказания медицинской помощи}

В рамках оказания первичной врачебной медикосанитарной помощи врачи-терапевты участковые, врачи-педиатры участковые, врачи общей практики (семейные врачи) при выявлении у больных высыпаний на коже, кожного зуда, симптомов или признаков атопического дерматита направляют больного в медицинскую организацию дерматовенерологического профиля или кабинет врача аллерголога-иммунолога для оказания ему первичной специализированной медико-санитарной помощи, а также осуществляют оказание медицинской помощи в соответствии с рекомендациями медицинской организации дерматовенерологического профиля и/или врача аллерголога-иммунолога при отсутствии медицинских показаний для направления в неё.

При невозможности оказания медицинской помощи в рамках первичной специализированной ме- дико-санитарной помощи и наличии медицинских показаний больной направляется в медицинскую организацию, оказывающую специализированную медицинскую помощь.

Специализированная, в том числе высокотехнологичная, медицинская помощь оказывается врачами-дерматовенерологами и/или врачами аллергологами-иммунологами в стационарных условиях.

Показания для плановой госпитализации в медицинскую организацию:

1) показания для оказания медицинской помощи в дневном стационаре:

- недостаточная эффективность лечения, проводимого в амбулаторных условиях, у пациентов с ограниченными высыпаниями;

2) показания для оказания медицинской помощи в стационарных условиях:

- отсутствие эффекта от проводимого лечения в амбулаторных условиях;

- тяжёлое течение атопического дерматита, требующее системной терапии или фототерапии;

- присоединение вторичной инфекции, не купируемое в амбулаторных условиях;

- развитие вирусной инфекции (герпетической экземы Капоши).

Показания к выписке пациента из медицинской организации:

• частичный или полный регресс высыпаний.

7. Дополнительная информация (в том числе факторы, влияющие на исход заболевания или состояния)

Отсутствует.

Критерии оценки качества медицинской помощи

\begin{tabular}{|c|c|c|c|}
\hline № & Критерии качества & $\begin{array}{l}\text { Уровень } \\
\text { убедительности } \\
\text { рекомендаций }\end{array}$ & $\begin{array}{l}\text { Уровень } \\
\text { достоверности } \\
\text { доказательств }\end{array}$ \\
\hline 1 & Выполнен общий (клинический) анализ крови & 4 & $\mathrm{C}$ \\
\hline 2 & Выполнен анализ крови биохимический общетерапевтический & 4 & $\mathrm{C}$ \\
\hline 3 & Выполнен общий (клинический) анализ мочи & 4 & $\mathrm{C}$ \\
\hline 4 & $\begin{array}{l}\text { Проведена терапия глюкокортикоидами, применяемыми в дерматологии } \\
\text { или препаратами для лечения дерматита, кроме глюкокортикоидов }\end{array}$ & 1 & A \\
\hline 5 & $\begin{array}{l}\text { Проведена терапия кортикостероидами системного действия и/или } \\
\text { циклоспорином и/или дупилумабоми/илиультрафиолетовое облучение кожи } \\
\text { при атопическом дерматите средней и тяжелой степени тяжести }\end{array}$ & 2 & B \\
\hline 6 & Проведена терапия антигистаминными препаратами системного действия & 2 & B \\
\hline 7 & $\begin{array}{l}\text { Проведена терапия антибиотиками и противомикробными средствами, } \\
\text { применяемыми в дерматологии, и/или глюкокортикоидами в комбинации } \\
\text { с антибиотиками или глюкокортикоидами в комбинации с другими } \\
\text { препаратами при вторичном инфицировании }\end{array}$ & 2 & $\mathrm{C}$ \\
\hline 8 & Достигнут частичный или полный регресс высыпаний & 3 & $\mathrm{C}$ \\
\hline
\end{tabular}




\section{Дополнительная информация}

Источник финансирования. Авторы заявляют об отсутствии внешнего финансирования при подготовке и публикации статьи.

Funding source. This study was not supported by any external sources of funding.

Конфликт интересов. Авторы декларируют отсутствие явных и потенциальных конфликтов интересов, связанных с публикацией настоящей статьи.

Competing interests. The authors declare that they have no competing interests.

Вклад авторов. Систематический поиск и отбор публикаций: В.В. Чикин, О.Г. Елисютина, А.Э. Карамова, С.И. Артемьева, А.Н. Львов, А.Н. Пампура, Л.Р. Селимзянова; составление тезис-рекомендаций: В.В. Чикин, О.Г. Елисютина, К.И. Плахова, А.Э. Карамова, Л.Ф. Знаменская, Л.Р. Селимзянова, С.И. Артемьева, А.Н. Львов, А.Н. Пампура; написание текста: В.В. Чикин, О.Г. Елисютина, Е.С. Феденко, С.И. Артемьева, А.Н. Львов, А.Н. Пампура, Е.А. Вишнева, В.А. Волнухин, Л.Ф. Знаменская, А.Э. Карамова; обсуждение тезис-рекомендаций: А.А. Кубанов, Л.С. Намазова-Баранова, Р.М. Хаитов, Н.И. Ильина, Е.А. Алексеева, Э.Т. Амбарчян, С.И. Артемьева, М.И. Аршинский, Н.Г. Астафьева, Е.А. Вишнева, В.А. Волнухин, И.В. Данилычева, О.Г. Елисютина, Р.В. Епишев, А.В. Жестков, М.Б. Жилова, О.В. Жукова, Д.В. Заславский, Л.Ф. Знаменская, А.Э. Карамова, Н.Г. Короткий, М.М. Кохан, Л.С. Круглова, Н.В. Кунгуров, Ю.Г. Левина, А.Н. Львов, А.И. Материкин, О.С. Мишина, К.Н. Монахов, Н.Н. Мурашкин, Н.М. Ненашева, А.Н. Пампура, К.И. Плахова, Н.Н. Потекаев, О.А. Притуло, К.И. Разнатовский, С.Г. Сапунцова, Л.Р. Селимзянова, О.В. Скороходкина, Е.С. Феденко, Д.С. Фомина, Н.В. Фриго, З.В. Фролова, М.Р. Хаитов, В.В. Чикин; редактирование статьи: А.А. Кубанов, Л.С. Намазова-Баранова, Р.М. Хаитов, Н.И. Ильина, Е.А. Алексеева, Э.Т. Амбарчян, С.И. Артемьева, М.И. Аршинский, Е.А. Вишнева, О.Г. Елисютина, Р.В. Епишев, М.Б. Жилова, О.В. Жукова, Д.В. Заславский, Л.Ф. Знаменская, А.Э. Карамова, Л.С. Круглова, Ю.Г. Левина, А.Н. Львов, А.И. Материкин, О.С. Мишина, К.Н. Монахов, Н.Н. Мурашкин, Н.М. Ненашева, А.Н. Пампура, К.И. Плахова, Н.Н. Потекаев, О.А. Притуло, С.Г. Сапунцова, Л.Р. Селимзянова, Е.С. Феденко, Д.С. Фомина, Н.В. Фриго, З.В. Фролова, М.Р. Хаитов, В.В. Чикин. Все авторы подтверждают соответствие своего авторства международным критериям ICMJE (все авторы внесли существенный вклад в разработку концепции, подготовку статьи, прочли и одобрили финальную версию перед публкацией).
Authors' contribution. Systematic search and selection of publications: V.V. Chikin, O.G. Elisyutina, A.E. Karamova, S.I. Artemyeva, A.N. Lviv, A.N. Pampura, L.R. Selimzyanova; preparation of thesis recommendations: V.V. Chikin, O.G. Elisyutina, K.I. Plakhova, A.E. Karamova, L.F. Znamenskaya, L.R. Selimzyanova, S.I. Artemyeva, A.N. Lviv, A.N. Pampura; writing of the text: V.V. Chikin, O.G. Yelisyutina, E.S. Fedenko, S.I. Artemyeva, A.N. Lvov, A.N. Pampura, E.A. Vishneva, V.A. Volnukhin, L.F. Znamenskaya, A.E. Karamova; discussion of thesis recommendations: A.A. Kubanov, L.S. Namazova-Baranova, R.M. Khaitov, N.I. Ilyina, E.A. Alekseeva, E.T. Ambarchyan, S.I. Artemyeva, M.I. Arshinsky, N.G. Astafyeva, E.A. Vishneva, V.A. Volnukhin, I.V. Danilycheva, O.G. Elisyutina, R.V. Epishev, A.V. Zhestkov, M.B. Zhilova, O.V. Zhukova, D.V. Zaslavsky, L.F. Znamenskaya, A.E. Karamova, N.G. Korotky, M.M. Kohan, L.S. Kruglova, N.V. Kungurov, Yu.G. Levina, A.N. Lvov, A.I. Materikin, O.S. Mishina, K.N. Monakhov, N.N. Murashkin, N.M. Nenasheva, A.N. Pampura, K.I. Plakhova, N.N. Potekaev, O.A. Pritulo, K.I. Raznatovsky, S.G. Sapuntsova, L.R. Selimzyanova, O.V. Skorokhodkina, E.S. Fedenko, D.S. Fomina, N.V. Frigo, Z.V. Frolova, M.R. Khaitov, V.V. Chikin; editing of the article: A.A. Kubanov, L.S. Namazova-Baranova, R.M. Khaitov, N.I. Ilyina, E.A. Alekseeva, E.T. Ambarchyan, S.I. Artemyeva, M.I. Arshinsky, E.A. Vishneva, O.G. Elisyutina, R.V. Epishev, M.B. Zhilova, O.V. Zhukova, D.V. Zaslavsky, L.F. Znamenskaya, A.E. Karamova, L.S. Kruglova, Yu.G. Levina, A.N. Lvov, A.I. Materikin, O.S. Mishina, K.N. Monakhov, N.N. Murashkin, N.M. Nenasheva, A.N. Pampura, K.I. Plakhova, N.N. Potekaev, O.A. Pritulo, S.G. Sapuntsova, L.R. Selimzyanova, E.S. Fedenko, D.S. Fomina, N.V. Frigo, Z.V. Frolova, M.R. Khaitov, V.V. Chikin. All authors made a substantial contribution to the conception of the work, acquisition, analysis, interpretation of data for the work, drafting and revising the work, final approval of the version to be published and agree to be accountable for all aspects of the work.

\section{ЛИТЕРАТУРА}

1. Palmer C.N., Irvine A.D., Terron-Kwiatkowski A., et al. Common loss-of-function variants of the epidermal barrier protein filaggrin are a major predisposing factor for atopic dermatitis // Nat Genet. 2006. Vol. 38, N 4. P. 441-446. doi: 10.1038/ng 1767

2. McGirt L.Y., Beck L.A. Innate immune defects in atopic dermatitis // J Allergy Clin Immunol. 2006. Vol. 118, N 1. P. 202-208. doi: 10.1016/j.jaci.2006.04.033

3. Bao L., Zhang H., Chan L.S. The involvement of the JAKSTAT signaling pathway in chronic inflammatory skin disease atopic dermatitis // JAKSTAT. 2013. Vol. 2, N 3. P. e24137. doi: $10.4161 /$ jkst.24137

4. Gandhi N.A., Pirozzi G., Graham N.M. Commonality of the IL-4/IL-13 pathway in atopic diseases // Expert Rev Clin Immunol. 2017. Vol. 13, N 5. P. 425-437. doi: 10.1080/1744666X.2017.1298443 
5. Werfel T., Allam J.P., Biedermann T., et al. Cellular and molecular immunologic mechanisms in patients with atopic dermatitis // J Allergy Clin Immunol. 2016. Vol. 138, N 2. P. 336-349. doi: 10.1016/j.jaci.2016.06.010

6. Wollenberg A., Barbarot S., Bieber T., et al. Consensusbased European guidelines for treatment of atopic eczema (atopic dermatitis) in adults and children: part I // J Eur Acad Dermatol Venereol. 2018. Vol. 32, N 5. P. 657-682. doi: $10.1111 /$ jdv.14891

7. Кубанов А.А., Богданова Е.В. Организация и результаты оказания медицинской помощи по профилю дерматовенерология в Российской Федерации. Итоги 2018 года // Вестник дерматологии и венерологии. 2019. Т. 95, № 4. C. 8-23. doi: 10.25208/0042-4609-2019-95-4-8-23

8. Schneider L., Hanifin J., Boguniewicz M., et al. Study of the atopic march: development of atopic comorbidities // Pediatr Dermatol. 2016. Vol. 33, N 4. P. 388-398. doi: $10.1111 /$ pde. 12867

9. Bieber T. Atopic dermatitis 2.0: from the clinical phenotype to the molecular taxonomy and stratified medicine // Allergy. 2012. Vol. 67, N 12. P. 1475-1482. doi: 10.1111/all.12049

10. Van der Hulst A.E., Klip H., Brand P.L. Risk of developing asthma in young children with atopic eczema: a systematic review // J Allergy Clin Immunol. 2007. Vol. 120, N 3. P. 565-569. doi: 10.1016/j.jaci.2007.05.042

11. Eckert L., Gupta S., Amand C., et al. The burden of atopic dermatitis in US adults: Health care resource utilization data from the 2013 National Health and Wellness Survey // J Am Acad Dermatol. 2018. Vol. 78, N 1. P. 54-61.e1. doi: 10.1016/j.jaad.2017.08.002

12. Illi S., von Mutius E., Lau S., et al. The pattern of atopic sensitization is associated with the development of asthma in childhood // J Allergy Clin Immunol. 2001. Vol. 108, N 5. P. 709-714. doi: 10.1067/mai.2001.118786

13. Aw M., Penn J., Gauvreau G.M., et al. Atopic march: collegium internationale allergologicum update 2020 // Int Arch Allergy Immunol. 2020. Vol. 181, N 1. P. 1-10. doi: 10.1159/000502958

14. Spergel J.M. Epidemiology of atopic dermatitis and atopic march in children // Immunol Allergy Clin N Am. 2010. Vol. 30, N 3. P. 269-280. doi: 10.1016/j.iac.2010.06.003

15. Hill D.A., Spergel J.M. The atopic march: Critical evidence and clinical relevance // Ann Allergy Asthma Immunol. 2018. Vol. 120, N 2. P. 131-137. doi: 10.1016/j.anai.2017.10.037

16. Williams H., Flohr C. How epidemiology has challenged 3 prevailing concepts about atopic dermatitis // J Allergy Clin Immunol. 2006. Vol. 118, N 1. P. 209-213. doi: 10.1016/j.jaci.2006.04.043

17. Illi S., von Mutius E., Lau S., et al. The natural course of atopic dermatitis from birth to age 7 years and the association with asthma // J Allergy Clin Immunol. 2004. Vol. 113, N 5. P. 925-931. doi: 10.1016/j.jaci.2004.01.778

18. Атопический дерматит: рекомендации для практических врачей. Российский согласительный национальный документ по атопическому дерматиту / под ред. Р.М. Хаитова, А.А. Кубановой. Москва: Фармакус Принт, 2002. $192 \mathrm{c.}$

19. Hanifin J.M., Rajka G. Diagnostic features of atopic dermatitis // Acta Derm Venereol. 1980. Vol. 60, N 92. P. 44-47. doi: 10.2340/00015555924447

20. Eichenfield L.F., Tom W.L., Chamlin S.L., et al. Guidelines of care for the management of atopic dermatitis: section 1. Diagno- sis and assessment of atopic dermatitis // J Am Acad Dermatol. 2014. Vol. 70, N 2. P. 338-351. doi: 10.1016/j.jaad.2013.10.010

21. Ryan C., Amor K.T., Menter A. The use of cyclosporine in dermatology: part II // J Am Acad Dermatol. 2010. Vol. 63, N 6. P. 949-972. doi: 10.1016/j.jaad.2010.02.062

22. Arbes S.J., Gergen P.J., Elliott L., Zeldin D.C. Prevalences of positive skin test responses to 10 common allergens in the US population: results from the third National Health and $\mathrm{Nu}-$ trition Examination Survey // J Allergy Clin Immunol. 2005. Vol. 116, N 2. P. 377-383. doi: 10.1016/j.jaci.2005.05.017

23. Клиническая дерматовенерология: в 2 т. Т. ІІ / под ред. Ю.К. Скрипкина, Ю.С. Бутова. Москва: ГЭОТАР-Медиа, 2009. 928 с.

24. Futamura M., Leshem Y.A., Thomas K.S., et al. A systematic review of Investigator Global Assessment (IGA) in atopic dermatitis (AD) trials: Many options, no standards // J Am Acad Dermatol. 2016. Vol. 74, N 2. P. 288-294. doi: 10.1016/j.jaad.2015.09.062

25. Oranje A.P., Stalder J.F., Taieb A., et al. Scoring of atopic dermatitis by SCORAD using a training atlas by investigators from different disciplines. ETAC Study Group. Early Treatment of the Atopic Child // Pediatr Allergy Immunol. 1997. Vol. 8, N 1. P. 28-34. doi: 10.1111/j.1399-3038.1997.tb00139.x

26. Schram M.E., Spuls P.I., Leeflang M.M., et al. EASI, (objective) SCORAD and POEM for atopic eczema: responsiveness and minimal clinically important difference // Allergy. 2012. Vol. 67, N 1. P. 99-106. doi: 10.1111/j.1398-9995.2011.02719.x

27. Giam Y.C., Hebert A.A., Dizon M.V. A review on the role of moisturizers for atopic dermatitis // Asia Pac Allergy. 2016. Vol. 6, N 2. P. 120-128. doi: 10.5415/apallergy.2016.6.2.120

28. Breternitz M., Kowatzki D., Langenauer M., et al. Placebocontrolled, double-blind, randomized, prospective study of a glycerol-based emollient on eczematous skin in atopic dermatitis: biophysical and clinical evaluation // Skin Pharmacol Physiol. 2008. Vol. 21, N 1. P. 39-45. doi: 10.1159/000111134

29. Verallo-Rowell V.M., Dillague K.M., Syah-Tjundawan B.S. Novel antibacterial and emollient effects of coconut and virgin olive oils in adult atopic dermatitis // Dermatitis. 2008. Vol. 19, N 6. P. 308-315.

30. Simpson E., Dutronc Y. A new body moisturizer increases skin hydration and improves atopic dermatitis symptoms among children and adults // J Drugs Dermatol. 2011. Vol. 10, N 7. P. 744-749.

31. Lindh J.D., Bradley M. Clinical effectiveness of moisturizers in atopic dermatitis and related disorders: a systematic review // Am J Clin Dermatol. 2015. Vol. 16, N 5. P. 341-359. doi: 10.1007/s40257-015-0146-4

32. Miller D.W., Koch S.B., Yentzer B.A., et al. An over-thecounter moisturizer is as clinically effective as, and more cost-effective than, prescription barrier creams in the treatment of children with mild-to-moderate atopic dermatitis: a randomized, controlled trial // J Drugs Dermatol. 2011. Vol. 10, N 5. P. 531-537.

33. Grimalt R., Mengeaud V., Cambazard F. The steroid-sparing effect of an emollient therapy in infants with atopic dermatitis: a randomized controlled study // Dermatology. 2007. Vol. 214, N 1. P. 61-67. doi: 10.1159/000096915

34. Msika P., De Belilovsky C., Piccardi N., et al. New emollient with topical corticosteroid-sparing effect in treatment of childhood atopic dermatitis: SCORAD and quality of life improvement // Pediatr Dermatol. 2008. Vol. 25, N 6. P. 606612. doi: $10.1111 / \mathrm{j} .1525-1470.2008 .00783 . \mathrm{x}$ 
35. Lucky A.W., Leach A.D., Laskarzewski P., Wenck H. Use of an emollient as a steroid-sparing agent in the treatment of mild to moderate atopic dermatitis in children $/ / \mathrm{Pe}$ diatr Dermatol. 1997. Vol. 14, N 4. P. 321-324. doi: 10.1111/j.1525-1470.1997.tb00968.x

36. Eberlein B., Eicke C., Reinhardt H.W., Ring J. Adjuvant treatment of atopic eczema: assessment of an emollient containing N-palmitoylethanolamine (ATOPA study) // J Eur Acad Dermatol Venereol. 2008. Vol. 22, N 1. P. 73-82. doi: 10.1111/j.1468-3083.2007.02351.x

37. Sugarman J.L., Parish L.C. Efficacy of a lipid-based barrier repair formulation in moderate-to-severe pediatric atopic dermatitis // J Drugs Dermatol. 2009. Vol. 8, N 12. P. 1106-1111.

38. Leung T.N., Chow C.M., Chow M.P., et al. Clinical guidelines on management of atopic dermatitis in children // Hong Kong J Paediatr (new series). 2013. Vol. 18, N 2. P. 96-104.

39. Darsow U., Wollenberg A., Simon D., et al. ETFAD/EADV Eczema Task Force 2009 position paper on diagnosis and treatment of atopic dermatitis // J Eur Acad Dermatol Venereol. 2010. Vol. 24, N 3. P. 317-328. doi: 10.1111/j.1468-3083.2009.03415.x

40. Chiang C., Eichenfield L.F. Quantitative assessment of combination bathing and moisturizing regimens on skin hydration in atopic dermatitis // Pediatr Dermatol. 2009. Vol. 26, N 3. P. 273-278. doi: 10.1111/j.1525-1470.2009.00911.x

41. Guidance on Prescribing. In: British National Formulary No.60. London: British Medical Association and Royal Pharmaceutical Society of Great Britain; 2010.

42. Dabade T.S., Davis D.M., Wetter D.A., et al. Wet dressing therapy in conjunction with topical corticosteroids is effective for rapid control of severe pediatric atopic dermatitis: experience with 218 patients over 30 years at Mayo Clinic // J Am Acad Dermatol. 2012. Vol. 67, N 1. P. 100-106. doi: 10.1016/j.jaad.2011.06.025

43. Devillers A.C., Oranje A.P. Efficacy and safety of 'wet-wrap' dressings as an intervention treatment in children with severe and/or refractory atopic dermatitis: a critical review of the literature // Br J Dermatol. 2006. Vol. 154, N 4. P. 579-585. doi: 10.1111/j.1365-2133.2006.07157.x

44. Devillers A.C., de Waard-van der Spek F.B., Mulder P.G., Oranje A.P. Treatment of refractory atopic dermatitis using 'wet-wrap' dressings and diluted corticosteroids: results of standardized treatment in both children and adults // Dermatology. 2002. Vol. 204, N 1. P. 50-55. doi: 10.1159/000051810

45. Goodyear H.M., Spowart K., Harper J.I. 'Wet-wrap' dressings for the treatment of atopic eczema in children // Br J Dermatol. 1991. Vol. 125, N 6. P. 604. doi: 10.1111/j.1365-2133.1991.tb14807.x

46. Brenninkmeijer E.E., Spuls P.I., Lindeboom R., et al. Excimer laser vs. clobetasol propionate $0.05 \%$ ointment in prurigo form of atopic dermatitis: a randomized controlled trial, a pilot // Br J Dermatol. 2010. Vol. 163, N 4. P. 823-831. doi: 10.1111/j.1365-2133.2010.09858.x

47. Pels R., Sterry W., Lademann J. Clobetasol propionate where, when, why? // Drugs Today (Barc). 2008. Vol. 44, N 7. P. 547-557. doi: $10.1358 /$ dot.2008.44.7.1122221

48. Breneman D., Fleischer A.B., Kaplan D., et al. Clobetasol propionate $0.05 \%$ lotion in the treatment of moderate to severe atopic dermatitis: a randomized evaluation versus clobetasol propionate emollient cream // J Drugs Dermatol. 2005. Vol. 4, N 3. P. 330-336.

49. Feldman S.R. Relative efficacy and interchangeability of various clobetasol propionate vehicles in the management of ste- roid-responsive dermatoses // Curr Ther Res Clin Exp. 2005. Vol. 66, N 3. P. 154-171. doi: 10.1016/j.curtheres.2005.06.010

50. Datz B., Yawalkar S. A double-blind, multicenter trial of $0.05 \%$ halobetasol propionate ointment and $0.05 \%$ clobetasol 17-propionate ointment in the treatment of patients with chronic, localized atopic dermatitis or lichen simplex chronicus // J Am Acad Dermatol. 1991. Vol. 25, N 6, Pt 2. P. 11571160. doi: 10.1016/0190-9622(91)70316-t

51. Viglioglia P., Jones M.L., Peets E.A. Once-daily $0.1 \%$ mometasone furoate cream versus twice-daily $0.1 \%$ betamethasone valerate cream in the treatment of a variety of dermatoses // J Int Med Res. 1990. Vol. 18, N 6. P. 460-467. doi: $10.1177 / 030006059001800603$

52. Vanderploeg D.E. Betamethasone dipropionate ointment in the treatment of psoriasis and atopic dermatitis: a doubleblind study // South Med J. 1976. Vol. 69, N 7. P. 862-863. doi: 10.1097/00007611-197607000-00017

53. Queille C., Pommarede R., Saurat J.H. Efficacy versus systemic effects of six topical steroids in the treatment of atopic dermatitis of childhood // Pediatr Dermatol. 1984. Vol. 1, N 3. P. 246-253.

54. Cabrera M.E. Treatment of severe or resistant corticosteroidresponsive dermatoses with Diprolene cream // J Int Med Res. 1984. Vol. 12, N3.P. 163-169. doi: 10.1177/030006058401200305

55. Lodolo J.C. Diprolene cream in the treatment of severe or resistant corticosteroid-responsive dermatoses // J Int Med Res. 1984. Vol. 12, N 2. P. 114-120. doi: 10.1177/030006058401200209

56. Peterkin G.A., Morley W.N., Chalmers D. Triamcinolone and fluocinolone acetonide ointments in atopic eczema // Br Med J. 1962. Vol. 1, N 5289. P. 1392. doi: 10.1136/bmj.1.5289.1392

57. Hanifin J.M. Atopic dermatitis. Special clinical complications // Postgrad Med. 1983. Vol. 74, N 3. P. 188-199. doi: 10.1080/00325481.1983.11698425

58. Cadmus S.D., Sebastian K.R., Warren D. et al. Efficacy and patient opinion of wet-wrap dressings using $0.1 \%$ triamcinolone acetonide ointment vs cream in the treatment of pediatric atopic dermatitis: a randomized split-body control study // PediatrDermatol. 2019. Vol. 36, N 4. P. 437-441.

59. Wolkerstorfer A., Strobos M.A., Glazenburg E.J., et al. Fluticasone propionate $0.05 \%$ cream once daily versus clobetasone butyrate $0.05 \%$ cream twice daily in children with atopic dermatitis // J Am Acad Dermatol. 1998. Vol. 39, N 2, Pt 1. P. 226-231. doi: 10.1016/s0190-9622(98)70080-5

60. Bleehen S.S., Chu A.C., Hamann I., et al. Fluticasone propionate $0.05 \%$ cream in the treatment of atopic eczema: a multicentre study comparing once-daily treatment and oncedaily vehicle cream application versus twice-daily treatment // Br J Dermatol. 1995. Vol. 133, N 4. P. 592-597. doi: 10.1111/j.1365-2133.1995.tb02711.x

61. Белоусова Т.А., Горячкина М.В. Опыт применения флутиказона пропионата (Кутивейт) в терапии псориаза, экземы и атопического дерматита // Эффективная фармакотерапия. 2010. № 9. Р. 24-29.

62. Prakash A., Benfield P. Topical mometasone. A review of its pharmacological properties and therapeutic use in the treatment of dermatological disorders // Drugs. 1998. Vol. 55, N 1. P. 145-163. doi: 10.2165/00003495-199855010-00009

63. Vernon H.J., Lane A.T., Weston W. Comparison of mometasone furoate $0.1 \%$ cream and hydrocortisone $1.0 \%$ cream in the treatment of childhood atopic dermati- 
tis // J Am Acad Dermatol. 1991. Vol. 24, N 4. P. 603-607. doi: 10.1016/0190-9622(91)70092-g

64. Lebwohl M. A comparison of once-daily application of mometasone furoate $0.1 \%$ cream compared with twice-daily hydrocortisone valerate $0.2 \%$ cream in pediatric atopic dermatitis patients who failed to respond to hydrocortisone: mometasone furoate study group // Int J Dermatol. 1999. Vol. 38, N 8. P. 604-606. doi: 10.1046/j.1365-4362.1999.00759.x

65. Томилова А.Ю., Торшхоева Р.М., Геворкян А.К., Вознесенская Н.И. Эффективность и безопасность применения мометазона фуроата при атопическом дерматите у детей // Педиатрическая фармакология. 2009. T. 6, №4. С. 123-127.

66. Шаипов Т.С., Мазитова Л.П. Применение мометазона фуроата при лечении атопического дерматита у детей // Педиатрическая фармакология. 2007. Т. 4, № 5. C. $41-44$.

67. Ненашева Н.М. Особенности атопического дерматита у взрослых пациентов Эффективная фармакотерапия // Дерматовенерология и дерматокосметология. 2012. № 3. С. $6-15$.

68. Lane A.T. Efficacy and safety of topical steroids in paediatric atopic dermatitis // J Eur Acad Dermatol Venereol. 1997. Vol. 8. P. S24-S27.

69. Faergemann J., Christensen O., Sjövall P. et al. An open study of efficacy and safety of long-term treatment with mometasone furoate fatty cream in the treatment of adult patients with atopic dermatitis // J Eur Acad Dermatol Venereol. 2000. Vol. 14, N 5. P. 393-396.

70. Haneke E. The treatment of atopic dermatitis with methylprednisolone aceponate (MPA), a new topical corticosteroid // J Dermatol Treatm. 2009. Vol. 3, Suppl. 2. P. 13-15. doi: 10.3109/09546639209092767

71. Luger T.A. Balancing efficacy and safety in the management of atopic dermatitis: the role of methylprednisolone aceponate // J Eur Acad Dermatol Venereol. 2011. Vol. 25, N 3. P. 251-258. doi: 10.1111/j.1468-3083.2010.03789.x

72. Bieber T., Vick K., Fölster-Holst R., et al. Efficacy and safety of methylprednisolone aceponate ointment $0.1 \%$ compared to tacrolimus $0.03 \%$ in children and adolescents with an acute flare of severe atopic dermatitis // Allergy. 2007. Vol. 62, N 2. P. 184-189. doi: 10.1111/j.1398-9995.2006.01269.x

73. Кондратьева Ю.С., Кархова В.В. Опыт применения $0,1 \%$ метилпреднизолона ацепоната в комплексной терапии стероидчувствительных дерматозов // Вестник дерматологии и венерологии. 2016. № 1. С. 93-98.

74. Чикин В.В. Метилпреднизолона ацепонат и декспантенол в топической терапии больных АтД // Вестник дерматологии и венерологии 2014. Т. 90, № 5. С. 112-116. doi: 10.25208/0042-4609-2014-90-5-112-116

75. Lassus A. Alclometasone dipropionate cream $0.05 \%$ versus clobetasone butyrate cream $0.05 \%$. A controlled clinical comparison in the treatment of atopic dermatitis in children // Int J Dermatol. 1984. Vol. 23, N 8. P. 565-566. doi: 10.1111/j.1365-4362.1984.tb04214.x

76. Panja S.K., Gangopadhaya A.K., Sharma S.D. A randomised, double-blind comparison of alclometasone dipropionate $0.05 \%$ cream in atopic dermatitis and other dermatoses // Indian J Dermatol. 1988. Vol. 33, N 1. P. 1-4.

77. Макарова И.В., Гайдук И.М., Жиглинская О.В., и др. Применение $0,05 \%$ крема алклометазона дипропионата в терапии атопического дерматита у детей раннего воз- раста // Вопросы современной педиатрии. 2004. Т. 3, № 4. C. $84-87$.

78. Короткий Н.Г., Тихомиров А.А., Гамаюнов Б.Н. Оценка клинической эффективности современного стероида алклометазонадипропионата (Афлодерма) в наружной терапии атопического дерматита у детей // Клиническая дерматология и венерология. 2007. № 6. С. 24-31.

79. Торопова Н.П., Черкасова Л.А., Платонова И.Н., и др. Опыт применения препарата «Афлодерм» (алклометазонадипропионат) в детской дерматологической практике // Российский журнал кожных и венерических болезней. 2003. № 3. С. 39-40.

80. Veien N.K., Hattel T., Justesen O., et al. Hydrocortisone 17-butyrate (Locoid) $0.1 \%$ cream versus hydrocortisone (Uniderm) $1 \%$ cream in the treatment of children suffering from atopic dermatitis // J Int Med Res. 1984. Vol. 12, N 5. P. 310-313. doi: 10.1177/030006058401200509

81. Rajka G., Verjans H.L. Hydrocortisone 17-butyrate (Locoid) $0.1 \%$ fatty cream versus desonide (Apolar) $0.1 \%$ ointment in the treatment of patients suffering from atopic dermatitis // J Int Med Res. 1986. Vol. 14, N 2. P. 85-90. doi: 10.1177/030006058601400206

82. Abramovits A., Oquendo M. Hydrocortisone butyrate $0.1 \%$ lipocream in pediatric patients with atopic dermatitis // SKINmed. 2010. Vol. 8, N 2. P. 72-79.

83. Koopmans B., Lasthein Andersen B., Mork N.J., et al. Multicentre randomized double-blind study of locoid lipocream fatty cream twice daily versus locoid lipocream once daily and locobase once daily // J Dermatol Treat. 1995. Vol. 6, N 2. P. 103-106. doi: 10.3109/09546639509097161

84. Saki N., Jowkar F., Alyaseen S., et al. Comparison of sertaconazole $2 \%$ cream versus hydrocortisone $1 \%$ ointment in the treatment of atopic dermatitis // J Dermatolog Treat. 2013. Vol. 24, N 6. P. 447-449. doi: 10.3109/09546634.2013.782384

85. Reitamo S., Rustin M., Ruzicka T., et al. Efficacy and safety of tacrolimus ointment compared with hydrocortisone butyrate ointment in adult patients with atopic dermatitis // J Allergy Clin Immunol. 2002. Vol. 109, N 3. P. 547-555. doi: 10.1067/mai.2002.121832

86. Matheson R., Kempers S., Breneman D., et al. Hydrocortisone butyrate $0.1 \%$ lotion in the treatment of atopic dermatitis in pediatric subjects // J Drugs Dermatol. 2008. Vol. 7, N 3. P. 266-271.

87. Sears H.W., Bailer J.W., Yeadon A. Efficacy and safety of hydrocortisone buteprate $0.1 \%$ cream in patients with atopic dermatitis // Clin Ther. 1997. Vol. 19, N 4. P. 710-719.

88. Игнатьев Д.В., Кочергин Н.Г. Местные кортикостероиды в практике врача-дерматолога. Особенности гидрокортизона бутирата (локоида) // Дерматология. Приложение к журналу Consilium Medicum. 2007. № 1. C. $50-54$.

89. Udompataikul M., Limpa-o-Vart D. Comparative trial of $5 \%$ dexpanthenol in water-in-oil formulation with $1 \%$ hydrocortisone ointment in the treatment of childhood atopic dermatitis: a pilot study // J Drugs Dermatol. 2012. Vol. 11, N 3. P. $366-374$.

90. Udompataikul M., Srisatwaja W. Comparative trial of moisturizer containing licochalcone A vs. hydrocortisone lotion in the treatment of childhood atopic dermatitis: a pilot study // J Eur Acad Dermatol Venereol. 2011. Vol. 25, N 6. Р. 660-665.

91. Сергеев Ю.В., Иванов О.Л., Новиков Д.К., и др. Атопический дерматит: современная диагностика и лече- 
ние // Иммунопатология, аллергология, инфектология. 2001. № 4. C. 39-63.

92. Ashcroft D.M., Dimmock P., Garside R., et al. Efficacy and tolerability of topical pimecrolimus and tacrolimus in the treatment of atopic dermatitis: meta-analysis of randomised controlled trials // BMJ. 2005. Vol. 330, N 7490. P. 516.

93. Ruzicka T., Bieber T., Schöpf E., et al. A shortterm trial of tacrolimus ointment for atopic dermatitis // N Engl J Med. 1997. Vol. 337, N 12. P. 816-821. doi: 10.1056/NEJM199709183371203

94. Reitamo S., Wollenberg A., Schöpf E., et al. Safety and efficacy of 1 year of tacrolimus ointment monotherapy in adults with atopic dermatitis // Arch Dermatol. 2000. Vol. 136, N 8. P. 999-1006. doi: 10.1001/archderm.136.8.999

95. Chen S.L., Yan J., Wang F.S. Two topical calcineurin inhibitors for the treatment of atopic dermatitis in pediatric patients: a meta-analysis of randomized clinical trials // J Dermatolog Treat. 2010. Vol. 21, N 3. P. 144-156. doi: 10.3109/09546630903401470

96. Bornhövd E.C., Burgdorf W.H., Wollenberg A. Immunomodulatory macrolactams for topical treatment of inflammatory skin diseases // Curr Opin Investig Drugs. 2002. Vol. 3, N 5. P. 708-712.

97. Lubbe J. Klinische Erfahrungen mit topischen Calcineurininhibitoren in der Praxis // Hautarzt. 2003. Vol. 54, N 5. P. 432-439.

98. Reitamo S., Ortonne J.P., Sand C., et al. A multicentre, randomized, double-blind, controlled study of long-term treatment with $0.1 \%$ tacrolimus ointment in adults with moderate to severe atopic dermatitis // Br J Dermatol. 2005. Vol. 152, N 6. P. 1282-1289. doi: 10.1111/j.1365-2133.2005.06592.x

99. Patel R.R., Vander Straten M.R., Korman N.J. The safety and efficacy of tacrolimus therapy in patients younger than 2 years with atopic dermatitis // Arch Dermatol. 2003. Vol. 139, N 9. P. 1184-1186. doi: 10.1001/archderm.139.9.1184

100. Wollenberg A., Sidhu M.K., Odeyemi I., et al. Economic evaluation of secondary prophylactic treatment with tacrolimus $0.1 \%$ ointment in adults with moderate to severe atopic dermatitis // Br J Dermatol. 2008. Vol. 159, N 6. P. 13221330. doi: 10.1111/j.1365-2133.2008.08807.x

101. Healy E., Bentley A., Fidler C., Chambers C. Cost-effectiveness of tacrolimus ointment in adults and children with moderate and severe atopic dermatitis: twice-weekly maintenance treatment vs. standard twicedaily reactive treatment of exacerbations from a third party payer (U.K. National Health Service) perspective // Br J Dermatol. 2011. Vol. 164, N 2. P. 387-395. doi: 10.1111/j.1365-2133.2010.10141.x

102. Reitamo S., Mandelin J., Rubins A., et al. The pharmacokinetics of tacrolimus after first and repeated dosing with $0.03 \%$ ointment in infants with atopic dermatitis // Int J Dermatol. 2009. Vol. 48, N 4. P. 348-355. doi: 10.1111/j.1365-4632.2009.03853.x

103. Reitamo S., Rustin M., Harper J., et al. A 4-year follow-up study of atopic dermatitis therapy with $0.1 \%$ tacrolimus ointment in children and adult patients $/ / \mathrm{Br}$ J Dermatol. 2008. Vol. 159, N 4. P. 942-951. doi: 10.1111/j.1365-2133.2008.08747.x Ruzicka

104. Mandelin J.M., Remitz A., Virtanen H.M., et al. A 10-year open follow-up of eczema and respiratory symptoms in patients with atopic dermatitis treated with topical tacrolimus for the first 4 years // J Dermatolog Treat. 2010. Vol. 21, N 3. P. 167-170. doi: 10.3109/09546630903493329
105. Mandelin J., Remitz A., Virtanen H.M., et al. One-year treatment with $0.1 \%$ tacrolimus ointment versus a corticosteroid regimen in adults with moderate to severe atopic dermatitis: a randomized, double-blind, comparative trial // Acta Derm Venereol. 2010. Vol. 90, N 2. P. 170-174. doi: 10.2340/00015555-0803

106. Boguniewicz M., Fiedler V.C., Raimer S., et al. A randomized, vehicle-controlled trial of tacrolimus ointment for treatment of atopic dermatitis in children. Pediatric Tacrolimus Study Group // J Allergy Clin Immunol. 1998. Vol. 102, N 4, Pt 1. P. 637-644. doi: 10.1016/s0091-6749(98)70281-7

107. Елисютина О.Г., Феденко Е.С., Штырбул О.В., Ниязов Д.Д. Применение такролимуса у больных атопическим дерматитом среднетяжелого и тяжелого течения. Первый клинический опыт в России // Российский аллергологический журнал. 2011. № 6. С. 68-76.

108. Прошутинская Д.В., Бутарева М.М., Иноятова Л.А. Новые возможности терапии атопического дерматита у детей и взрослых // Вестник дерматологии и венерологии. 2013. № 3. С. 78-82.

109. Самцов А.В., Сухарев А.В., Патрушев А.В., Бондарь О.И. Клиническая эффективность, безопасность и переносимость $0,1 \%$ мази такролимус при лечении атопического дерматита средней и тяжелой степени тяжести // Вестник дерматологии и венерологии. 2012. № 2. C. 71-77.

110. Самцов А.В., Сухарев А.В., Патрушев А.В. Лечение атопического дерматита: преимущества такролимуса перед топическими кортикостероидами // Эффективная фармакотерапия. 2014. № 19. С. 4-10.

111. Van Leent E.J., Graber M., Thurston M., et al. Effectiveness of the ascomycin macrolactam SDZ ASM 981 in the topical treatment of atopic dermatitis // Arch Dermatol. 1998. Vol. 134, N 7. P. 805-809. doi: 10.1001/archderm.134.7.805

112. Meurer M., Fölster-Holst R., Wozel G., et al. Pimecrolimus cream in the long-term management of atopic dermatitis in adults: a six-month study // Dermatology. 2002. Vol. 205, N 3. P. 271-277. doi: $10.1159 / 000065863$

113. Wahn U., Bos J., Goodfield M., et al. Efficacy and safety of pimecrolimus cream in the long-term management of atopic dermatitis in children // Pediatrics. 2002. Vol. 110, N 1, Pt 1. P. e2. doi: 10.1542/peds.110.1.e2

114. Ho V.C., Gupta A., Kaufmann R., et al. Safety and efficacy of nonsteroid pimecrolimus cream $1 \%$ in the treatment of atopic dermatitis in infants // J Pediatr. 2003. Vol. 142, N 2. P. 155-162. doi: $10.1067 / \mathrm{mpd} .2003 .65$

115. Eichenfield L.F., Lucky A.W., Boguniewicz M., et al. Safety and efficacy of pimecrolimus (ASM 981) cream $1 \%$ in the treatment of mild and moderate atopic dermatitis in children and adolescents // J Am Acad Dermatol. 2002. Vol. 46, N 4. P. 495-504. doi: 10.1067/mjd.2002.122187

116. Langley R.G., Eichenfield L.F., Lucky A.W., et al. Sustained efficacy and safety of pimecrolimus cream $1 \%$ when used long-term (up to 26 weeks) to treat children withatopic dermatitis // Pediatr Dermatol. 2008. Vol. 25, N 3. P. 301307. doi: 10.1111/j.1525-1470.2008.00671.x

117. Luger T., van Leent E.J., Graeber M., et al. SDZ ASM 981: an emerging safe and effective treatment for atopic dermatitis // Br J Dermatol. 2001. Vol. 144, N 4. P. 788-794. doi: 10.1046/j.1365-2133.2001.04134.x

118. Eichenfield L.F., Thaci D., de Prost Y., et al. Clinical management of atopic eczema with pimecrolimus cream $1 \%$ 
(Elidel) in paediatric patients // Dermatology. 2007. Vol. 11, Suppl 1. P. 3-17. doi: 10.1159/000102116

119. Reda A.M., Elgendi A., Ebraheem A.I., et al. A practical algorithm for topical treatment of atopic dermatitis in the Middle East emphasizing the importance of sensitive skin areas // J Dermatolog Treat. 2019. Vol. 30, N 4. P. 366-373. doi: 10.1080/09546634.2018.1524823

120. Кубанов А.А., Петровский Ф.И. Активированный пиритион цинка (Скин-кап). Механизмы действия. Клиническое применение // Вестник дерматологии и венерологии. 2009. № 5. С. 35-42.

121. Фассахов Р.С., Пампура А.Н., Коростовцев Д.С., и др. Скин-Кап в терапии атопического дерматита у детей (по результатам российского многоцентрового исследования КАДЕТ) // Российский аллергологический журнал. 2007. № 2. С. 75-81.

122. Фассахов Р.С., Пампура А.Н., Коростовцев Д.С., и др. Эффективность и безопасность активированного цинк пиритиона (скин-кап) в лечении атопического дерматита у детей (результаты российского многоцентрового исследования) // Вестник педиатрической фармакологии и нутрициологии. 2006. Т. 3, № 6. С. 28-31.

123. Нейродерматозы. В кн.: Кожные и венерические болезни: Руководство для врачей. В двух томах. 2-е изд., перераб. и доп. Т. 2 / под ред. Ю.К. Скрипкина, В.Н. Мордовцева. Москва: Медицина, 1999. С. 9-49.

124. Yoshida H., Niimura M., Ueda H., et al. Clinical evaluation of ketotifen syrup on atopic dermatitis: a comparative multicenter double-blind study of ketotifen and clemastine // Ann Allergy. 1989. Vol. 62, N 6. P. 507-512.

125. Григорьева И., Сергеев А., Манина И., Кудрявцева Е. Иммунопатология и биохимические основы атопических состояний // Врач. 2012. № 4. С. 86-91.

126. Морозова С.В., Лусс Л.В. Хлоропирамин: современные аспекты применения // Вопросы современной педиатрии. 2007. Т. 6, № 1. С. 137-140.

127. Горячкина М.В., Белоусова Т.А. Хлоропирамин: клинические аспекты применения // Русский медицинский журнал. Медицинское обозрение. 2014. Т. 22, № 24. С. 1785-1789.

128. Петрова К.С., Петрова Г.А. Хлоропирамин (супрастин) - современные аспекты применения в терапии аллергодерматозов // Русский медицинский журнал. 2014. T. 22, № 8. C. 617-620.

129. Ревякина В.А. Антигистаминные препараты в клинической практике // Русский медицинский журнал. 2014. T. 22, № 11. C. 854-856.

130. Behrendt H., Ring J. Histamine, antihistamines and atopic eczema // Clin Exp Allergy. 1990. Vol. 20, Suppl 4. P. 2530. doi: 10.1111/j.1365-2222.1990.tb02473.x

131. Langeland T., Fagertun H.E., Larsen S. Therapeutic effect of loratadine on pruritus in patients with atopic dermatitis. A multi-crossover-designed study // Allergy. 1994. Vol. 49, N 1. P. 22-26. doi: 10.1111/j.1398-9995.1994.tb00768.x

132. Monroe E.W. Relative efficacy and safety of loratadine, hydroxyzine, and placebo in chronic idiopathic urticaria and atopic dermatitis // Clin Ther 1992. Vol. 14, N 1. P. 17-21.

133. Попова И.С., Матушевская Е.В., Свирщевская Е.В. Двойное слепое плацебоконтролируемое исследование эффективности и переносимости кларотадина при атопическом дерматите // РМЖ. 2001. Т. 9, № 4. C. $477-483$.
134. Hannuksela M., Kalimo K., Lammintausta K., et al. Dose ranging study: cetirizine in the treatment of atopic dermatitis in adults // Ann Allergy. 1993. Vol. 70, N 2. P. 127-133.

135. La Rosa M., Ranno C., Musarra I., et al. Double-blind study of cetirizine in atopic eczema in children // Ann Allergy. 1994. Vol. 73, N 2. P. 117-122.

136. Павлова О.В. Опыт применения цетиризина (аллертека) в терапии больных атопическим дерматитом и экземой // Вестник дерматологии и венерологии. 2005. № 4. C. 41-43.

137. Макарова И.В., Жиглинская О.В., Михайлова Е.А., Сухорукова В.Г. Сравнительная эффективность препаратов цетиризина дженерика (производство Эгис, Венгрия) и оригинального в форме капель в комплексной терапии атопического дерматита у детей раннего возраста // Вопросы современной педиатрии. 2007. Т. 6, № 3. C. $85-88$.

138. Самсыгина Г.А. Аллергические болезни у детей. Москва: ГЭОТАР-Медиа, 2019. 272 с.

139. Делягин В.М., Уразбагамбетов А. Применение Супрастинекса (левоцетиризина) при атопии у детей и подростков // Русский медицинский журнал. 2012. T. 20, № 16. С. 828-830.

140. Елисютина О.Г., Феденко Е.С., Федоскова Т.Г., Лусс Л.В. Эффективность терапии левоцетиризином больных с аллергодерматозами // Российский аллергологический журнал. 2012. № 5. С. 69-75.

141. Тамразова О.Б. Патогенетическая терапия детей, страдающих тяжелыми формами атопического дерматита // Русский медицинский журнал. 2013. № 2. C. $108-114$.

142. Нажмутдинова Д.К., Швец О.И. Левоцетиризин: перезагрузка // Русский медицинский журнал. 2011. Т. 19, № 21. С. 1324-1326.

143. Камаев А.В., Трусова О.В., Камаева И.А. Зуд при атопическом дерматите у детей: известные механизмы и возможности его долгосрочного контроля // Русский медицинский журнал. 2015. Т. 23, № 3. С. 142-146.

144. Монахов С.А., Коржачкина Н.Б., Олисова О.Ю. Узковолновая фототерапия 311 нм в лечении больных атопическим дерматитом // Российский журнал кожных и венерических болезней. 2012. № 3. С. 25-27.

145. Majoie I.M., Oldhoff J.M., van Weelden H., et al. Narrowband ultraviolet B and medium-dose ultraviolet A1 are equally effective in the treatment of moderate to severe atopic dermatitis // J Am Acad Dermatol. 2009. Vol. 60, N 1. P. 77-84. doi: 10.1016/j.jaad.2008.08.048

146. Reynolds N.J., Franklin V., Gray J.C., et al. Narrowband ultraviolet $\mathrm{B}$ and broad-band ultraviolet A phototherapy in adult atopic eczema: a randomised controlled trial // Lancet. 2001. Vol. 357, N 9273. P. 2012-2016. doi: 10.1016/S0140-6736(00)05114-X

147. Clayton T.H., Clark S.M., Turner D., Goulden V. The treatment of severe atopic dermatitis in childhood with narrowband ultraviolet B phototherapy // Clin Exp Dermatol. 2007. Vol. 32, N 1. P. 28-33.

148. Seccombe L., Wynne M.D., Clancy C., et al. A retrospective review of phototherapy in children, at a tertiary paediatric dermatology unit // Photodermatol Photoimmunol Photomed. 2021. Vol. 37, N 1. P. 34-38.

149. Gambichler T., Othlinghaus N., Tomi N.S., et al. Mediumdose ultraviolet (UV) A1 vs. narrowband UVB photother- 
apy in atopic eczema: a randomized crossover study // Br J Dermatol. 2009. Vol. 160, N 3. P. 652-658. doi: 10.1111/j.1365-2133.2008.08984.x

150. Bogaczewicz J., Malinowska K., Sysa-Jedrzejowska A., Wozniacka A. Medium-dose ultraviolet A1 phototherapy improves SCORAD index and increases mRNA expression of interleukin-4 without direct effect on human $\beta$ defensin-1, interleukin-10, and interleukin-31 // Int J Dermatol. 2016. Vol. 55, N 7. P. e380-385. doi: 10.1111/ijd.13213

151. TzanevaS., Seeber A., Schwaiger M., et al. High-dose versus medium-dose UVA1 phototherapy for patients with severe generalized atopic dermatitis // J Am Acad Dermatol. 2001. Vol. 45. P. 503-507.

152. Malinowska K., Wozniacka A., Bogaczewicz J. The impact of medium dose UVA1 phototherapy on pruritus, DLQI and SCORAD index in patients with atopic dermatitis // Postepy Dermatol Alergol. 2020. Vol. 37, N 6. P. 962-967.

153. Abeck D., Schmidt T., Fesq H., et al. Long-term efficacy of medium-dose UVA1 phototherapy in atopic dermatitis // J Am Acad Dermatol. 2000. Vol. 42, N 2, Pt 1. P. 254-257.

154. Pugashetti R., Lim H.W., Koo J. Broadband UVB revisited: is the narrowband UVB fad limiting our therapeutic options? // J Dermatolog Treat. 2010. Vol. 21, N 6. P. 326330. doi: 10.3109/09546630903341986

155. Tzaneva S., Kittler H., Holzer G., et al. 5-Methoxypsoralen plus ultraviolet (UV) A is superior to medium-dose UVA1 in the treatment of severe atopic dermatitis: a randomized crossover trial // Br J Dermatol. 2010. Vol. 162, N 3. P. 655660. doi: 10.1111/j.1365-2133.2009.09514.x

156. Garritsen F.M., Brouwer M.W., Limpens J., Spuls P.I. Photo(chemo)therapy in the management of atopic dermatitis: an updated systematic review with implications for practice and research // Br J Dermatol. 2014. Vol. 170, N 3. P. 501-513. doi: 10.1111/bjd.12645

157. Pérez-Ferriols A., Aranegui B., Pujol-Montcusí J.A., et al. Phototherapy in atopic dermatitis: a systematic review of the literature // Actas Dermosifiliogr. 2015. Vol. 106, N 5. P. 387-401. doi: 10.1016/j.ad.2014.12.017

158. Uetsu N., Horio T. Treatment of persistent severe atopic dermatitis in 113 Japanese patients with oral psoralen photochemotherapy // J Dermatol. 2003. Vol. 30, N 6. P. 450457. doi: 10.1111/j.1346-8138.2003.tb00415.x

159. Физическая и реабилитационная медицина. Национальное руководство / под ред. Г.Н. Пономаренко. Москва: ГЭОТАР-Медиа, 2016. 688 с.

160. Частная физиотерапия: Учебное пособие / под ред. Г.Н. Пономаренко. Москва: Медицина, 2005. 744 с.

161. Patrizi A., Raone B., Ravaioli G.M. Management of atopic dermatitis: safety and efficacy of phototherapy // Clin Cosmet Investig Dermatol. 2015. Vol. 8. P. 511-520. doi: 10.2147/CCID.S87987

162. Dogra S., Mahajan R. Indian Association of Dermatologists, Venereologists and Leprologists. Phototherapy for atopic dermatitis // Indian J Dermatol Venereol Leprol. 2015. Vol. 81, N 1. P. 10-15. doi: 10.4103/0378-6323.148557

163. Кубанова А.А., Самсонов В.А., Волнухин В.А., и др. Терапия больных псориазом, атопическим дерматитом и витилиго узкополосным средневолновым ультрафиолетовым излучением с длиной волны 311 нм. Медицинская технология № ФС-2006/250 от 15 августа 2006 года // Вестник дерматологии и венерологии. 2008. № 3. C. 17-20.
164. Thompson K.G., Kim N. Distinguishing myth from fact: photocarcinogenesis and phototherapy // Dermatol Clin. 2020. Vol. 38, N 1. P. 25-35. doi: 10.1016/j.det.2019.08.003

165. Paller A.S., Siegfried E.C., Thaçi D., et al. Efficacy and safety of dupilumab with concomitant topical corticosteroids in children 6 to 11 years old with severe atopic dermatitis: A randomized, double-blinded, placebo-controlled phase 3 trial // J Am Acad Dermatol. 2020. Vol. 83, N 5. P. 1282-1293.

166. Paller A.S., Bansal A., Simpson E.L., et al. Clinically meaningful responses to dupilumab in adolescents with uncontrolled moderate-to-severe atopic dermatitis: Post-hoc analyses from a randomized clinical trial // Am J Clin Dermatol. 2020. Vol. 21, N 1. P. 119-131.

167. Simpson E.L., Paller A.S., Siegfried E.C., et al. Efficacy and safety of dupilumab in adolescents with uncontrolled moderate to severe atopic dermatitis: A phase 3 randomized clinical trial // JAMA Dermatol. 2020. Vol. 156, N 1. P. 44-56.

168. Cork M.J., Thaçi D., Eichenfield L.F., et al. Dupilumab in adolescents with uncontrolled moderate-to-severe atopic dermatitis: results from a phase IIa open-label trial and subsequent phase III open-label extension // Br J Dermatol. 2020. Vol. 182, N 1. P. 85-96.

169. Simpson E.L., Bieber T., Guttman-Yassky E., et al. Two phase 3 trials of dupilumab versus placebo in atopic dermatitis // N Engl J Med. 2016. Vol. 375, N 24. P. 2335-2348. doi: 10.1056/NEJMoa1610020

170. Blauvelt A., de Bruin-Weller M., Gooderham M., et al. Long-term management of moderate-to-severe atopic dermatitis with dupilumab and concomitant topical corticosteroids (LIBERTY AD CHRONOS): a 1-year, randomised, double-blinded, placebo-controlled, phase 3 trial // Lancet. 2017. Vol. 389, N 10086. P. 2287-2303. doi: 10.1016/S0140-6736(17)31191-1

171. De Bruin-Weller M., Thaçi D., Smith C.H., et al. Dupilumab with concomitant topical corticosteroid treatment in adults with atopic dermatitis with an inadequate response or intolerance to ciclosporin A or when this treatment is medically inadvisable: a placebo-controlled, randomized phase III clinical trial (LIBERTY AD CAFÉ) // Br J Dermatol. 2018. Vol. 178, N 5. P. 1083-1101. doi: 10.1111/bjd.16156

172. Thaçi D., L Simpson E., Deleuran M., et al. Efficacy and safety of dupilumab monotherapy in adults with moderateto-severe atopic dermatitis: a pooled analysis of two phase 3 randomized trials (LIBERTY AD SOLO 1 and LIBERTY AD SOLO 2) // J Dermatol Sci. 2019. Vol. 94, N 2. P. 266275. doi: 10.1016/j.jdermsci.2019.02.002

173. Cork M.J., Eckert L., Simpson E.L., et al. Dupilumab improves patient-reported symptoms of atopic dermatitis, symptoms of anxiety and depression, and health-related quality of life in moderate-to-severe atopic dermatitis: analysis of pooled data from the randomized trials SOLO 1 and SOLO 2 // J Dermatolog Treat. 2020. Vol. 31, N 6. P. 606614. doi: 10.1080/09546634.2019.1612836

174. Snast I., Reiter O., Hodak E., et al. Are biologics efficacious in atopic dermatitis? A systematic review and meta-analysis // Am J Clin Dermatol. 2018. Vol. 19, N 2. P. 145-165. doi: 10.1007/s40257-017-0324-7

175. Wang F.P., Tang X.J., Wei C.Q., et al. Dupilumab treatment in moderate-to-severe atopic dermatitis: A systematic review and meta-analysis // J Dermatol Sci. 2018. Vol. 90, N 2. P. 190-198. doi: 10.1016/j.jdermsci.2018.01.016 
176. Czech W., Brautigam M., Weidinger G., Schöpf E. Body weight independent dosing regimen of cyclosporine microemulsion is effective in severe atopic dermatitis and improves the quality of life // J Am Acad Dermatol. 2000. Vol. 42, N 4. P. 653-659.

177. Harper J.I., Ahmed I., Barclay G., et al. Cyclosporin for severe childhood atopic dermatitis: short course versus continuous therapy // Br J Dermatol 2000. Vol. 142, N 1. P. 52-58. doi: 10.1046/j.1365-2133.2000.03241.x

178. Granlund H., Erkko P., Remitz A., et al. Comparison of cyclosporin and UVAB phototherapy for intermittent one-year treatment of atopic dermatitis // Acta Derm Venereol 2001. Vol. 81, N 1. P. 22-27. doi: 10.1080/00015550120235

179. Zurbriggen B., Wuthrich B., Cachelin A.B., et al. Comparison of two formulations of cyclosporin $\mathrm{A}$ in the treatment of severe atopic dermatitis. A double-blind, single-centre, cross-over pilot study // Dermatology. 1999. Vol. 198, N 1. P. 56-60. doi: 10.1159/000018065

180. Hijnen D.J., Ten Berge O., Timmer-de Mik L., et al. Efficacy and safety of long-term treatment with cyclosporin A for atopic dermatitis // J Eur Acad Dermatol Venereol. 2007. Vol. 21, N 1. P. 85-89. doi: 10.1111/j.1468-3083.2006.01877.x

181. Schmitt J., Schmitt N., Meurer M. Cyclosporin in the treatment of patients with atopic eczema a systematic review and meta-analysis // J Eur Acad Dermatol Venereol. 2007. Vol. 21, N 5. P. 606-619. doi: 10.1111/j.1468-3083.2006.02023.x

182. Amor K.T., Ryan K., Menter A. The use of cyclosporine in dermatology: Part I // J Am Acad Dermatol. 2010. Vol. 63, N6. P. 925-946. quiz 947-948. doi: 10.1016/j.jaad.2010.02.063

183. Wollenberg A., Barbarot S., Bieber T., et al. Consensusbased European guidelines for treatment of atopic eczema (atopic dermatitis) in adults and children: part II // J Eur Acad Dermatol Venereol. 2018. Vol. 32, N 6. P. 850-878. doi: $10.1111 /$ jdv.14888

184. Шамов Б.А. Атопический дерматит: клинические проявления и лечение // Дневник Казанской медицинской школы. 2014. № 1. С. 63-65.

185. Jung M.Y., Chung J.Y., Lee H.Y., et al. Antibiotic susceptibility of Staphylococcus aureus in atopic dermatitis: current prevalence of methicillin-resistant Staphylococcus aureus in Korea and treatment strategies // Ann Dermatol. 2015. Vol. 27, N 4. P. 398-403. doi: 10.5021/ad.2015.27.4.398

186. Lübbe J. Secondary infections in patients with atopic dermatitis // Am J Clin Dermatol. 2003. Vol. 4, N 9. P. 641654. doi: 10.2165/00128071-200304090-00006

187. Масюкова С.А., Гладько Е.В., Тарасенко Г.Н. и др. Фузидиевая кислота в лечении пиодермитов и аллергодерматозов, осложненных бактериальной инфекцией // Вестник дерматологии и венерологии. 2007. № 6. C. $54-57$.

188. Дворянкова Е.В., Корсунская И.М., Захарова А.Б., Жуковский Р.О. Атопический дерматит, осложненный вторичной инфекцией: подходы к терапии // Эффективная фармакотерапия. 2011. № 26. С. 74-76.

189. Ларькова И.А. Эффективная терапия атопического дерматита у детей, осложненного вторичной инфекцией // Медицинский совет. 2016. № 1. С. 162-167. doi: 10.21518/2079-701Х-2016-1-162-167

190. Матушевская Е.В., Свирщевская Е.В. Атопический дерматит в практике врача-дерматовенеролога: рациональный выбор терапии // Русский медицинский журнал. 2013. Т. 21, № 8. С. 410-412.
191. Gong J.Q., Lin L., Lin T., et al. Skin colonization by Staphylococcus aureus in patients with eczema and atopic dermatitis and relevant combined topical therapy: a double-blind multicentre randomized controlled trial // Br J Dermatol. 2006. Vol. 155, N 4. P. 680-687. doi: 10.1111/j.1365-2133.2006.07410.x

192. Lever R., Hadley K., Downey D., Mackie R. Staphylococcal colonization in atopic dermatitis and the effect of topical mupirocin therapy // Br J Dermatol. 1988. Vol. 119, N 2. P. 189-198. doi: 10.1111/j.1365-2133.1988.tb03201.x

193. Альбанова В. Наружное лечение атопического дерматита // Врач. 2006. № 2. С. 76-78.

194. Батыршина С.В., Хаертдинова Л.А. Концепция местной терапии больных атопическим дерматитом // Практическая медицина. 2009. Т. 35, № 3. С. 41-45.

195. Wachs G.N., Maibach H.I. Co-operative double-blind trial of an antibiotic/corticoid combination in impetiginized atopic dermatitis // Br J Dermatol. 1976. Vol. 95, N 3. P. 323-328. doi: 10.1111/j.1365-2133.1976.tb07021.x

196. Schuttelaar M.L., Coenraads P.J. A randomized, double-blind study to assess the efficacy of addition of tetracycline to triamcinolone acetonide in the treatment of moderate to severe atopic dermatitis // J Eur Acad Dermatol Venereol. 2008. Vol. 22, N 9. P. 1076-1082. doi: $10.1111 / \mathrm{j} .1468-3083.2008 .02716 . x$

197. Васенова В.Ю., Бутов Ю.С. Применение Полькортолона ТС для лечения зудящих дерматозов, осложненных вторичной инфекцией // Русский медицинский журнал. 2013. Т. 21, № 22. С. 1096-1098.

198. Скрипкин Ю.К., Хамаганова И.В. Опыт применения аэрозолей оксикорт и полькортолон ТС в лечении аллергических дерматозов, осложненных пиодермией // Вестник дерматологии и венерологии. 2004. № 1. C. $42-43$.

199. Ramsay C., Savoie J., Gilbert M., et al. The treatment of atopic dermatitis with topical fusidic acid and hydrocortisone acetate // J Eur Acad Dermatol Venereol. 1996. Vol. 7, Suppl. 1. P. S15-22. doi: 10.1016/0926-9959(96)00032-3

200. Hjorth N., Schmidt H., Thomsen K. Fusidic acid plus betamethasone in infected or potentially infected eczema // Pharmatherapeutica. 1985. Vol. 4, N 1. P. 126-131.

201. Тарасова М.В., Марина Т.В., Сорокина Е.А., и др. Целесообразность применения комбинированных топических глюкокортикостероидов в комплексной терапии атопического дерматита // Здоровье и образование в XXI веке. 2008. Т. 10, № 3. С. 383.

202. Кубанова А.А., Прошутинская Д.В., Текучева Л.В., Авдиенко И.Н. Интегральный подход к наружной терапии больных атопическим дерматитом // Вестник дерматологии и венерологии. 2010. № 1. С. 20-26.

203. Ненашева Н.М. Особенности местной (наружной) терапии осложненного инфекцией атопического дерматита // РМЖ. 2015. Т. 23, № 19. С. 1159-1165.

204. Кунгуров Н.В., Кениксфест Ю.В., Кохан М.М., и др. Комбинированная наружная терапия осложненных дерматозов // Клиническая дерматология и венерология. 2005. № 2. С. 33-37.

205.Niebuhr M., Mai U., Kapp A., Werfel T. Antibiotic treatment of cutaneous infections with Staphylococcus aureus in patients with atopic dermatitis: current antimicrobial resistances and susceptibilities // Exp Dermatol. 2008. Vol. 17, N 11. P. 953-957. doi: 10.1111/j.1600-0625.2008.00734.x 
206. Boguniewicz M., Sampson H., Leung S., et al. Effects of cefuroxime axetil on Staphylococcus aureus colonizing and superantigen production in atopic dermatitis // J Allergy Clin Immunol. 2001. Vol. 108, N 4. P. 651-652. doi: $10.1067 /$ mai.2001.118598

207. Тренева М.С., Пампура А.Н. Стратегия выбора антибактериальных препаратов у детей с микробным инфицированием атопического дерматита // Практическая медицина. 2011. № 3. С. 136-139.

208. Boguniewicz M., Leung D.Y. Recent insights into atopic dermatitis and implications for management of infectious complications // J Allergy Clin Immunol. 2010. Vol. 125, N 1. P. 4-13. quiz 14-15. doi: 10.1016/j.jaci.2009.11.027

209. Tognetti L., Martinelli C., Berti S., et al. Bacterial skin and soft tissue infections: review of the epidemiology, microbiology, aetiopathogenesis and treatment: a collaboration between dermatologists and infectivologists // J Eur Acad Dermatol Venereol. 2012. Vol. 26, N 8. P. 931-941. doi: 10.1111/j.1468-3083.2011.04416.x

210. Petry V., Bessa G.R., Poziomczyck C.S., et al. Bacterial skin colonization and infections in patients with atopic dermatitis // An Bras Dermatol. 2012. Vol. 87, N 5. P. 729-734. doi: $10.1590 / \mathrm{s} 0365-05962012000500010$

211. Wollenberg A. Eczema herpeticum // Chem Immunol Allergy. 2012. Vol. 96. P. 89-95. doi: 10.1159/000331892

212. Niimura M., Nishikawa T. Treatment of eczema herpeticum with oral acyclovir // Am J Med.1988. Vol. 85, N 2A. P. 49-52.

213. Bussmann C., Bockenhoff A., Henke H., et al. Does allergenspecific immunotherapy represent a therapeutic option for patients with atopic dermatitis? // J Allergy Clin Immunol. 2006. Vol. 118, N 6. P. 1292-1298. doi: 10.1016/j.jaci.2006.07.054

214. Darsow U., Forer I., Ring J. Allergen-specific immunotherapy in atopic eczema // Curr Allergy Asthma Rep. 2011. Vol. 11, N 4. P. 277-283. doi: 10.1007/s11882-011-0194-7

215. Bae J.M., Choi Y.Y., Park C.O., et al. Efficacy of allergenspecific immunotherapy for atopic dermatitis: a systematic review and meta-analysis of randomized controlled trials // J Allergy Clin Immunol. 2013. Vol. 132, N 1. P. 110117. doi: $10.1016 /$ j.jaci.2013.02.044

216. Ring J. Successful hyposensitization treatment in atopic eczema: results of a trial in monozygotic twins // Br J Dermatol. 1982. Vol. 107, N 5. P. 597-602. doi: 10.1111/j.1365-2133.1982.tb00412.x

217. Glover M.T., Atherton D.J. A double-blind controlled trial of hyposensitization to Dermatophagoides pteronyssinus in children with atopic eczema // Clin Exp Allergy. 1992. Vol. 22, N 4. P. 440-446. doi: 10.1111/j.1365-2222.1992.tb00145.x

218. Zachariae H., Cramers M., Herlin T., et al. Non-specific immunotherapy and specific hyposensitization in severe atopic dermatitis // Acta Derm Venereol Suppl (Stockh). 1985. Vol. 114. P. 48-54. doi: 10.2340/000155551144854

219. Елисютина О.Г., Феденко Е.С. Место специфической иммунотерапии в лечении больных атопическим дерматитом, осложненным рецидивирующей пиодермией // Физиология и патология иммунной системы. 2006. № 8. C. 15.

220. Novak N., Bieber T., Hoffmann M., et al. Efficacy and safety of subcutaneous allergen-specific immunotherapy with depigmented polymerized mite extract in atopic dermatitis // J Allergy Clin Immunol. 2012. Vol. 130, N 4. P. 925931e4. doi: 10.1016/j.jaci.2012.08.004
221. Pajno G.B., Caminiti L., Vita D., et al. Sublingual immunotherapy in mite-sensitized children with atopic dermatitis: a randomized, double-blind, placebo-controlled study // J Allergy Clin Immunol. 2007. Vol. 120, N 1. P. 164-170. doi: 10.1016/j.jaci.2007.04.008

222. Qin Y.E., Mao J.R., Sang Y.C., Li W.X. Clinical efficacy and compliance of sublingual immunotherapy with Dermatophagoides farinae drops in patients with atopic dermatitis // Int J Dermatol. 2014. Vol. 53, N 5. P. 650-655. doi: 10.1111/ijd.12302

223. Liu L., Guo D., Liang Q., et al. The efficacy of sublingual immunotherapy with Dermatophagoides farinae vaccine in a murine atopic dermatitis model // Clin Exp Allergy. 2015. Vol. 45, N 4. P. $815-822$. doi: $10.1111 /$ cea. 12417

224. Roduit C., Frei R., Loss G., et al. Development of atopic dermatitis according to age of onset and association with early-life exposures // J Allergy Clin Immunol. 2012. Vol. 130, N 1. P. 130-136 e5. doi: 10.1016/j.jaci.2012.02.043

225. Perkin M.R., Logan K., Tseng A., et al. Randomized trial of introduction of allergenic foods in breast-fed infants // N Engl J Med. 2016. Vol. 374, N 18. P. 1733-1743. doi: 10.1056/NEJMoa1514210

226. Prell C., Koletzko B. Breastfeeding and complementary feeding // Dtsch Arztebl Int. 2016. Vol. 113, N 25. P. 435444. doi: 10.3238/arztebl.2016.0435

227. Vandenplas Y., Al-Hussaini B., Al-Mannaei K., et al. Prevention of allergic sensitization and treatment of cow's milk protein allergy in early life: the middle-east step-down consensus // Nutrients. 2019. Vol. 11, N 7. P. 1444. doi: $10.3390 /$ nu 11071444

228. Gruber C. Probiotics and prebiotics in allergy prevention and treatment: future prospects // Exp Rev Clin Immunol. 2012. Vol. 8, N 1. P. 17 -19. doi: 10.1586/eci.11.74

229. Cuello-Garcia C.A., Brozek J.L., Fiocchi A., et al. Probiotics for the prevention of allergy: a systematic review and meta-analysis of randomized controlled trials // J Allergy Clin Immunol. 2015. Vol. 136, N 4. P. 952-961. doi: 10.1016/j.jaci.2015.04.031

230. Panduru M., Panduru N.M., Sălăvăstru C.M., Tiplica G.S. Probiotics and primary prevention of atopic dermatitis: a meta-analysis of randomized controlled studies // J Eur Acad Dermatol Venereol. 2015. Vol. 29, N 2. P. 232-242. doi: $10.1111 /$ jdv.12496

231. Muraro A., Halken S., Arshad S.H., et al. EAACI food allergy and anaphylaxis guidelines. Primary prevention of food allergy // Allergy. 2014. Vol. 69, N 5. P. 590-601. doi: 10.1111/all.12398

232. Kantor R., Kim A., Thyssen J.P., Silverberg J.I. Association of atopic dermatitis with smoking: a systematic review and meta-analysis // J Am Acad Dermatol. 2016. Vol. 75, N 6. P. 1119-1125e1. doi: 10.1016/j.jaad.2016.07.017

233. Kathuria P., Silverberg J.I. Association of pollution and climate with atopic eczema in US children // Pediatr Allergy Immunol. 2016. Vol. 27, N 5. P. 478-485. doi: 10.1111/pai.12543

234. Morgenstern V., Zutavern A., Cyrys J., et al. Atopic diseases, allergic sensitization, and exposure to traffic-related air pollution in children // Am J Respir Crit Care Med. 2008. Vol. 177, N 12. P. 1331-1337. doi: $10.1164 / \mathrm{rccm} .200701-036 \mathrm{OC}$

235. Hidaka T., Ogawa E., Kobayashi E.H., et al. The aryl hydrocarbon receptor AhR links atopic dermatitis and air pollution via induction of the neurotrophic factor artemin // Nat Immunol. 2017. Vol. 18, N 1. P. 64-73. doi: 10.1038/ni.3614 
236. Ricci G., Bendandi B., Aiazzi R., et al. Three years of Italian experience of an educational program for parents of young children affected by atopic dermatitis: improving knowledge produces lower anxiety levels in parents of children with atopic dermatitis // Pediatr Dermatol. 2009. Vol. 26, N 1. P. 1-5. doi: 10.1111/j.1525-1470.2008.00813.x

237. Staab D., Diepgen T.L., Fartasch M., et al. Age related, structured educational programmes for the management of atopic dermatitis in children and adolescents: multicentre, randomised controlled trial // BMJ. 2006. Vol. 332, N 7547. P. 933-938. doi: 10.1136/bmj.332.7547.933

238. Lambert J., Bostoen J., Geusens B., et al. A novel multidisciplinary educational programme for patients with chronic skin diseases: Ghent pilot project and first results // Arch Dermatol Res. 2011. Vol. 303, N 1. P. 57-63. doi: $10.1007 / \mathrm{s} 00403-010-1082-\mathrm{z}$

239. Kupfer J., Gieler U., Diepgen T.L., et al. Structured education program improves the coping with atopic dermatitis in children and their parents-a multicenter, randomized controlled trial // J Psychosom Res. 2010. Vol. 68, N 4. P. 353358. doi: 10.1016/j.jpsychores.2009.04.014

240. Staab D., von Rueden U., Kehrt R., et al. Evaluation of a parental training program for the management of childhood atopic dermatitis // Pediatr Allergy Immunol. 2002. Vol. 13, N 2. P. 84-90. doi: 10.1034/j.1399-3038.2002.01005.x Veien

241. Kiriyama T., Sugiura H., Uehara M. Residual washing detergent in cotton clothes: a factor of winter deterioration of dry skin in atopic dermatitis // J Dermatol. 2003. Vol. 30, N 10. P. 708-712. doi: 10.1111/j.1346-8138.2003.tb00463.x

242. Schmid-Wendtner M.H., Korting H.C. The $\mathrm{pH}$ of the skin surface and its impact on the barrier function // Skin Pharmacol Physiol. 2006. Vol. 19, N 6. P. 296-302. doi: $10.1159 / 000094670$

243. Simpson E., Trookman N.S., Rizer R.L., et al. Safety and tolerability of a body wash and moisturizer when applied to infants and toddlers with a history of atopic dermatitis: results from an open-label study // Pediatr Dermatol. 2012. Vol. 29, N 5. P. 590-597. doi: 10.1111/j.1525-1470.2012.01809.x

244. Hon K.L., Leung T.F., Wong Y., et al. A survey of bathing and showering practices in children with atopic eczema // Clin Exp Dermatol. 2005. Vol. 30, N 4. P. 351-354. doi: 10.1111/j.1365-2230.2005.01748.x

245. Wollenberg A., Vogel S., Renner E.D. [Vaccinations with atopic dermatitis and other chronic inflammatory skin diseases. (In German)] // Hautarzt. 2010. Vol. 61, N 11. P. 985-993. doi: 10.1007/s00105-010-2019-3

246. Bath-Hextall F., Delamere F., Williams H. Dietary exclusions for improving established atopic eczema in adults and children systematic review // Allergy. 2009. Vol. 64, N 2. P. 258-264. doi: 10.1111/j.1398-9995.2008.01917.x

247. Национальный календарь профилактических прививок. Приложение N 1 к приказу Министерства здравоохранения РФ от 21 марта 2014 г. N 125н. Режим доступа: https://base.garant.ru/70647158/53f89421bbdaf741eb2 d1ecc4ddb4c33/. Дата обращения: 15.12.2020.

248. Аллергология и иммунология: национальное руководство / под ред. Р.М. Хаитова, Н.И. Ильиной. Москва: ГЭОТАР-Медиа, 2009. 634 с.

249. Campana R., Dzoro S., Mittermann I., et al. Molecular aspects of allergens in atopic dermatitis // Curr Opin Allergy Clin Immunol. 2017. Vol. 17, N 4. P. 269-277. doi: 10.1097/ACI.0000000000000378
250. Cartledge N., Chan S. Atopic Dermatitis and food allergy: a paediatric approach // Curr Pediatr Rev. 2018. Vol. 14, N 3. P. 171-179. doi: 10.2174/1573396314666180613083616

251. Darsow U., Laifaoui J., Kerschenlohr K., et al. The prevalence of positive reactions in the atopy patch test with aeroallergens and food allergens in subjects with atopic eczema: A European multicenter study // Allergy. 2004. Vol. 59, N 12. P. 1318-1325. doi: 10.1111/j.1398-9995.2004.00556.x

252. Tamagawa-Mineoka R, Katoh N. Atopic dermatitis: identification and management of complicating factors // Int J Mol Sci. 2020. Vol. 21, N 8. P. 2671. doi: $10.3390 /$ ijms 21082671

253. Werfel T., Heratizadeh A., Niebuhr M., et al. Exacerbation of atopic dermatitis on grass pollen exposure in an environmental challenge chamber // J Allergy Clin Immunol. 2015. Vol. 136, N 1. P. 96-103.e9. doi: 10.1016/j.jaci.2015.04.015

254. Caut C., Leach M., Steel A. Dietary guideline adherence during preconception and pregnancy: A systematic review // Matern Child Nutr. 2020. Vol. 16, N 2. P. e12916. doi: $10.1111 / \mathrm{mcn} .12916$

255. Sugita K., Akdis C.A. Recent developments and advances in atopic dermatitis and food allergy // Allergol Int. 2020. Vol. 69, N 2. P. 204-214. doi: 10.1016/j.alit.2019.08.013

256. Fedenko E., Elisyutina O., Shtyrbul O., et al. Microarraybased IgE serology improves management of severe atopic dermatitis in two children // Pediatr Allergy Immunol. 2016. Vol. 27, N 6. P. 645-649. doi: 10.1111/pai.12572

257. Alexander D.D., Cabana M.D. Partially hydrolyzed $100 \%$ whey protein infant formula and reduced risk of atopic dermatitis: a meta-analysis // J Pediatr Gastroenterol Nutr. 2010. Vol. 50, N 4. P. 422-430.

258. Niggemann B., Reibel S., Wahn U. The atopy patch test (APT) - a useful tool for the diagnosis of food allergy in children with atopic dermatitis // Allergy. 2000. Vol. 55, N 3. P. 281-285.

259. Sampson H.A., Albergo R. Comparison of results of skin tests, RAST, and double-blind, placebo-controlled food challenges in children with atopic dermatitis // J Allergy Clin Immunol. 1984. Vol. 74, N 1. P. 26-33.

260. Roehr C.C., Reibel S., Ziegert M., et al. Atopy patch tests, together with determination of specific IgE levels, reduce the need for oral food challenges in children with atopic dermatitis // J Allergy Clin Immunol. 2001. Vol. 107, N 3. P. 548-553. doi: 10.1067/mai.2001.112849

\section{REFERENCES}

1. Palmer CN, Irvine AD, Terron-Kwiatkowski A, et al. Common loss-of-function variants of the epidermal barrier protein filaggrin are a major predisposing factor for atopic dermatitis. Nat Genet. 2006;38(4):441-446. doi: 10.1038/ng 1767

2. McGirt LY, Beck LA. Innate immune defects in atopic dermatitis. J Allergy Clin Immunol. 2006;118(1):202-208. doi: 10.1016/j.jaci.2006.04.033

3. Bao L, Zhang H, Chan LS. The involvement of the JAKSTAT signaling pathway in chronic inflammatory skin disease atopic dermatitis. JAKSTAT. 2013;2(3):e24137. doi: $10.4161 / \mathrm{jkst} .24137$

4. Gandhi NA, Pirozzi G, Graham N.M. Commonality of the IL-4/IL-13 pathway in atopic diseases. Expert Rev Clin Immunol. 2017;13(5):425-437. doi: 10.1080/1744666X.2017.1298443

5. Werfel T, Allam JP, Biedermann T, et al. Cellular and molecular immunologic mechanisms in patients with atopic der- 
matitis. J Allergy Clin Immunol. 2016;138(2):336-349. doi: 10.1016/j.jaci.2016.06.010

6. Wollenberg A, Barbarot S, Bieber T, et al. Consensus-based European guidelines for treatment of atopic eczema (atopic dermatitis) in adults and children: part I. $J$ Eur Acad Dermatol Venereol. 2018;32(5):657-682. doi: 10.1111/jdv.14891

7. Kubanov AA, Bogdanova EV. Organization and results of medical care in the profile of dermatovenerology in the Russian Federation. The results of 2018. Bulletin of Dermatology and Venereology. 2019;95(4):8-23. (In Russ). doi: 10.25208/0042-4609-2019-95-4-8-23

8. Schneider L, Hanifin J, Boguniewicz M, et al. Study of the atopic march: development of atopic comorbidities. Pediatr Dermatol. 2016;33(4):388-398. doi: 10.1111/pde.12867

9. Bieber T. Atopic dermatitis 2.0: from the clinical phenotype to the molecular taxonomy and stratified medicine. Allergy. 2012;67(12):1475-1482. doi: 10.1111/all.12049

10. Van der Hulst AE, Klip H, Brand PL. Risk of developing asthma in young children with atopic eczema: a systematic review. J Allergy Clin Immunol. 2007;120(3):565-569. doi: 10.1016/j.jaci.2007.05.042

11. Eckert L, Gupta S, Amand C, et al. The burden of atopic dermatitis in US adults: Health care resource utilization data from the 2013 National Health and Wellness Survey. J Am Acad Dermatol. 2018;78(1):54-61.e1. doi: 10.1016/j.jaad.2017.08.002

12. Illi S, von Mutius E, Lau S, et al. The pattern of atopic sensitization is associated with the development of asthma in childhood. J Allergy Clin Immunol. 2001;108(5):709-714. doi: $10.1067 /$ mai.2001.118786

13. Aw M, Penn J, Gauvreau GM, et al. Atopic march: collegium internationale allergologicum update 2020. Int Arch Allergy Immunol. 2020;181(1):1-10. doi: 10.1159/000502958

14. Spergel JM. Epidemiology of atopic dermatitis and atopic march in children. Immunol Allergy Clin N Am. 2010;30(3):269-280. doi: 10.1016/j.iac.2010.06.003

15. Hill DA, Spergel JM. The atopic march: Critical evidence and clinical relevance. Ann Allergy Asthma Immunol. 2018;120(2):131-137. doi: 10.1016/j.anai.2017.10.037

16. Williams H, Flohr C. How epidemiology has challenged 3 prevailing concepts about atopic dermatitis. J Allergy Clin Immunol. 2006;118(1):209-213. doi: 10.1016/j.jaci.2006.04.043

17. Illi S, von Mutius E, Lau S, et al. The natural course of atopic dermatitis from birth to age 7 years and the association with asthma. J Allergy Clin Immunol. 2004;113(5):925-931. doi: 10.1016/j.jaci.2004.01.778

18. Atopic dermatitis: recommendations for practitioners. The Russian conciliatory national document on atopic dermatitis. Ed. by P.M. Khaitov, A.A. Kubanov. Moscow: Pharmacus Print; 2002. 192 p. (In Russ).

19. Hanifin JM, Rajka G. Diagnostic features of atopic dermatitis. Acta Derm Venereol. 1980;60(92):44-47. doi: 10.2340/00015555924447

20. Eichenfield LF, Tom WL, Chamlin SL, et al. Guidelines of care for the management of atopic dermatitis: section 1. Diagnosis and assessment of atopic dermatitis. J Am Acad Dermatol. 2014;70(2):338-351. doi: 10.1016/j.jaad.2013.10.010

21. Ryan C, Amor KT, Menter A. The use of cyclosporine in dermatology: part II. J Am Acad Dermatol. 2010;63(6):949-972. doi: $10.1016 /$ j.jaad.2010.02.062

22. Arbes SJ, Gergen PJ, Elliott L, Zeldin DC. Prevalences of positive skin test responses to 10 common allergens in the US population: results from the third National Health and
Nutrition Examination Survey. J Allergy Clin Immunol. 2005;116(2):377-383. doi: 10.1016/j.jaci.2005.05.017

23. Clinical dermatovenerology. Vol. II. Ed. by Yu.K. Skripkin, Yu.S. Butov. Moscow: GEOTAR-Media; 2009. 928 p.

24. Futamura M, Leshem YA, Thomas KS, et al. A systematic review of Investigator Global Assessment (IGA) in atopic dermatitis (AD) trials: Many options, no standards. J Am Acad Dermatol. 2016;74(2):288-294. doi: 10.1016/j.jaad.2015.09.062

25. Oranje AP, Stalder JF, Taieb A, et al. Scoring of atopic dermatitis by SCORAD using a training atlas by investigators from different disciplines. ETAC Study Group. Early Treatment of the Atopic Child. Pediatr Allergy Immunol. 1997;8(1):28-34. doi: 10.1111/j.1399-3038.1997.tb00139.x

26. Schram ME, Spuls PI, Leeflang MM, et al. EASI, (objective) SCORAD and POEM for atopic eczema: responsiveness and minimal clinically important difference. Allergy. 2012;67(1):99-106. doi: 10.1111/j.1398-9995.2011.02719.x

27. Giam Y.C., Hebert A.A., Dizon M.V. A review on the role of moisturizers for atopic dermatitis. Asia Pac Allergy. 2016;6(2):120-128. doi: 10.5415/apallergy.2016.6.2.120

28. Breternitz M, Kowatzki D, Langenauer M, et al. Placebocontrolled, double-blind, randomized, prospective study of a glycerol-based emollient on eczematous skin in atopic dermatitis: biophysical and clinical evaluation. Skin Pharmacol Physiol. 2008;21(1):39-45. doi: 10.1159/000111134

29. Verallo-Rowell VM, Dillague KM, Syah-Tjundawan BS. Novel antibacterial and emollient effects of coconut and virgin olive oils in adult atopic dermatitis. Dermatitis. 2008;19(6):308-315.

30. Simpson E, Dutronc Y. A new body moisturizer increases skin hydration and improves atopic dermatitis symptoms among children and adults. J Drugs Dermatol. 2011;10(7):744-749.

31. Lindh JD, Bradley M. Clinical effectiveness of moisturizers in atopic dermatitis and related disorders: a systematic review. Am J Clin Dermatol. 2015;16(5):341-359. doi: 10.1007/s40257-015-0146-4

32. Miller DW, Koch SB, Yentzer BA, et al. An over-the-counter moisturizer is as clinically effective as, and more cost-effective than, prescription barrier creams in the treatment of children with mild-to-moderate atopic dermatitis: a randomized, controlled trial. J Drugs Dermatol. 2011;10(5):531-537.

33. Grimalt R, Mengeaud V, Cambazard F. The steroid-sparing effect of an emollient therapy in infants with atopic dermatitis: a randomized controlled study. Dermatology. 2007;214(1):61-67. doi: 10.1159/000096915

34. Msika P, De Belilovsky C, Piccardi N, et al. New emollient with topical corticosteroid-sparing effect in treatment of childhood atopic dermatitis: SCORAD and quality of life improvement. Pediatr Dermatol. 2008;25(6):606-612. doi: 10.1111/j.1525-1470.2008.00783.x

35. Lucky AW, Leach AD, Laskarzewski P, Wenck H. Use of an emollient as a steroid-sparing agent in the treatment of mild to moderate atopic dermatitis in children. Pediatr Dermatol. 1997;14(4):321-324. doi: 10.1111/j.1525-1470.1997.tb00968.x

36. Eberlein B, Eicke C, Reinhardt HW, Ring J. Adjuvant treatment of atopic eczema: assessment of an emollient containing N-palmitoylethanolamine (ATOPA study). J Eur Acad Dermatol Venereol. 2008;22(1):73-82. doi: 10.1111/j.1468-3083.2007.02351.x

37. Sugarman JL, Parish LC. Efficacy of a lipid-based barrier repair formulation in moderate-to-severe pediatric atopic dermatitis. J Drugs Dermatol. 2009;8(12):1106-1111. 
38. Leung TN, Chow CM, Chow MP, et al. Clinical guidelines on management of atopic dermatitis in children. Hong Kong $J$ Paediatr (new series). 2013;18(2):96-104.

39. Darsow U, Wollenberg A, Simon D, et al. ETFAD/EADV Eczema Task Force 2009 position paper on diagnosis and treatment of atopic dermatitis. J Eur Acad Dermatol Venereol. 2010;24(3):317-328. doi: 10.1111/j.1468-3083.2009.03415.x

40. Chiang C, Eichenfield LF. Quantitative assessment of combination bathing and moisturizing regimens on skin hydration in atopic dermatitis. Pediatr Dermatol. 2009;26(3):273-278. doi: 10.1111/j.1525-1470.2009.00911.x

41. Guidance on Prescribing. In: British National Formulary No.60. London: British Medical Association and Royal Pharmaceutical Society of Great Britain; 2010.

42. Dabade TS, Davis DM, Wetter DA, et al. Wet dressing therapy in conjunction with topical corticosteroids is effective for rapid control of severe pediatric atopic dermatitis: experience with 218 patients over 30 years at Mayo Clinic. J Am Acad Dermatol. 2012;67(1):100-106. doi: 10.1016/j.jaad.2011.06.025

43. Devillers AC, Oranje AP. Efficacy and safety of 'wet-wrap' dressings as an intervention treatment in children with severe and/or refractory atopic dermatitis: a critical review of the literature. Br J Dermatol. 2006;154(4):579-585. doi: 10.1111/j.1365-2133.2006.07157.x

44. Devillers AC, de Waard-van der Spek FB, Mulder PG, Oranje AP. Treatment of refractory atopic dermatitis using 'wet-wrap' dressings and diluted corticosteroids: results of standardized treatment in both children and adults. Dermatology. 2002;204(1):50-55. doi: 10.1159/000051810

45. Goodyear HM, Spowart K, Harper JI. 'Wet-wrap' dressings for the treatment of atopic eczema in children. Br J Dermatol. 1991;125(6):604. doi: 10.1111/j.1365-2133.1991.tb14807.x

46. Brenninkmeijer EE, Spuls PI, Lindeboom R, et al. Excimer laser vs. clobetasol propionate $0.05 \%$ ointment in prurigo form of atopic dermatitis: a randomized controlled trial, a pilot. $B r J$ Dermatol. 2010;163(4):823-831. doi: 10.1111/j.1365-2133.2010.09858.x

47. Pels R, Sterry W, Lademann J. Clobetasol propionate where, when, why? Drugs Today (Barc). 2008;44(7):547-557. doi: 10.1358/dot.2008.44.7.1122221

48. Breneman D, Fleischer AB, Kaplan D, et al. Clobetasol propionate $0.05 \%$ lotion in the treatment of moderate to severe atopic dermatitis: a randomized evaluation versus clobetasol propionate emollient cream. J Drugs Dermatol. 2005;4(3):330-336.

49. Feldman SR. Relative efficacy and interchangeability of various clobetasol propionate vehicles in the management of steroid-responsive dermatoses. Curr Ther Res Clin Exp. 2005;66(3):154-171. doi: 10.1016/j.curtheres.2005.06.010

50. Datz B, Yawalkar S. A double-blind, multicenter trial of $0.05 \%$ halobetasol propionate ointment and $0.05 \%$ clobetasol 17-propionate ointment in the treatment of patients with chronic, localized atopic dermatitis or lichen simplex chronicus. J Am Acad Dermatol. 1991;25(6 Pt 2):1157-1160. doi: 10.1016/0190-9622(91)70316-t

51. Viglioglia P, Jones ML, Peets EA. Once-daily $0.1 \%$ mometasone furoate cream versus twice-daily $0.1 \%$ betamethasone valerate cream in the treatment of a variety of dermatoses. J Int Med Res. 1990;18(6):460-467. doi: $10.1177 / 030006059001800603$

52. Vanderploeg DE. Betamethasone dipropionate ointment in the treatment of psoriasis and atopic dermatitis: a dou- ble-blind study. South Med J. 1976;69(7):862-863. doi: 10.1097/00007611-197607000-00017

53. Queille C, Pommarede R, Saurat JH. Efficacy versus systemic effects of six topical steroids in the treatment of atopic dermatitis of childhood. Pediatr Dermatol. 1984;1(3):246-253.

54. Cabrera ME. Treatment of severe or resistant corticosteroidresponsive dermatoses with Diprolene cream. J Int Med Res. 1984;12(3):163-169. doi: 10.1177/030006058401200305

55. Lodolo JC. Diprolene cream in the treatment of severe or resistant corticosteroid-responsive dermatoses. $J$ Int Med Res. 1984;12(2):114-120. doi: 10.1177/030006058401200209

56. Peterkin GA, Morley WN, Chalmers D. Triamcinolone and fluocinolone acetonide ointments in atopic eczema. $\mathrm{Br} \mathrm{Med}$ J. 1962;1(5289):1392. doi: 10.1136/bmj.1.5289.1392

57. Hanifin JM. Atopic dermatitis. Special clinical complications. Postgrad Med. 1983;74(3):188-199. doi: $10.1080 / 00325481.1983 .11698425$

58. Cadmus SD, Sebastian KR, Warren D, et al. Efficacy and patient opinion of wet-wrap dressings using $0.1 \%$ triamcinolone acetonide ointment vs cream in the treatment of pediatric atopic dermatitis: A randomized split-body control study. Pediatr Dermatol. 2019;36(4):437-441.

59. Wolkerstorfer A, Strobos MA, Glazenburg EJ, et al. Fluticasone propionate $0.05 \%$ cream once daily versus clobetasone butyrate $0.05 \%$ cream twice daily in children with atopic dermatitis. J Am Acad Dermatol. 1998;39(2 Pt 1):226-231. doi: 10.1016/s0190-9622(98)70080-5

60. Bleehen SS, Chu AC, Hamann I, et al. Fluticasone propionate $0.05 \%$ cream in the treatment of atopic eczema: a multicentre study comparing once-daily treatment and once-daily vehicle cream application versus twice-daily treatment. Br J Dermatol. 1995;133(4):592-597. doi: 10.1111/j.1365-2133.1995.tb02711.x

61. Belousova TA, Goryachkina MV. Experience of using fluticasone propionate (Kutivate) in the treatment of psoriasis, eczema and atopic dermatitis. Effective Pharmacotherapy. 2010;(9):24-29. (In Russ).

62. Prakash A, Benfield P. Topical mometasone. A review of its pharmacological properties and therapeutic use in the treatment of dermatological disorders. Drugs. 1998;55(1):145-163. doi: 10.2165/00003495-199855010-00009

63. Vernon HJ, Lane AT, Weston W. Comparison of mometasone furoate $0.1 \%$ cream and hydrocortisone $1.0 \%$ cream in the treatment of childhood atopic dermatitis. J Am Acad Dermatol. 1991;24(4):603-607. doi: 10.1016/0190-9622(91)70092-g

64. Lebwohl M. A comparison of once-daily application of mometasone furoate $0.1 \%$ cream compared with twice-daily hydrocortisone valerate $0.2 \%$ cream in pediatric atopic dermatitis patients who failed to respond to hydrocortisone: mometasone furoate study group. Int $J$ Dermatol. 1999;38(8):604-606. doi: 10.1046/j.1365-4362.1999.00759.x

65. Tomilova AYu, Torshkhoeva RM, Gevorkyan AK, Voznesenskaya NI. Efficacy and safety of mometasone furoate in atopic dermatitis in children. Pediatric Pharmacology. 2009;6(4):123-127. (In Russ).

66. Shaipov TS, Mazitova LP. The use of mometasone furoate in the treatment of atopic dermatitis in children. Pediatric Pharmacology. 2007;4(5):41-44. (In Russ).

67. Nenasheva NM. Features of atopic dermatitis in adult patients Effective pharmacotherapy. Dermatovenerology and Dermatocosmetology. 2012;(3):6-15. (In Russ). 
68. Lane AT. Efficacy and safety of topical steroids in paediatric atopic dermatitis. J Eur Acad Dermatol Venereol. 1997;8:S24_ S27.

69. Faergemann J, Christensen O, Sjövall P, et al. An open study of efficacy and safety of long-term treatment with mometasone furoate fatty cream in the treatment of adult patients with atopic dermatitis. $J$ Eur Acad Dermatol Venereol. 2000;14(5):393-396.

70. Haneke E. The treatment of atopic dermatitis with methylprednisolone aceponate (MPA), a new topical corticosteroid. J Dermatol Treatm. 2009;3(Suppl. 2):13-15. doi: $10.3109 / 09546639209092767$

71. Luger TA. Balancing efficacy and safety in the management of atopic dermatitis: the role of methylprednisolone aceponate. J Eur Acad Dermatol Venereol. 2011;25(3):251-258. doi: 10.1111/j.1468-3083.2010.03789.x

72. Bieber T, Vick K, Fölster-Holst R, et al. Efficacy and safety of methylprednisolone aceponate ointment $0.1 \%$ compared to tacrolimus $0.03 \%$ in children and adolescents with an acute flare of severe atopic dermatitis. Allergy. 2007;62(2):184-189. doi: 10.1111/j.1398-9995.2006.01269.x

73. Kondratieva YuS, Karkhova VV. Experience of using $0.1 \%$ methylprednisolone aceponate in the complex therapy of steroid-sensitive dermatoses. Bulletin of Dermatology and Venereology. 2016;(1):93-98. (In Russ).

74. Chikin VV. Methylprednisolone aceponate and dexpanthenol in topical therapy of patients with AtD. Bulletin of Dermatology and Venereology. 2014;90(5):112-116. (In Russ). doi: 10.25208/0042-4609-2014-90-5-112-116

75. Lassus A. Alclometasone dipropionate cream $0.05 \%$ versus clobetasone butyrate cream $0.05 \%$. A controlled clinical comparison in the treatment of atopic dermatitis in children. Int J Dermatol. 1984;23(8):565-566. doi: 10.1111/j.1365-4362.1984.tb04214.x

76. Panja SK, Gangopadhaya AK, Sharma SD. A randomised, double-blind comparison of alclometasone dipropionate $0.05 \%$ cream in atopic dermatitis and other dermatoses. Indian J Dermatol. 1988;33(1):1-4.

77. Makarova IV, Gaiduk IM, Zhiglinskaya OV, et al. The use of $0.05 \%$ cream of alclomethasone dipropionate in the treatment of atopic dermatitis in young children. Questions of Modern Pediatrics. 2004;3(4):84-87. (In Russ).

78. Korotky NG, Tikhomirov AA, Gamayunov BN. Evaluation of the clinical efficacy of the modern steroid alclomethasone dipropionate (Afloderm) in the external therapy of atopic dermatitis in children. Clinical Dermatology and Venereology. 2007;(6):24-31. (In Russ).

79. Toropova NP, Cherkasova LA, Platonova IN, et al. Experience of using the drug "Afloderm" (alclomethasone dipropionate) in pediatric dermatological practice. Russian Journal of Skin and Venereal Diseases. 2003;(3):39-40. (In Russ).

80. Veien NK, Hattel T, Justesen O, et al. Hydrocortisone 17-butyrate (Locoid) $0.1 \%$ cream versus hydrocortisone (Uniderm) $1 \%$ cream in the treatment of children suffering from atopic dermatitis. $J$ Int Med Res. 1984;12(5):310-313. doi: 10.1177/030006058401200509

81. Rajka G, Verjans HL. Hydrocortisone 17-butyrate (Locoid) $0.1 \%$ fatty cream versus desonide (Apolar) $0.1 \%$ ointment in the treatment of patients suffering from atopic dermatitis. J Int Med Res. 1986;14(2):85-90. doi: $10.1177 / 030006058601400206$
82. Abramovits A, Oquendo M. Hydrocortisone butyrate $0.1 \%$ lipocream in pediatric patients with atopic dermatitis. SKINmed. 2010;8(2):72-79.

83. Koopmans B, Lasthein Andersen B, Mork NJ, et al. Multicentre randomized double-blind study of locoid lipocream fatty cream twice daily versus locoid lipocream once daily and locobase once daily. J Dermatol Treat. 1995;6(2):103106. doi: 10.3109/09546639509097161

84. Saki N, Jowkar F, Alyaseen S, et al. Comparison of sertaconazole $2 \%$ cream versus hydrocortisone $1 \%$ ointment in the treatment of atopic dermatitis. $J$ Dermatolog Treat. 2013;24(6):447-449. doi: 10.3109/09546634.2013.782384

85. Reitamo S, Rustin M, Ruzicka T, et al. Efficacy and safety of tacrolimus ointment compared with hydrocortisone butyrate ointment in adult patients with atopic dermatitis. J Allergy Clin Immunol. 2002;109(3):547-555. doi: 10.1067/mai.2002.121832

86. Matheson R, Kempers S, Breneman D, et al. Hydrocortisone butyrate $0.1 \%$ lotion in the treatment of atopic dermatitis in pediatric subjects. J Drugs Dermatol. 2008;7(3):266-271.

87. Sears HW, Bailer JW, Yeadon A. Efficacy and safety of hydrocortisone buteprate $0.1 \%$ cream in patients with atopic dermatitis. Clin Ther. 1997;19(4):710-719.

88. Ignatiev DV, Kochergin NG. Local corticosteroids in the practice of a dermatologist. Features of hydrocortisone butyrate (locoid). Dermatology. Appendix Journal Consilium Medicum. 2007;(1):50-54. (In Russ).

89. Udompataikul M, Limpa-o-Vart D. Comparative trial of $5 \%$ dexpanthenol in water-in-oil formulation with $1 \%$ hydrocortisone ointment in the treatment of childhood atopic dermatitis: a pilot study. J Drugs Dermatol. 2012;11(3):366-374.

90. Udompataikul M, Srisatwaja W. Comparative trial of moisturizer containing licochalcone A vs. hydrocortisone lotion in the treatment of childhood atopic dermatitis: a pilot study. $J$ Eur Acad Dermatol Venereol. 2011;25(6):660-665.

91. Sergeev YuV, Ivanov OL, Novikov DK, et al. Atopic dermatitis: modern diagnosis and treatment. Immunopathology, Allergology, Infectology. 2001;(4):39-63. (In Russ).

92. Ashcroft DM, Dimmock P, Garside R, et al. Efficacy and tolerability of topical pimecrolimus and tacrolimus in the treatment of atopic dermatitis: meta-analysis of randomised controlled trials. BMJ. 2005;330(7490):516.

93. Ruzicka T, Bieber T, Schöpf E, et al. A short-term trial of tacrolimus ointment for atopic dermatitis. $N$ Engl $\mathrm{J} \mathrm{Med}$. 1997;337(12):816-821. doi: 10.1056/NEJM199709183371203

94. Reitamo S, Wollenberg A, Schöpf E, et al. Safety and efficacy of 1 year of tacrolimus ointment monotherapy in adults with atopic dermatitis. Arch Dermatol. 2000;136(8):999-1006. doi: 10.1001/archderm.136.8.999

95. Chen SL, Yan J, Wang FS. Two topical calcineurin inhibitors for the treatment of atopic dermatitis in pediatric patients: a meta-analysis of randomized clinical trials. $J$ Dermatolog Treat. 2010;21(3):144-156. doi: 10.3109/09546630903401470

96. Bornhövd EC, Burgdorf WH, Wollenberg A. Immunomodulatory macrolactams for topical treatment of inflammatory skin diseases. Curr Opin Investig Drugs. 2002;3(5):708-712.

97. Lubbe J. Klinische Erfahrungen mit topischen Calcineurininhibitoren in der Praxis. Hautarzt. 2003;54(5):432-439.

98. Reitamo S, Ortonne JP, Sand C, et al. A multicentre, randomized, double-blind, controlled study of long-term treatment with $0.1 \%$ tacrolimus ointment in adults with moderate 
to severe atopic dermatitis. Br J Dermatol. 2005;152(6):12821289. doi: $10.1111 / \mathrm{j} .1365-2133.2005 .06592 . x$

99. Patel RR, Vander Straten MR, Korman NJ. The safety and efficacy of tacrolimus therapy in patients younger than 2 years with atopic dermatitis. Arch Dermatol. 2003;139(9):11841186. doi: 10.1001/archderm.139.9.1184

100. Wollenberg A, Sidhu MK, Odeyemi I, et al. Economic evaluation of secondary prophylactic treatment with tacrolimus $0.1 \%$ ointment in adults with moderate to severe atopic dermatitis. Br J Dermatol. 2008;159(6):1322-1330. doi: 10.1111/j.1365-2133.2008.08807.x

101. Healy E, Bentley A, Fidler C, Chambers C. Cost-effectiveness of tacrolimus ointment in adults and children with moderate and severe atopic dermatitis: twice-weekly maintenance treatment vs. standard twicedaily reactive treatment of exacerbations from a third party payer (U.K. National Health Service) perspective. $\mathrm{Br} J$ Dermatol. 2011;164(2):387-395. doi: 10.1111/j.1365-2133.2010.10141.x

102. Reitamo S, Mandelin J, Rubins A, et al. The pharmacokinetics of tacrolimus after first and repeated dosing with $0.03 \%$ ointment in infants with atopic dermatitis. Int J Dermatol. 2009;48(4):348-355. doi: 10.1111/j.1365-4632.2009.03853.x

103. Reitamo S, Rustin M, Harper J, et al. A 4-year follow-up study of atopic dermatitis therapy with $0.1 \%$ tacrolimus ointment in children and adult patients. Br J Dermatol. 2008;159(4):942951. doi: 10.1111/j.1365-2133.2008.08747.x Ruzicka

104. Mandelin JM, Remitz A, Virtanen HM, et al. A 10-year open follow-up of eczema and respiratory symptoms in patients with atopic dermatitis treated with topical tacrolimus for the first 4 years. J Dermatolog Treat. 2010;21(3):167-170. doi: 10.3109/09546630903493329

105. Mandelin J, Remitz A, Virtanen HM, et al. One-year treatment with $0.1 \%$ tacrolimus ointment versus a corticosteroid regimen in adults with moderate to severe atopic dermatitis: a randomized, double-blind, comparative trial. Acta Derm Venereol. 2010;90(2):170-174. doi: 10.2340/00015555-0803

106. Boguniewicz M, Fiedler VC, Raimer S, et al. A randomized, vehicle-controlled trial of tacrolimus ointment for treatment of atopic dermatitis in children. Pediatric Tacrolimus Study Group. J Allergy Clin Immunol. 1998;102(4 Pt 1):637-644. doi: 10.1016/s0091-6749(98)70281-7

107. Elisyutina OG, Fedenko ES, Shtyrbul OV, Niyazov DD. The use of tacrolimus in patients with moderate and severe atopic dermatitis. The first clinical experience in Russia. Russian Journal of Allergy. 2011;(6):68-76. (In Russ).

108. Proshutinskaya DV, Butareva MM, Inoyatova LA. New possibilities of therapy of atopic dermatitis in children and adults. Bulletin of Dermatology and Venereology. 2013;(3):7882. (In Russ).

109. Samtsov AV, Sukharev AV, Patrushev AV, Bondar OI. Clinical efficacy, safety and tolerability of $0.1 \%$ tacrolimus ointment in the treatment of moderate and severe atopic dermatitis. Bulletin of Dermatology and Venereology. 2012;(2):7177. (In Russ).

110. Samtsov AV, Sukharev AV, Patrushev AV. Treatment of atopic dermatitis: advantages of tacrolimus over topical corticosteroids. Effective Pharmacotherapy. 2014;(19):410. (In Russ).

111. Van Leent EJ, Graber M, Thurston M, et al. Effectiveness of the ascomycin macrolactam SDZ ASM 981 in the topical treatment of atopic dermatitis. Arch Dermatol. 1998;134(7):805-809. doi: 10.1001/archderm.134.7.805
112. Meurer M, Fölster-Holst R, Wozel G, et al. Pimecrolimus cream in the long-term management of atopic dermatitis in adults: a six-month study. Dermatology. 2002;205(3):271277. doi: $10.1159 / 000065863$

113. Wahn U, Bos J, Goodfield M, et al. Efficacy and safety of pimecrolimus cream in the long-term management of atopic dermatitis in children. Pediatrics. 2002;110(1 Pt 1):e2. doi: 10.1542/peds.110.1.e2

114. Ho VC, Gupta A, Kaufmann R, et al. Safety and efficacy of nonsteroid pimecrolimus cream $1 \%$ in the treatment of atopic dermatitis in infants. $J$ Pediatr. 2003;142(2):155-162. doi: $10.1067 / \mathrm{mpd} .2003 .65$

115. Eichenfield LF, Lucky AW, Boguniewicz M, et al. Safety and efficacy of pimecrolimus (ASM 981) cream $1 \%$ in the treatment of mild and moderate atopic dermatitis in children and adolescents. J Am Acad Dermatol. 2002;46(4):495-504. doi: $10.1067 / \mathrm{mjd} .2002 .122187$

116. Langley RG, Eichenfield LF, Lucky AW, et al. Sustained efficacy and safety of pimecrolimus cream $1 \%$ when used long-term (up to 26 weeks) to treat children withatopic dermatitis. Pediatr Dermatol. 2008;25(3):301-307. doi: 10.1111/j.1525-1470.2008.00671.x

117. Luger T, van Leent EJ, Graeber M, et al. SDZ ASM 981: an emerging safe and effective treatment for atopic dermatitis. Br J Dermatol. 2001;144(4):788-794. doi: 10.1046/j.1365-2133.2001.04134.X

118. Eichenfield LF, Thaci D, de Prost Y, et al. Clinical management of atopic eczema with pimecrolimus cream $1 \%$ (Elidel) in paediatric patients. Dermatology. 2007;11(Suppl 1):3-17. doi: 10.1159/000102116

119. Reda AM, Elgendi A, Ebraheem AI, et al. A practical algorithm for topical treatment of atopic dermatitis in the Middle East emphasizing the importance of sensitive skin areas. J Dermatolog Treat. 2019;30(4):366-373. doi: 10.1080/09546634.2018.1524823

120. Kubanov AA, Petrovsky FI. Activated zinc pyrithione (Skin cap). Mechanisms of action. Clinical application. Bulletin of Dermatology and Venereology. 2009;(5):35-42. (In Russ).

121. Fassakhov RS, Pampura AN, Korostovtsev DS, et al. Skin-Cap in the treatment of atopic dermatitis in children (according to the results of the Russian multicenter study KADET). Russian Journal of Allergy. 2007;(2):75-81. (In Russ).

122. Fassakhov RS, Pampura AN, Korostovtsev DS, et al. Efficacy and safety of activated zinc pyrithione (skin cap) in the treatment of atopic dermatitis in children (results of a Russian multicenter study). Bulletin of Pediatric Pharmacology and Nutriciology. 2006;3(6):28-31. (In Russ).

123. Neurodermatoses. In: Skin and venereal diseases: A guide for doctors. In two volumes. 2nd ed., reprint. and additional vol. 2. Ed. by Yu.K. Skripkin, V.N. Mordovtsev. Moscow: Meditsina; 1999. P. 9-49. (In Russ).

124. Yoshida H, Niimura M, Ueda H, et al. Clinical evaluation of ketotifen syrup on atopic dermatitis: a comparative multicenter double-blind study of ketotifen and clemastine. Ann Allergy. 1989;62(6):507-512.

125. Grigorieva I, Sergeev A, Manina I, Kudryavtseva E. Immunopathology and biochemical bases of atopic states. Doctor. 2012;(4):86-91. (In Russ).

126. Morozova SV, Luss LV. Chloropyramine: modern aspects of application. Current Pediatrics. 2007;6:(1):137-140. (In Russ). 
127. Goryachkina MV, Belousova TA. Chloropyramine: clinical aspects of application. Russian Medical Journal. Medical Review. 2014;22(24):1785-1789. (In Russ).

128. Petrova KS, Petrova GA. Chloropyramine (suprastin) modern aspects of the use in the treatment of allergodermatoses. Russian Medical Journal. 2014;22(8):617-620. (In Russ).

129. Revyakina VA. Antihistamines in clinical practice. Russian Medical Journal. 2014;22(11):854-856. (In Russ).

130. Behrendt H, Ring J. Histamine, antihistamines and atopic eczema. Clin Exp Allergy. 1990;20(Suppl 4):25-30. doi: 10.1111/j.1365-2222.1990.tb02473.x

131. Langeland T, Fagertun HE, Larsen S. Therapeutic effect of loratadine on pruritus in patients with atopic dermatitis. A multi-crossover-designed study. Allergy. 1994;49(1):22-26. doi: 10.1111/j.1398-9995.1994.tb00768.x

132. Monroe EW. Relative efficacy and safety of loratadine, hydroxyzine, and placebo in chronic idiopathic urticaria and atopic dermatitis. Clin Ther. 1992;14(1):17-21.

133. Popova IS, Matushevskaya EV, Svirshchevskaya EV. Double-blind placebo-controlled study of the efficacy and tolerability of clarotadine in atopic dermatitis. $R M J$. 2001;9(4):477-483. (In Russ).

134. Hannuksela M, Kalimo K, Lammintausta K, et al. Dose ranging study: cetirizine in the treatment of atopic dermatitis in adults. Ann Allergy. 1993;70(2):127-133.

135. La Rosa M, Ranno C, Musarra I, et al. Double-blind study of cetirizine in atopic eczema in children. Ann Allergy. 1994;73(2):117-122.

136. Pavlova OV. Experience of using cetirizine (allertek) in the treatment of patients with atopic dermatitis and eczema. Bulletin of Dermatology and Venereology. 2005;(4):41-43. (In Russ).

137. Makarova IV, Zhiglinskaya OV, Mikhailova EA, Sukhorukova VG. Comparative efficacy of generic cetirizine (Egis production, Hungary) and original in the form of drops in the complex therapy of atopic dermatitis in young children. Current Pediatrics. 2007;6(3):85-88. (In Russ).

138. Samsygina GA. Allergic diseases in children. Moscow: GEOTAR-Media; 2019. 272 p. (In Russ).

139. Delyagin VM, Urazbagambetov A. The use of Suprastinex (levocetirizine) in atopy in children and adolescents. Russian Medical Journal. 2012;20(16):828-830. (In Russ).

140. Elisyutina OG, Fedenko ES, Fedoskova TG, Luss LV. Efficacy of levocetirizine therapy in patients with allergodermatoses. Russian Journal of Allergy. 2012;(5):69-75. (In Russ).

141. Tamrazova OB. Pathogenetic therapy of children suffering from severe forms of atopic dermatitis. Russian Medical Journal. 2013;(2):108-114. (In Russ).

142. Nazhmutdinova DK, Shvets OI. Levocetirizine: reboot. Russian Medical Journal. 2011;19(21):1324-1326. (In Russ).

143. Kamaev AV, Trusova OV, Kamaeva IA. Itching in atopic dermatitis in children: known mechanisms and possibilities of its long-term control. Russian Medical Journal. 2015;23(3):142-146. (In Russ).

144. Monakhov SA, Korzhachkina NB, Olisova OYu. Narrowwave phototherapy $311 \mathrm{~nm}$ in the treatment of patients with atopic dermatitis. Russian Journal of Skin and Venereal Diseases. 2012;(3):25-27. (In Russ).

145. Majoie IM, Oldhoff JM, van Weelden H, et al. Narrowband ultraviolet $\mathrm{B}$ and medium-dose ultraviolet $\mathrm{A} 1$ are equally effective in the treatment of moderate to severe atopic dermatitis. J Am Acad Dermatol. 2009;60(1):77-84. doi: 10.1016/j.jaad.2008.08.048

146. Reynolds NJ, Franklin V, Gray JC, et al. Narrowband ultraviolet $\mathrm{B}$ and broad-band ultraviolet A phototherapy in adult atopic eczema: a randomised controlled trial. Lancet. 2001;357(9273):2012-2016. doi: 10.1016/S0140-6736(00)05114-X

147. Clayton TH, Clark SM, Turner D, Goulden V. The treatment of severe atopic dermatitis in childhood with narrowband ultraviolet B phototherapy. Clin Exp Dermatol. 2007;32(1):28-33.

148. Seccombe L, Wynne MD, Clancy C, et al. A retrospective review of phototherapy in children, at a tertiary paediatric dermatology unit. Photodermatol Photoimmunol Photomed. 2021;37(1):34-38.

149. Gambichler T, Othlinghaus N, Tomi NS, et al. Medium-dose ultraviolet (UV) A1 vs. narrowband UVB phototherapy in atopic eczema: a randomized crossover study. Br J Dermatol. 2009;160(3):652-658. doi: 10.1111/j.1365-2133.2008.08984.x

150. Bogaczewicz J, Malinowska K, Sysa-Jedrzejowska A, Wozniacka A. Medium-dose ultraviolet A1 phototherapy improves SCORAD index and increases mRNA expression of interleukin-4 without direct effect on human $\beta$ defensin-1, interleukin-10, and interleukin-31. Int J Dermatol. 2016;55(7):e380-385. doi: 10.1111/ijd.13213

151. Tzaneva S, Seeber A, Schwaiger M, et al. High-dose versus medium-dose UVA1 phototherapy for patients with severe generalized atopic dermatitis. $J$ Am Acad Dermatol. 2001;45:503-507.

152. Malinowska K, Wozniacka A, Bogaczewicz J. The impact of medium dose UVA1 phototherapy on pruritus, DLQI and SCORAD index in patients with atopic dermatitis. Postepy Dermatol Alergol. 2020;37(6):962-967.

153. Abeck D, Schmidt T, Fesq H, et al. Long-term efficacy of medium-dose UVA1 phototherapy in atopic dermatitis. J Am Acad Dermatol. 2000;42 (2 Pt 1):254-257.

154. Pugashetti R, Lim HW, Koo J. Broadband UVB revisited: is the narrowband UVB fad limiting our therapeutic options? J Dermatolog Treat. 2010;21(6):326-330. doi: 10.3109/09546630903341986

155. Tzaneva S, Kittler H, Holzer G, et al. 5-Methoxypsoralen plus ultraviolet (UV) A is superior to medium-dose UVA1 in the treatment of severe atopic dermatitis: a randomized crossover trial. Br J Dermatol. 2010;162(3):655-660. doi: 10.1111/j.1365-2133.2009.09514.x

156. Garritsen FM, Brouwer MW, Limpens J, Spuls PI Photo(chemo)therapy in the management of atopic dermatitis: an updated systematic review with implications for practice and research. Br J Dermatol. 2014;170(3):501-513. doi: $10.1111 /$ bjd. 12645

157. Pérez-Ferriols A, Aranegui B, Pujol-Montcusí JA, et al. Phototherapy in atopic dermatitis: a systematic review of the literature. Actas Dermosifiliogr. 2015;106(5):387-401. doi: 10.1016/j.ad.2014.12.017

158. Uetsu N, Horio T. Treatment of persistent severe atopic dermatitis in 113 Japanese patients with oral psoralen photo-chemotherapy. J Dermatol. 2003;30(6):450-457. doi: 10.1111/j.1346-8138.2003.tb00415.x

159. Physical and rehabilitation medicine. The National Guide. Ed. by G.N. Ponomarenko. Moscow: GEOTAR-Media; 2016. 688 p. (In Russ). 
160. Private physiotherapy: A textbook. Ed. by G.N. Ponomarenko. Moscow: Meditsina; 2005. 744 p. (In Russ).

161. Patrizi A, Raone B, Ravaioli GM. Management of atopic dermatitis: safety and efficacy of phototherapy. Clin Cosmet Investig Dermatol. 2015;(8):511-520. doi: 10.2147/CCID.S87987

162. Dogra S, Mahajan R. Indian Association of Dermatologists, Venereologists and Leprologists. Phototherapy for atopic dermatitis. Indian J Dermatol Venereol Leprol. 2015;81(1):10-15. doi: 10.4103/0378-6323.148557

163. Kubanova AA, Samsonov VA, Volnukhin VA, et al. Therapy of patients with psoriasis, atopic dermatitis and vitiligo with narrow-band medium-wave ultraviolet radiation with a wavelength of $311 \mathrm{~nm}$. Medical technology No. FS2006/250 of August 15, 2006. Bulletin of Dermatology and Venereology. 2008;(3):17-20. (In Russ).

164. Thompson KG, Kim N. Distinguishing myth from fact: photocarcinogenesis and phototherapy. Dermatol Clin. 2020;38(1):25-35. doi: 10.1016/j.det.2019.08.003

165. Paller AS, Siegfried EC, Thaçi D, et al. Efficacy and safety of dupilumab with concomitant topical corticosteroids in children 6 to 11 years old with severe atopic dermatitis: A randomized, double-blinded, placebo-controlled phase 3 trial. J Am Acad Dermatol. 2020;83(5):1282-1293.

166. Paller AS, Bansal A, Simpson EL, et al. Clinically meaningful responses to dupilumab in adolescents with uncontrolled moderate-to-severe atopic dermatitis: Post-hoc analyses from a randomized clinical trial. Am J Clin Dermatol. 2020;21(1):119-131.

167. Simpson EL, Paller AS, Siegfried EC, et al. Efficacy and safety of dupilumab in adolescents with uncontrolled moderate to severe atopic dermatitis: a phase 3 randomized clinical trial. JAMA Dermatol. 2020;156(1):44-56.

168. Cork MJ, Thaçi D, Eichenfield LF, et al. Dupilumab in adolescents with uncontrolled moderate-to-severe atopic dermatitis: results from a phase IIa open-label trial and subsequent phase III open-label extension. Br J Dermatol. 2020;182(1):85-96.

169. Simpson EL, Bieber T, Guttman-Yassky E, et al. Two phase 3 trials of dupilumab versus placebo in atopic dermatitis. $N$ Engl $J$ Med. 2016;375(24):2335-2348. doi: 10.1056/NEJMoa1610020

170. Blauvelt A, de Bruin-Weller M, Gooderham M, et al. Longterm management of moderate-to-severe atopic dermatitis with dupilumab and concomitant topical corticosteroids (LIBERTY AD CHRONOS): a 1-year, randomised, double-blinded, placebo-controlled, phase 3 trial. Lancet. 2017;389(10086):22872303. doi: 10.1016/S0140-6736(17)31191-1

171. De Bruin-Weller M, Thaçi D, Smith CH, et al. Dupilumab with concomitant topical corticosteroid treatment in adults with atopic dermatitis with an inadequate response or intolerance to ciclosporin A or when this treatment is medically inadvisable: a placebo-controlled, randomized phase III clinical trial (LIBERTY AD CAFÉ). Br J Dermatol. 2018;178(5):1083-1101. doi: 10.1111/bjd.16156

172. Thaçi D, L Simpson E, Deleuran M, et al. Efficacy and safety of dupilumab monotherapy in adults with moderateto-severe atopic dermatitis: a pooled analysis of two phase 3 randomized trials (LIBERTY AD SOLO 1 and LIBERTY AD SOLO 2). J Dermatol Sci. 2019;94(2):266-275. doi: 10.1016/j.jdermsci.2019.02.002

173. Cork MJ, Eckert L, Simpson EL, et al. Dupilumab improves patient-reported symptoms of atopic dermatitis, symptoms of anxiety and depression, and health-related quality of life in moderate-to-severe atopic dermatitis: analysis of pooled data from the randomized trials SOLO 1 and SOLO 2. J Dermatolog Treat. 2020;31(6):606-614. doi: $10.1080 / 09546634.2019 .1612836$

174. Snast I, Reiter O, Hodak E, et al. Are biologics efficacious in atopic dermatitis? A systematic review and metaanalysis. Am J Clin Dermatol. 2018;19(2):145-165. doi: 10.1007/s40257-017-0324-7

175. Wang FP, Tang XJ, Wei CQ, et al. Dupilumab treatment in moderate-to-severe atopic dermatitis: A systematic review and meta-analysis. J Dermatol Sci. 2018;90(2):190-198. doi: 10.1016/j.jdermsci.2018.01.016

176. Czech W, Brautigam M, Weidinger G, Schöpf E. Body weight independent dosing regimen of cyclosporine microemulsion is effective in severe atopic dermatitis and improves the quality of life. J Am Acad Dermatol. 2000;42(4):653-659.

177. Harper JI, Ahmed I, Barclay G, et al. Cyclosporin for severe childhood atopic dermatitis: short course versus continuous therapy. Br J Dermatol. 2000;142(1):52-58. doi: 10.1046/j.1365-2133.2000.03241.x

178. Granlund H, Erkko P, Remitz A, et al. Comparison of cyclosporin and UVAB phototherapy for intermittent oneyear treatment of atopic dermatitis. Acta Derm Venereol. 2001;81(1):22-27. doi: 10.1080/00015550120235

179. Zurbriggen B, Wuthrich B, Cachelin AB, et al. Comparison of two formulations of cyclosporin $A$ in the treatment of severe atopic dermatitis. A double-blind, single-centre, cross-over pilot study. Dermatology. 1999;198(1):56-60. doi: 10.1159/000018065

180. Hijnen DJ, Ten Berge O, Timmer-de Mik L, et al. Efficacy and safety of long-term treatment with cyclosporin A for atopic dermatitis. $J$ Eur Acad Dermatol Venereol. 2007;21(1):85-89. doi: 10.1111/j.1468-3083.2006.01877.x

181. Schmitt J, Schmitt N, Meurer M. Cyclosporin in the treatment of patients with atopic eczema a systematic review and meta-analysis. J Eur Acad Dermatol Venereol. 2007;21(5):606-619. doi: 10.1111/j.1468-3083.2006.02023.x

182. Amor KT, Ryan K, Menter A. The use of cyclosporine in dermatology: Part I. J Am Acad Dermatol. 2010;63(6):925946. quiz 947-948. doi: 10.1016/j.jaad.2010.02.063

183. Wollenberg A, Barbarot S, Bieber T, et al. Consensusbased European guidelines for treatment of atopic eczema (atopic dermatitis) in adults and children: part II. J Eur Acad Dermatol Venereol. 2018;32(6):850-878. doi: $10.1111 / j d v .14888$

184. Shamov BA. Atopic dermatitis: clinical manifestations and treatment. Diary of the Kazan Medical School. 2014;(1):6365. (In Russ).

185. Jung MY, Chung JY, Lee HY, et al. Antibiotic susceptibility of Staphylococcus aureus in atopic dermatitis: current prevalence of methicillin-resistant Staphylococcus aureus in Korea and treatment strategies. Ann Dermatol. 2015;27(4):398403. doi: 10.5021/ad.2015.27.4.398

186. Lübbe J. Secondary infections in patients with atopic dermatitis. Am J Clin Dermatol. 2003;4(9):641-654. doi: 10.2165/00128071-200304090-00006

187. Masyukova SA, Gladko EV, Tarasenko GN, et al. Fusidic acid in the treatment of pyodermatitis and allergodermatoses complicated by bacterial infection. Bulletin of Dermatology and Venereology. 2007;(6):54-57. (In Russ).

188. Dvoryankova EV, Korsunskaya IM, Zakharova AB, Zhukovsky RO. Atopic dermatitis complicated by secondary 
infection: approaches to therapy. Effective Pharmacotherapy. 2011;(26):74-76. (In Russ).

189. Larkova IA. Effective therapy of atopic dermatitis in children complicated by secondary infection. Medical Advice. 2016;(1):162167. (In Russ). doi: 10.21518/2079-701X-2016-1-162-167

190. Matushevskaya EV, Svirshchevskaya EV. Atopic dermatitis in the practice of a dermatovenerologist: a rational choice of therapy. Russian Medical Journal. 2013;21(8):410-412. (In Russ).

191. Gong JQ, Lin L, Lin T, et al. Skin colonization by Staphylococcus aureus in patients with eczema and atopic dermatitis and relevant combined topical therapy: a double-blind multicentre randomized controlled trial. $\mathrm{Br} J$ Dermatol. 2006;155(4):680-687. doi: 10.1111/j.1365-2133.2006.07410.x

192. Lever R, Hadley K, Downey D, Mackie R. Staphylococcal colonization in atopic dermatitis and the effect of topical mupirocin therapy. Br J Dermatol. 1988;119(2):189-198. doi: 10.1111/j.1365-2133.1988.tb03201.x

193. Albanova V. External treatment of atopic dermatitis. Doctor. 2006;(2):76-78.

194. Batyrshina SV, Khaertdinova LA. The concept of local therapy of patients with atopic dermatitis. Practical Medicine. 2009;35(3):41-45.

195. Wachs GN, Maibach HI. Co-operative double-blind trial of an antibiotic/corticoid combination in impetiginized atopic dermatitis. Br J Dermatol. 1976;95(3):323-328. doi: 10.1111/j.1365-2133.1976.tb07021.x

196. Schuttelaar ML, Coenraads PJ. A randomized, double-blind study to assess the efficacy of addition of tetracycline to triamcinolone acetonide in the treatment of moderate to severe atopic dermatitis. $J$ Eur Acad Dermatol Venereol. 2008;22(9):1076-1082. doi: 10.1111/j.1468-3083.2008.02716.x

197. Vasenova VYu, Butov YuS. The use of Polcortolone TS for the treatment of itchy dermatoses complicated by secondary infection. Russian Medical Journal. 2013;21(22):10961098. (In Russ).

198. Skripkin YuK, Khamaganova IV. Experience of using oxycort and polcortolon TS aerosols in the treatment of allergic dermatoses complicated by pyoderma. Bulletin of Dermatology and Venereology. 2004;(1):42-43. (In Russ).

199. Ramsay C, Savoie J, Gilbert M, et al. The treatment of atopic dermatitis with topical fusidic acid and hydrocortisone acetate. J Eur Acad Dermatol Venereol. 1996;7(Suppl. 1):S1522. doi: 10.1016/0926-9959(96)00032-3

200. Hjorth N, Schmidt H, Thomsen K. Fusidic acid plus betamethasone in infected or potentially infected eczema. Pharmatherapeutica. 1985;4(1):126-131.

201. Tarasova MV, Marina TV, Sorokina EA, et al. The expediency of using combined topical glucocorticosteroids in the complex therapy of atopic dermatitis. Health and Education in the XXI century. 2008;10(3):383. (In Russ).

202. Kubanova AA, Proshutinskaya DV, Tekucheva LV, Avdienko IN. Integral approach to external therapy of patients with atopic dermatitis. Bulletin of Dermatology and Venereology. 2010;(1):20-26. (In Russ).

203. Nenasheva NM. Features of local (external) therapy of atopic dermatitis complicated by infection. RMJ. 2015;23(19):1159-1165. (In Russ).

204. Kungurov NV, Keniksfest YuV, Kohan MM, et al. Combined external therapy of complicated dermatoses. Clinical Dermatology and Venereology. 2005;(2):33-37. (In Russ).
205. Niebuhr M, Mai U, Kapp A, Werfel T. Antibiotic treatment of cutaneous infections with Staphylococcus aureus in patients with atopic dermatitis: current antimicrobial resistances and susceptibilities. Exp Dermatol. 2008;17(11):953957. doi: 10.1111/j.1600-0625.2008.00734.x

206. Boguniewicz M, Sampson H, Leung S, et al. Effects of cefuroxime axetil on Staphylococcus aureus colonizing and superantigen production in atopic dermatitis. J Allergy Clin Immunol. 2001;108(4):651-652. doi: 10.1067/mai.2001.118598

207. Treneva MS, Pampura AN. Strategy of choosing antibacterial drugs in children with microbial infection of atopic dermatitis. Practical Medicine. 2011;(3):136-139. (In Russ).

208. Boguniewicz M, Leung DY. Recent insights into atopic dermatitis and implications for management of infectious complications. J Allergy Clin Immunol. 2010;125(1):4-13. quiz 14-15. doi: 10.1016/j.jaci.2009.11.027

209. Tognetti L, Martinelli C, Berti S, et al. Bacterial skin and soft tissue infections: review of the epidemiology, microbiology, aetiopathogenesis and treatment: a collaboration between dermatologists and infectivologists. J Eur Acad Dermatol Venereol. 2012;26(8):931-941. doi: 10.1111/j.1468-3083.2011.04416.x

210. Petry V, Bessa GR, Poziomczyck CS, et al. Bacterial skin colonization and infections in patients with atopic dermatitis. An Bras Dermatol. 2012;87(5):729-734. doi: 10.1590/s0365-05962012000500010

211. Wollenberg A. Eczema herpeticum. Chem Immunol Allergy. 2012;(96):89-95. doi: 10.1159/000331892

212. Niimura M, Nishikawa T. Treatment of eczema herpeticum with oral acyclovir. Am J Med.1988;85(2A):49-52.

213. Bussmann C, Bockenhoff A, Henke H, et al. Does allergenspecific immunotherapy represent a therapeutic option for patients with atopic dermatitis? J Allergy Clin Immunol. 2006;118(6):1292-1298. doi: 10.1016/j.jaci.2006.07.054

214. Darsow U, Forer I, Ring J. Allergen-specific immunotherapy in atopic eczema. Curr Allergy Asthma Rep. 2011;11(4):277283. doi: 10.1007/s11882-011-0194-7

215. Bae JM, Choi YY, Park CO, et al. Efficacy of allergenspecific immunotherapy for atopic dermatitis: a systematic review and meta-analysis of randomized controlled trials. J Allergy Clin Immunol. 2013;132(1):110-117. doi: 10.1016/j.jaci.2013.02.044

216. Ring J. Successful hyposensitization treatment in atopic eczema: results of a trial in monozygotic twins. $\mathrm{Br} J$ Dermatol. 1982;107(5):597-602. doi: 10.1111/j.1365-2133.1982.tb00412.x

217. Glover MT, Atherton DJ. A double-blind controlled trial of hyposensitization to Dermatophagoides pteronyssinus in children with atopic eczema. Clin Exp Allergy. 1992;22(4):440446. doi: 10.1111/j.1365-2222.1992.tb00145.x

218. Zachariae H, Cramers M, Herlin T, et al. Non-specific immunotherapy and specific hyposensitization in severe atopic dermatitis. Acta Derm Venereol Suppl (Stockh). 1985;(114):48-54. doi: 10.2340/000155551144854

219. Yelisyutina OG, Fedenko ES. The place of specific immunotherapy in the treatment of patients with atopic dermatitis complicated by recurrent pyoderma. Physiology and Pathology of the Immune System. 2006;(8):15. (In Russ).

220. Novak N, Bieber T, Hoffmann M, et al. Efficacy and safety of subcutaneous allergen-specific immunotherapy with depigmented polymerized mite extract in atopic dermatitis. J Allergy Clin Immunol. 2012;130(4):925- 931e4. doi: 10.1016/j.jaci.2012.08.004 
221. Pajno GB, Caminiti L, Vita D, et al. Sublingual immunotherapy in mite-sensitized children with atopic dermatitis: a randomized, double-blind, placebo-controlled study. J Allergy Clin Immunol. 2007;120(1):164-170. doi: 10.1016/j.jaci.2007.04.008

222. Qin YE, Mao JR, Sang YC, Li WX. Clinical efficacy and compliance of sublingual immunotherapy with Dermatophagoides farinae drops in patients with atopic dermatitis. Int J Dermatol. 2014;53(5):650-655. doi: 10.1111/ijd.12302

223. Liu L, Guo D, Liang Q, et al. The efficacy of sublingual immunotherapy with Dermatophagoides farinae vaccine in a murine atopic dermatitis model. Clin Exp Allergy. 2015;45(4):815-822. doi: 10.1111/cea.12417

224. Roduit C, Frei R, Loss G, et al. Development of atopic dermatitis according to age of onset and association with earlylife exposures. J Allergy Clin Immunol. 2012;130(1):130136e5. doi: 10.1016/j.jaci.2012.02.043

225. Perkin MR, Logan K, Tseng A, et al. Randomized trial of introduction of allergenic foods in breast-fed infants. $N \mathrm{Engl} \mathrm{J}$ Med. 2016;374(18):1733-1743. doi: 10.1056/NEJMoa1514210

226. Prell C, Koletzko B. Breastfeeding and complementary feeding. Dtsch Arztebl Int. 2016;113(25):435-444. doi: 10.3238/arztebl.2016.0435

227. Vandenplas Y, Al-Hussaini B, Al-Mannaei K, et al. Prevention of allergic sensitization and treatment of cow's milk protein allergy in early life: the middle-east step-down consensus. Nutrients. 2019;11(7):1444. doi: $10.3390 /$ nu 11071444

228. Gruber C. Probiotics and prebiotics in allergy prevention and treatment: future prospects. Exp Rev Clin Immunol. 2012;8(1):17-19. doi: 10.1586/eci.11.74

229. Cuello-Garcia CA, Brozek JL, Fiocchi A, et al. Probiotics for the prevention of allergy: a systematic review and metaanalysis of randomized controlled trials. J Allergy Clin Immunol. 2015;136(4):952-961. doi: 10.1016/j.jaci.2015.04.031

230. Panduru M, Panduru NM, Sălăvăstru CM, Tiplica GS. Probiotics and primary prevention of atopic dermatitis: a metaanalysis of randomized controlled studies. J Eur Acad Dermatol Venereol. 2015;29(2):232-242. doi: 10.1111/jdv.12496

231. Muraro A, Halken S, Arshad SH, et al. EAACI food allergy and anaphylaxis guidelines. Primary prevention of food allergy. Allergy. 2014;69(5):590-601. doi: 10.1111/all.12398

232. Kantor R, Kim A, Thyssen JP, Silverberg JI. Association of atopic dermatitis with smoking: a systematic review and meta-analysis. J Am Acad Dermatol. 2016;75(6):1119-1125e1. doi: 10.1016/j.jaad.2016.07.017

233. Kathuria P, Silverberg JI. Association of pollution and climate with atopic eczema in US children. Pediatr Allergy Immunol. 2016;27(5):478-485. doi: 10.1111/pai.12543

234. Morgenstern V, Zutavern A, Cyrys J, et al. Atopic diseases, allergic sensitization, and exposure to traffic-related air pollution in children. Am J Respir Crit Care Med. 2008;177(12):1331-1337. doi: 10.1164/rccm.200701-036OC

235. Hidaka T, Ogawa E, Kobayashi EH, et al. The aryl hydrocarbon receptor AhR links atopic dermatitis and air pollution via induction of the neurotrophic factor artemin. Nat Immunol. 2017;18(1):64-73. doi: 10.1038/ni.3614

236. Ricci G, Bendandi B, Aiazzi R, et al. Three years of Italian experience of an educational program for parents of young children affected by atopic dermatitis: improving knowledge produces lower anxiety levels in parents of children with atopic dermatitis. Pediatr Dermatol. 2009;26(1):1-5. doi: 10.1111/j.1525-1470.2008.00813.x
237. Staab D, Diepgen TL, Fartasch M, et al. Age related, structured educational programmes for the management of atopic dermatitis in children and adolescents: multicentre, randomised controlled trial. BMJ. 2006;332(7547):933-938. doi: $10.1136 /$ bmj.332.7547.933

238. Lambert J, Bostoen J, Geusens B, et al. A novel multidisciplinary educational programme for patients with chronic skin diseases: Ghent pilot project and first results. Arch Dermatol Res. 2011;303(1):57-63. doi: 10.1007/s00403-010-1082-z

239. Kupfer J, Gieler U, Diepgen TL, et al. Structured education program improves the coping with atopic dermatitis in children and their parents-a multicenter, randomized controlled trial. J Psychosom Res. 2010;68(4):353-358. doi: 10.1016/j.jpsychores.2009.04.014

240. Staab D, von Rueden U, Kehrt R, et al. Evaluation of a parental training program for the management of childhood atopic dermatitis. Pediatr Allergy Immunol. 2002;13(2):8490. doi: 10.1034/j.1399-3038.2002.01005.x

241. Kiriyama T, Sugiura H, Uehara M. Residual washing detergent in cotton clothes: a factor of winter deterioration of dry skin in atopic dermatitis. J Dermatol. 2003;30(10):708-712. doi: 10.1111/j.1346-8138.2003.tb00463.x

242. Schmid-Wendtner MH, Korting HC. The $\mathrm{pH}$ of the skin surface and its impact on the barrier function. Skin Pharmacol Physiol. 2006;19(6):296-302. doi: 10.1159/000094670

243. Simpson E, Trookman NS, Rizer RL, et al. Safety and tolerability of a body wash and moisturizer when applied to infants and toddlers with a history of atopic dermatitis: results from an open-label study. Pediatr Dermatol. 2012;29(5):590-597. doi: 10.1111/j.1525-1470.2012.01809.x

244. Hon KL, Leung TF, Wong Y, et al. A survey of bathing and showering practices in children with atopic eczema. Clin Exp Dermatol. 2005;30(4):351-354. doi: $10.1111 / \mathrm{j} .1365-2230.2005 .01748 . \mathrm{x}$

245. Wollenberg A, Vogel S, Renner ED. Vaccinations with atopic dermatitis and other chronic inflammatory skin diseases. (In German). Hautarzt. 2010;61(11):985-993. doi: 10.1007/s00105-010-2019-3

246. Bath-Hextall F, Delamere F, Williams H. Dietary exclusions for improving established atopic eczema in adults and children systematic review. Allergy. 2009;64(2):258-264. doi: 10.1111/j.1398-9995.2008.01917.x

247. National calendar of preventive vaccinations. Appendix No. 1 to the order of the Ministry of Health of the Russian Federation of March 21, 2014. No. 125n. (In Russ). Available from: https://base.garant.ru/70647158/53f89421bbdaf741e b2d1ecc4ddb4c33/. Accessed: December 15, 2020.

248. Allergology and immunology: national guidelines. Ed. by R.M. Khaitov, N.I. Ilyina. Moscow: GEOTAR-Media; 2009. 634 p. (In Russ).

249. Campana R, Dzoro S, Mittermann I, et al. Molecular aspects of allergens in atopic dermatitis. Curr Opin Allergy Clin Immunol. 2017;17(4):269-277. doi: 10.1097/ACI.0000000000000378

250. Cartledge N, Chan S. Atopic Dermatitis and food allergy: a paediatric approach. Curr Pediatr Rev. 2018;14(3):171-179. doi: 10.2174/1573396314666180613083616

251. Darsow U, Laifaoui J, Kerschenlohr K, et al. The prevalence of positive reactions in the atopy patch test with aeroallergens and food allergens in subjects with atopic eczema: A European multicenter study. Allergy. 2004;59(12):13181325. doi: $10.1111 /$ j.1398-9995.2004.00556.x 
252. Tamagawa-Mineoka R, Katoh N. Atopic dermatitis: identification and management of complicating factors. Int $\mathrm{J} \mathrm{Mol}$ Sci. 2020;21(8):2671. doi: 10.3390/ijms21082671

253. Werfel T, Heratizadeh A, Niebuhr M, et al. Exacerbation of atopic dermatitis on grass pollen exposure in an environmental challenge chamber. J Allergy Clin Immunol. 2015;136(1):96-103.e9. doi: 10.1016/j.jaci.2015.04.015

254. Caut C, Leach M, Steel A. Dietary guideline adherence during preconception and pregnancy: A systematic review. $\mathrm{Ma}$ tern Child Nutr. 2020;16(2):e12916. doi: 10.1111/mcn.12916

255. Sugita K, Akdis CA. Recent developments and advances in atopic dermatitis and food allergy. Allergol Int. 2020;69(2):204-214. doi: 10.1016/j.alit.2019.08.013

256. Fedenko E, Elisyutina O, Shtyrbul O, et al. Microarraybased IgE serology improves management of severe atopic dermatitis in two children. Pediatr Allergy Immunol. 2016;27(6):645-649. doi: 10.1111/pai.12572
257. Alexander DD, Cabana MD. Partially hydrolyzed $100 \%$ whey protein infant formula and reduced risk of atopic dermatitis: a meta-analysis. $J$ Pediatr Gastroenterol Nutr. 2010;50(4):422-430.

258. Niggemann B, Reibel S, Wahn U. The atopy patch test (APT) - a useful tool for the diagnosis of food allergy in children with atopic dermatitis. Allergy. 2000;55(3):281285.

259. Sampson HA, Albergo R. Comparison of results of skin tests, RAST, and double-blind, placebo-controlled food challenges in children with atopic dermatitis. J Allergy Clin Immunol. 1984;74(1):26-33.

260. Roehr CC, Reibel S, Ziegert M, et al. Atopy patch tests, together with determination of specific IgE levels, reduce the need for oral food challenges in children with atopic dermatitis. J Allergy Clin Immunol. 2001;107(3):548-553. doi: 10.1067/mai.2001.112849

\section{Приложение A1.}

Состав рабочей группы по разработке и пересмотру клинических рекомендаций

1. Кубанов Алексей Алексеевич, д.м.н., профессор, член-корреспондент РАН, президент Российского общества дерматовенерологов и косметологов; директор ФГБУ «Государственный научный центр дерматовенерологии и косметологии» Минздрава России

2. Намазова-Баранова Лейла Сеймуровна, д.м.н., профессор, академик РАН, президент Союза педиатров России; руководитель НИИ педиатрии и охраны здоровья детей ЦКБ РАН, зав. кафедрой факультетской педиатрии педиатрического факультета ФГАОУ ВО «РНИМУ им. Н.И. Пирогова» Минздрава России, главный внештатный детский специалист по профилактической медицине Минздрава России

3. Хаитов Рахим Мусаевич, д.м.н., профессор, академик РАН, президент Российской ассоциации аллергологов и клинических иммунологов; научный руководитель ФГБУ «ГНЦ Институт иммунологии» ФМБА России, главный внештатный специалист аллерголог-иммунолог Минздрава России

4. Ильина Наталия Ивановна, д.м.Н., профессор, вице-президент Российской ассоциации аллергологов и клинических иммунологов; зам. директора по клинической работе, главный врач ФГБУ «ГНЦ Институт иммунологии» ФМБА России

5. Алексеева Елена Александровна, к.м.н., член Союза педиатров России; зав. многопрофильным педиатрическим дневным стационаром; ведущий научный сотрудник отдела клинической иммунологии и аллергологии НИИ педиатрии и охраны здоровья детей ЦКБ РАН; зам. руководителя КДЦ для детей НИИ педиатрии и охраны здоровья детей ФГБУЗ ЦКБ РАН

6. Амбарчян Эдуард Тигранович, К.м.н., врач-дерматолог отделения дерматологии с группой лазерной хирургии ФГАУ «Национальный медицинский исследовательский центр здоровья детей» Минздрава России, научной лаборатории кожи у детей НИИ детской дерматологии ФГАУ «Национальный медицинский исследовательский центр здоровья детей» Минздрава России; старший научный сотрудник отдела орфанных болезней и профилактики инвалидизирующих заболеваний НИИ педиатрии и охраны здоровья детей ЦКБ РАН

7. Артемьева Софья Иосифовна, член Национального альянса дерматовенерологов и косметологов; врачдерматовенеролог, младший научный сотрудник ГБУЗ «Московский научно-практический центр дерматовенерологии и косметологии» Департамента здравоохранения г. Москвы

8. Аршинский Марк Иванович, член Российского общества дерматовенерологов и косметологов; главный врач Краевого государственного бюджетного учреждения здравоохранения «Краевой кожно-венерологический диспансер» Минздрава Хабаровского края; главный внештатный дерматовенеролог Дальневосточного федерального округа

9. Астафьева Наталия Григорьевна, д.м.н., профессор, член Российской ассоциации аллергологов и клинических иммунологов; зав. кафедрой клинической иммунологии и аллергологии ФГБОУ ВО «Саратовский государственный медицинский университет им. В.И. Разумовского» Минздрава России; главный внештатный специалист аллерголог-иммунолог Саратовской области

10. Вишнева Елена Александровна, д.м.н., член Российской ассоциации аллергологов и клинических иммунологов; член Союза педиатров России; заместитель руководителя по науке НИИ педиатрии и охраны здоровья детей ЦКБ РАН, профессор кафедры факультетской педиатрии педиатрического факультета ФГАОУ ВО «РНИМУ им. Н.И. Пирогова» Минздрава России

11. Волнухин Владимир Анатольевич, д.м.н., профессор, член Национального альянса дерматовенерологов 
и косметологов; главный научный сотрудник отдела клинической дерматовенерологии и косметологии ГБУЗ «Московский научно-практический центр дерматовенерологии и косметологии» Департамента здравоохранения г. Москвы

12. Данилычева Инна Владимировна, к.м.н., член Российской ассоциации аллергологов и клинических иммунологов; ведущий научный сотрудник отделения аллергологии и иммунотерапии ФГБУ «ГНЦ Институт иммунологии» ФМБА России

13. Елисютина Ольга Гурьевна, Д.м.Н., член Российской ассоциации аллергологов и клинических иммунологов; ведущий научный сотрудник отделения аллергологии и иммунопатологии кожи ФГБУ «ГНЦ Институт иммунологии» ФМБА России

14. Епишев Роман Владимирович, к.м.Н., член Союза педиатров России; врач-дерматовенеролог отделения дерматологии с группой лазерной хирургии ФГАУ «Национальный медицинский исследовательский центр здоровья детей» Минздрава России; старший научный сотрудник отдела детской дерматологии НИИ педиатрии и охраны здоровья детей ЦКБ РАН; врач-дерматовенеролог консультативного отделения НИИ педиатрии и охраны здоровья детей ЦКБ РАН

15. Жестков Александр Викторович, Д.м.Н., профессор, член Российской ассоциации аллергологов и клинических иммунологов; зав. кафедрой микробиологии, иммунологии и аллергологии ФГБОУ ВО «Самарский государственный медицинский университет» Минздрава России; главный внештатный специалист аллерголог-иммунолог Самарской области

16. Жилова Марьяна Борисовна, д.м.н., член Российского общества дерматовенерологов и косметологов; зав. отделением физиотерапии ФГБУ «Государственный научный центр дерматовенерологии и косметологии» Минздрава России

17. Жукова Ольга Валентиновна, д.м.н., профессор, исполнительный директор Национального альянса дерматовенерологов и косметологов, главный врач ГБУЗ «Московский научно-практический центр дерматовенерологии и косметологии» Департамента здравоохранения г. Москвы

18. Заславский Денис Владимирович, д.м.н., профессор, член Российского общества дерматовенерологов и косметологов; член совета директоров Европейской академии дерматологии и венерологии (EADV) от России; профессор кафедры дерматовенерологии Санкт-Петербургского государственного педиатрического медицинского университета

19. Знаменская Людмила Федоровна, д.м.н., член Российского общества дерматовенерологов и косметологов; ведущий научный сотрудник отдела дерматологии ФГБУ «Государственный научный центр дерматовенерологии и косметологии» Минздрава России

20. Карамова Арфеня Эдуардовна, к.м.н., член Российского общества дерматовенерологов и косметологов; зав. отделом дерматологии ФГБУ «Государственный научный центр дерматовенерологии и косметологии» Минздрава России
21. Короткий Николай Гаврилович, д.м.н., профессор, вице-президент Национального альянса дерматовенерологов и косметологов; зав. кафедрой дерматовенерологии педиатрического факультета ФГАОУ ВО «РНИМУ им. Н.И. Пирогова» Минздрава России

22. Кохан Муза Михайловна, д.м.н., профессор, член Российского общества дерматовенерологов и косметологов; член Национального альянса дерматовенерологов и косметологов; руководитель научного клинического отдела дерматологии ГБУ СО «Уральский научно-исследовательский институт дерматовенерологии и иммунопатологии»

23. Круглова Лариса Сергеевна, д.м.н., профессор, член Национального альянса дерматовенерологов и косметологов; проректор по учебной работе, зав. кафедрой дерматовенерологии и косметологии ФГБУ ДПО «Центральная государственная медицинская академия» Управления делами Президента Российской Федерации

24. Кунгуров Николай Васильевич, д.м.н., профессор, член Национального альянса дерматовенерологов и косметологов; директор ГБУ Свердловской области «Уральский научно-исследовательский институт дерматовенерологии и иммунопатологии»

25. Левина Юлия Григорьевна, к.м.н., член Союза педиатров России; зав. отделом клинической иммунологии и аллергологии ФГБУ «Центральная клиническая больница» Российской академии наук

26. Львов Андрей Николаевич, д.м.н., профессор, член Национального альянса дерматовенерологов и косметологов; начальник отдела аспирантуры и ординатуры, профессор кафедры дерматовенерологии и косметологии ФГБУ ДПО «Центральная государственная медицинская академия» Управления делами Президента Российской Федерации; главный научный сотрудник Медицинского научно-образовательного центра Московского государственного университета им. М.В. Ломоносова

27. Материкин Александр Игоревич, к.м.н., член Союза педиатров России; врач-дерматовенеролог отделения дерматологии с группой лазерной хирургии ФГАУ «Национальный медицинский исследовательский центр здоровья детей» Минздрава России; старший научный сотрудник отдела детской дерматологии НИИ педиатрии и охраны здоровья детей ЦКБ РАН

28. Мишина Олеся Сергеевна, к.м.н., зав. научно-организационным отделом ФГБУ «Государственный научный центр дерматовенерологии и косметологии» Минздрава России

29. Монахов Константин Николаевич, д.м.н., профессор, член Российского общества дерматовенерологов и косметологов; профессор кафедры дерматовенерологии с клиникой ФБГОУ ВО «Первый СанктПетербургский государственный медицинский университет им. И.П. Павлова».

30. Мурашкин Николай Николаевич, д.м.Н., член Российского общества дерматовенерологов и косметологов, член Союза педиатров России; руководитель НИИ детской дерматологии; зав. отделением дерматологии 
с группой лазерной хирургии ФГАУ «Национальный медицинский исследовательский центр здоровья детей» Минздрава России; профессор кафедры дерматовенерологии и косметологии ФГБУ ДПО «Центральная государственная медицинская академия» Управления делами Президента Российской Федерации

31. Ненашева Наталья Михайловна, д.м.н., профессор, член Российской ассоциации аллергологов и клинических иммунологов; зав. кафедрой аллергологии и иммунологии ФГБОУ ВПО «Российская медицинская академия непрерывного профессионального образования» Минздрава России

32. Пампура Александр Николаевич, д.м.н., член Российской ассоциации аллергологов и клинических иммунологов; главный внештатный детский специалист аллерголог-иммунолог Департамента здравоохранения г. Москвы; зав. отделом аллергологии и клинической иммунологии Научно-исследовательского клинического института педиатрии имени академика Ю.Е. Вельтищева ФГАОУ ВО «РНИМУ им. Н.И. Пирогова» Минздрава России

33. Плахова Ксения Ильинична, д.м.Н., член Российского общества дерматовенерологов и косметологов; ученый секретарь ФГБУ «Государственный научный центр дерматовенерологии и косметологии» Минздрава России, и.о. зав. отделом ИППП ФГБУ «Государственный научный центр дерматовенерологии и косметологии» Минздрава России

34. Потекаев Николай Николаевич, д.м.н., профессор, президент Национального альянса дерматовенерологов и косметологов; главный внештатный специалист по дерматовенерологии и косметологии Минздрава России и Департамента здравоохранения г. Москвы; зав. кафедрой кожных болезней и косметологии ФДПО ФГАОУ ВО «РНИМУ им. Н.И. Пирогова» Минздрава России

35. Притуло Ольга Александровна, Д.м.н., профессор, член Российского общества дерматовенерологов и косметологов; зав. кафедрой дерматовенерологии с курсом косметологии Медицинской академии имени С.И. Георгиевского ФГАОУ ВО «Крымский федеральный университет имени В.И. Вернадского»

36. Разнатовский Константин Игоревич, д.м.н., профессор, член Национального альянса дерматовенерологов и косметологов; главный дерматовенеролог и косметолог Комитета здравоохранения Правительства Санкт-Петербурга; главный дерматовенеролог и косметолог Северо-Западного федерального округа; зав. кафедрой дерматовенерологии ФГБОУ ВO «Северо-Западный государственный медицинский университет им. И.И. Мечникова» Минздрава России

37. Сапунцова Светлана Геннадьевна, к.м.н., член Российского общества дерматовенерологов и косметологов; зав. кафедрой дерматовенерологии ФГБОУ ВО «Дальневосточный государственный медицинский университет» Минздрава России
38. Селимзянова Лилия Робертовна, к.м.н., член Союза педиатров России; ведущий научный сотрудник НИИ педиатрии и охраны здоровья детей ЦКБ РАН; доцент кафедры факультетской педиатрии педиатрического факультета ФГАОУ ВО «РНИМУ им. Н.И. Пирогова» Минздрава России; доцент кафедры педиатрии и детской ревматологии Клинического института детского здоровья имени Н.Ф. Филатова ФГАОУ «Первый Московский государственный медицинский университет имени И.М. Сеченова» Минздрава России (Сеченовский Университет)

39. Скороходкина Олеся Валерьевна, д.м.н., професcop, член Российской ассоциации аллергологов и клинических иммунологов; главный внештатный аллерголог-иммунолог Приволжского федерального округа и республики Татарстан; зав. кафедрой клинической иммунологии с аллергологией ФГБОУ ВO «Казанский государственный медицинский университет»

40. Феденко Елена Сергеевна, д.м.н., профессор, член Российской ассоциации аллергологов и клинических иммунологов; зав. отделением аллергологии и иммунопатологии кожи ФГБУ «ГНЦ Институт иммунологии» ФМБА России

41. Фомина Дарья Сергеевна, к.м.н., член Российской ассоциации аллергологов и клинических иммунологов; главный внештатный специалист аллерголог-иммунолог Департамента здравоохранения г. Москвы; руководитель Московского городского научно-практического центра аллергологии и иммунологии; доцент кафедры клинической иммунологии и аллергологии ФГАОУ ВО «Первый Московский государственный медицинский университет имени И.М. Сеченова» Минздрава России (Сеченовский Университет)

42. Фриго Наталья Владиславовна, д.м.н., член Национального альянса дерматовенерологов и косметологов; зам. директора по науке ГБУЗ «Московский научно-практический центр дерматовенерологии и косметологии» Департамента здравоохранения г. Москвы

43. Фролова Зоя Владимировна, член Российского общества дерматовенерологов и косметологов; зам. главного врача по медицинской части КГБУЗ «Краевой кожно-венерологический диспансер» Минздрава Хабаровского края

44. Хаитов Муса Рахимович, д.м.н., профессор, членкорреспондент РАН, член Российской ассоциации аллергологов и клинических иммунологов; директор ФГБУ «ГНЦ Институт иммунологии» ФМБА России; зав. кафедрой иммунологии ФГАОУ ВО РНИМУ им. Н.И. Пирогова Минздрава России

45. Чикин Вадим Викторович, д.м.н., член Российского общества дерматовенерологов и косметологов; старший научный сотрудник отдела дерматологии ФГБУ «Государственный научный центр дерматовенерологии и косметологии» Минздрава России. 


\section{Приложение}

\section{A2. Методология разработки клинических рекомендаций}

Целевая аудитория данных клинических рекомендаций

1. Врачи-специалисты: врачи-дерматовенерологи, врачи аллергологи-иммунологи, врачи-педиатры, врачи общей практики (семейные врачи), врачи-терапевты.

2. Ординаторы и слушатели циклов повышения квалификации по указанным специальностям.

Таблица 1. Шкала оценки уровней достоверности доказательств (УДД) для методов диагностики (диагностических вмешательств)

\begin{tabular}{|c|l|}
\hline УДД & \multicolumn{1}{|c|}{ Расшифровка } \\
\hline 1 & $\begin{array}{l}\text { Систематические обзоры исследований с контролем референсным методом или систематический обзор } \\
\text { рандомизированных клинических исследований с применением метаанализа }\end{array}$ \\
\hline 2 & $\begin{array}{l}\text { Отдельные исследования с контролем референсным методом или отдельные рандомизированные клинические } \\
\text { исследования и систематические обзоры исследований любого дизайна, за исключением рандомизированных } \\
\text { клинических исследований, с применением метаанализа }\end{array}$ \\
\hline 3 & $\begin{array}{l}\text { Исследования без последовательного контроля референсным методом или исследования с референсным } \\
\text { методом, не являющимся независимым от исследуемого метода или нерандомизированные сравнительные } \\
\text { исследования, в том числе когортные исследования }\end{array}$ \\
\hline 4 & Несравнительные исследования, описание клинического случая \\
\hline 5 & Имеется лишь обоснование механизма действия или мнение экспертов \\
\hline
\end{tabular}

Таблица 2. Шкала оценки уровней достоверности доказательств (УДД) для методов профилактики, лечения и реабилитации (профилактических, лечебных, реабилитационных вмешательств)

\begin{tabular}{|c|l|}
\hline УДД & \multicolumn{1}{|c|}{ Расшифровка } \\
\hline 1 & Систематический обзор рандомизированных клинических исследований с применением метаанализа \\
\hline 2 & $\begin{array}{l}\text { Отдельные рандомизированные клинические исследования и систематические обзоры исследований любого } \\
\text { дизайна, за исключением рандомизированных клинических исследований, с применением метаанализа }\end{array}$ \\
\hline 3 & Нерандомизированные сравнительные исследования, в т.ч. когортные исследования \\
\hline 4 & Несравнительные исследования, описание клинического случая или серии случаев, исследования «случай-контроль» \\
\hline 5 & Имеется лишь обоснование механизма действия вмешательства (доклинические исследования) или мнение экспертов \\
\hline
\end{tabular}

Таблица 3. Шкала оценки уровней убедительности рекомендаций (УУР) для методов профилактики, диагностики, лечения и реабилитации (профилактических, диагностических, лечебных, реабилитационных вмешательств)

\begin{tabular}{|c|l|}
\hline УУР & \multicolumn{1}{|c|}{ Расшифровка } \\
\hline А & $\begin{array}{l}\text { Сильная рекомендация (все рассматриваемые критерии эффективности (исходы) являются важными, все } \\
\text { исследования имеют высокое или удовлетворительное методологическое качество, их выводы по интересующим } \\
\text { исходам являются согласованными) }\end{array}$ \\
\hline В & $\begin{array}{l}\text { Условная рекомендация (не все рассматриваемые критерии эффективности (исходы) являются важными, } \\
\text { не все исследования имеют высокое или удовлетворительное методологическое качество и/или их выводы } \\
\text { по интересующим исходам не являются согласованными) }\end{array}$ \\
\hline С & $\begin{array}{l}\text { Слабая рекомендация (отсутствие доказательств надлежащего качества: все рассматриваемые критерии } \\
\text { эффективности (исходы) являются неважными, все исследования имеют низкое методологическое качество } \\
\text { и их выводы по интересующим исходам не являются согласованными) }\end{array}$ \\
\hline
\end{tabular}

\section{Порядок обновления клинических рекомендаций}

Механизм обновления клинических рекомендаций предусматривает их систематическую актуализацию - не реже чем один раз в три года, а также при появлении новых данных с позиции доказательной медицины по вопросам диагностики, лечения, профилактики и реабилитации конкретных заболеваний, наличии обоснованных дополнений/замечаний к ранее утверждённым клиническим рекомендациям, но не чаще 1 раза в 6 месяцев.

\section{Приложение А3. \\ Справочные материалы, включая соответствие показаний к применению и противопоказаний, способов применения и доз лекарственных препаратов, инструкции по применению лекарственного препарата}

Данные клинические рекомендации разработаны с учётом следующих нормативно-правовых документов: 1. Порядок оказания медицинской помощи по профилю «дерматовенерология», утверждённый Приказом Министерства здравоохранения Российской Федерации № 924н от 15 ноября 2012 г.

2. Порядок оказания медицинской помощи населению по профилю «аллергология и иммунология», утверждённый Приказом Министерства здравоохранения Российской Федерации № 606н от 7 ноября 2012 г. 


\section{Приложение Б.}

Алгоритмы действий врача

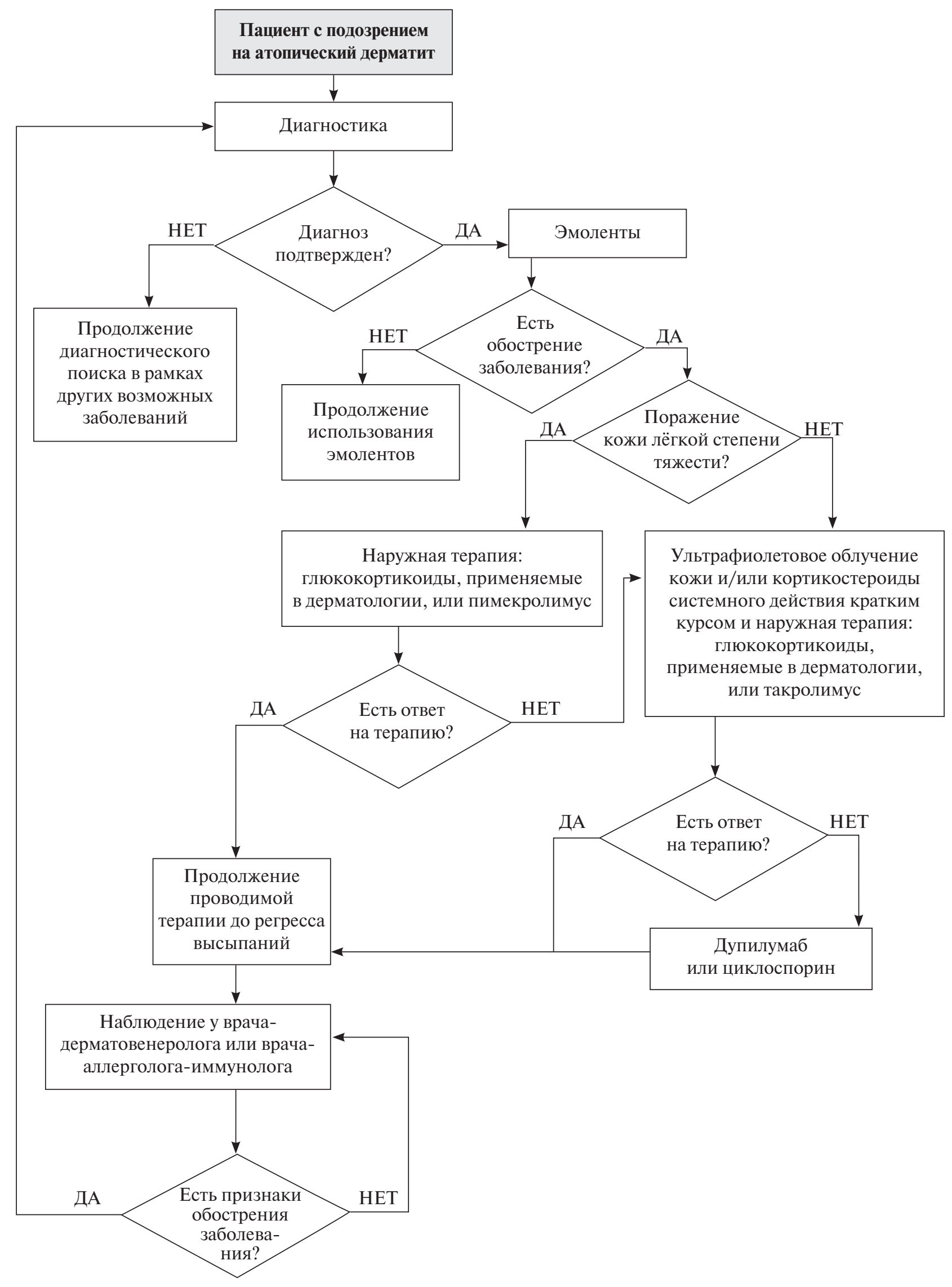




\section{Приложение В.}

\section{Информация для пациента}

1. Учитывая, что атопический дерматит является хроническим заболеванием, для предотвращения рецидивов необходимо проведение регулярной базисной терапии увлажняющими и смягчающими наружными средствами.

2. При наличии в семье отягощённого наследственного аллергологического анамнеза рекомендуется соблюдать профилактические мероприятия в отношении соблюдения диеты кормящей матери и введения прикорма ребёнку первого года жизни.

3. Во избежание развития побочных эффектов следует избегать самостоятельного бесконтрольного применения топических глюкокортикостероидных и антибактериальных препаратов.

Приложение Г1-ГЗ. Шкалы оценки, вопросники и другие оценочные инструменты состояния пациента, приведённые в клинических рекомендациях

\section{Приложение Г1. Общая оценка заболевания исследователем IGA}

Оригинальное название: Investigator's global assessment (IGA).

Источник (официальный сайт разработчиков, публикация с валидацией): https://www.eczemacouncil. org/research/investigator-global-assessment-scale/

Тип (подчеркнуть):

- шкала оценки

- индекс

- вопросник

- другое (уточнить).

Назначение: оценка общей степени тяжести атопического дерматита.

Содержание (шаблон):

\begin{tabular}{|c|c|c|}
\hline Балл & Категория & Описание* \\
\hline 0 & Чистая кожа & $\begin{array}{l}\text { Проявления атопического дерматита полностью исчезли, за исключением } \\
\text { остаточных очагов депигментации (поствоспалительная гиперпигментация и/или } \\
\text { гипопигментация) }\end{array}$ \\
\hline 1 & $\begin{array}{c}\text { Практически } \\
\text { чистая кожа }\end{array}$ & $\begin{array}{l}\text { Проявления атопического дерматита в целом не полностью исчезли, а оставшиеся } \\
\text { очаги представляют собой светло-розовые (за исключением поствоспалительной } \\
\text { гиперпигментации) и/или едва заметные при пальпации твёрдые участки утолщения } \\
\text { кожи и/или папулы и/или едва заметные при пальпации участки лихенизации, } \\
\text { экскориации; экссудация/образование струпьев отсутствует }\end{array}$ \\
\hline 2 & Лёгкая степень & $\begin{array}{l}\text { Проявления атопического дерматита в целом представляют собой очаги светло- } \\
\text { красного цвета; с незначительными, но чётко выраженными твёрдыми участками } \\
\text { утолщения кожи и/или папулами с незначительными, но чётко выраженными } \\
\text { линейными или прерывистыми следами расчёсывания или проникающего } \\
\text { поверхностного поражения; с незначительным, но чётко выраженным утолщением } \\
\text { кожи, мелкими отметинами на коже и мелкопластинчатым лихеноидным шелушением; } \\
\text { экссудация/образование струпьев отсутствует }\end{array}$ \\
\hline 3 & Средняя степень & $\begin{array}{l}\text { Проявления атопического дерматита в целом представляют собой очаги красного цвета; } \\
\text { с легко определяемыми при пальпации умеренно выраженными твёрдыми участками } \\
\text { утолщения кожи и/или папулами; с умеренными линейными или прерывистыми } \\
\text { следами расчёсывания или проникающего поверхностного поражения; с умеренным } \\
\text { утолщением кожи, грубыми отметинами на коже и крупнопластинчатым лихеноидным } \\
\text { шелушением; с незначительной экссудацией/образованием струпьев }\end{array}$ \\
\hline 4 & Тяжёлая степень & $\begin{array}{l}\text { Проявления атопического дерматита в целом представляют собой глубокие очаги } \\
\text { тёмно-красного цвета; с выраженными твёрдыми участками утолщения кожи и/или } \\
\text { папулами; выраженными линейными или прерывистыми следами расчёсывания или } \\
\text { проникающего поверхностного поражения; выраженным утолщением кожи с очень } \\
\text { грубыми отметинами на коже и крупнопластинчатым лихеноидным шелушением; с } \\
\text { экссудацией/образованием струпьев от средней до тяжёлой степени }\end{array}$ \\
\hline
\end{tabular}

* Из оценки/подсчёта баллов IGA исключаются волосистая часть головы, ладони и подошвы. 
Показатель IGA используется для оценки степени тяжести атопического дерматита. Оценивается тяжесть атопического дерматита на момент проведения оценки.

Поражение кожи оценивается визуально и пальпаторно. IGA представляет собой оценку по 5-балльной шкале от 0 баллов до 4 баллов и отражает выраженность эритемы, утолщения (уплотнения) кожи и шелушения. Оценка 0 баллов соответствует чистой коже, максимальная оценка 4 балла соответствует атопическому дерматиту тяжёлой степени тяжести.

\section{Приложение Г2. Индекс SCORAD}

Индекс SCORAD предназначен для оценки степени тяжести атопического дерматита.

Оригинальное название: Scoring of Atopic Dermatitis (SCORAD).

Источник (официальный сайт разработчиков, публикация с валидацией): Consensus report of the European Task Force on Atopic Dermatitis. Severity of scoring of atopic dermatitis: the SCORAD index. Dermatology. 1993;186:23-31.

Тип (подчеркнуть):

- шкала оценки

- индекс

- вопросник

- другое (уточнить).

Назначение: оценка степени тяжести атопического дерматита.

Содержание (шаблон):

А. Площадь поражения (оценивается врачом)

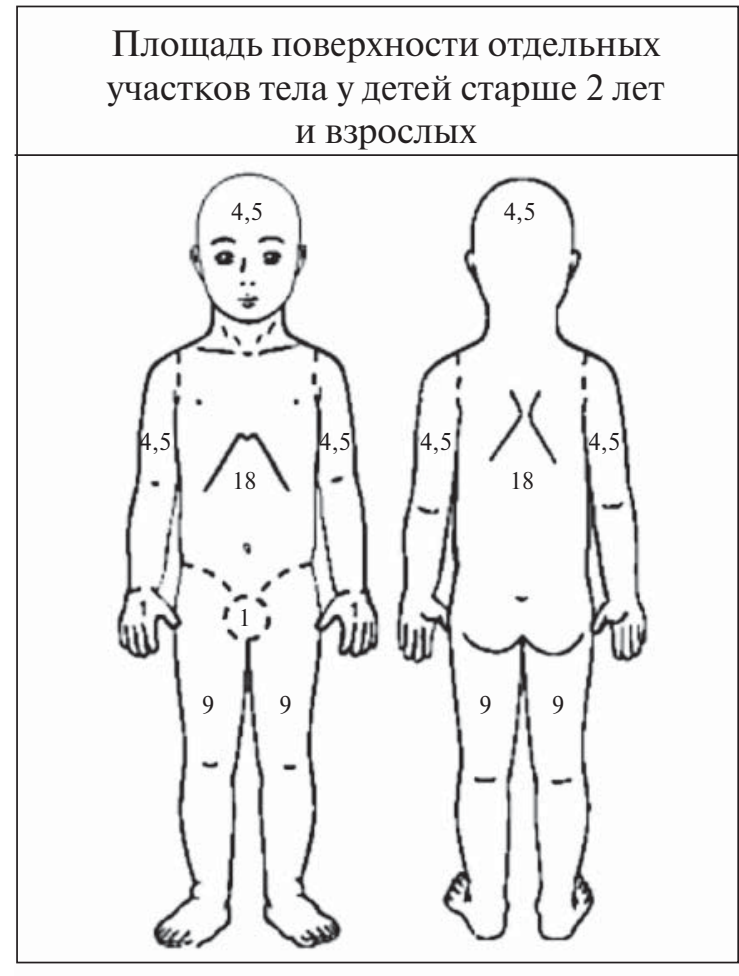

Показатель $\mathrm{A}=$
Площадь проявлений атопического дерматита на отдельных участках тела

\begin{tabular}{l|c}
\hline \multicolumn{1}{c|}{ Участок тела } & $\begin{array}{c}\text { Площадь } \\
\text { поражения }\end{array}$ \\
\hline Передняя поверхность головы (4,5\%) & \\
\hline Задняя поверхность головы (4,5\%) & \\
\hline Передняя поверхность туловища (18\%) & \\
\hline Задняя поверхность туловища (18\%) & \\
\hline Гениталии (1\%) & \\
\hline Передняя поверхность левой руки (4,5\%) & \\
\hline Задняя поверхность левой руки (4,5\%) & \\
\hline Передняя поверхность правой руки (4,5\%) & \\
\hline Задняя поверхность правой руки (4,5\%) & \\
\hline Передняя поверхность левой ноги (9\%) & \\
\hline Задняя поверхность левой ноги (9\%) & \\
\hline Передняя поверхность правой ноги (9\%) & \\
\hline Задняя поверхность правой ноги (9\%) & \\
\hline Итого & \\
\hline
\end{tabular}




\section{В. Интенсивность клинических проявлений (оценивается врачом)}

Оценка клинических проявлений атопического дерматита:

\begin{tabular}{|c|c|}
\hline Клинические проявления & Оценка в баллах \\
\hline Эритема & \\
\hline Отек или папулезность & \\
\hline Мокнутие/корки & \\
\hline Расчесы & \\
\hline Лихенификация & \\
\hline Сухость & \\
\hline Итого & \\
\hline
\end{tabular}

\section{Способ оценки:}

$0=$ отстутствие проявлений

1 = лёгкие проявления

2 = умеренные проявления

3 = тяжёлые проявления

\section{Показатель В =}

\section{С. Выраженность субъективных симптомов (оценивается пациентом)}

Отсутствие

зуда

Очень

сильный зуд

\begin{tabular}{|l|l|l|l|l|l|l|l|l|l|l|}
\hline 0 & 1 & 2 & 3 & 4 & 5 & 6 & 7 & 8 & 9 & 10 \\
\hline
\end{tabular}

Отсутствие

Очень сильное

нарушений сна

\begin{tabular}{|l|l|l|l|l|l|l|l|l|l|l|}
\hline 0 & 1 & 2 & 3 & 4 & 5 & 6 & 7 & 8 & 9 & 10 \\
\hline
\end{tabular}

Показатель $\mathrm{C}=$

$$
\mathrm{SCORAD}=\mathrm{A} / 5+7 * \mathrm{~B} / 2+\mathrm{C}=
$$

Ключ (интерпретация):

SCORAD предусматривает балльную оценку шести объективных симптомов: эритема, отёк/папулёзные элементы, корки/мокнутие, экскориации, лихенификация/шелушение, сухость кожи. Интенсивность каждого признака оценивается по 4-уровневой шкале: 0 - отсутствие, 1 - слабая, 2 - умеренная, 3 сильная. При оценке площади поражения кожного покрова следует использовать правило «девятки», в котором за единицу измерения принята площадь поверхности ладони больного, эквивалентная одному проценту всей поверхности кожи. Цифрами указано значение площади для больных в возрасте старше 2 лет, а в скобках - для детей в возрасте до 2 лет (рис. 1). Оценку субъективных симптомов (ощущение зуда, нарушение сна) проводят у детей в возрасте старше 7 лет и взрослых; у детей младшего возраста оценку субъективных симптомов проводят с помощью родителей, которым предварительно объясняют принцип оценки.

Расчёт индекса SCORAD производится по формуле: SCORAD = A/5 + 7B/2 + C, где: A - распространённость поражения кожи; В - сумма уровней интенсивности клинических симптомов атопического дерматита; C - сумма оценок субъективных нарушений по визуальной аналоговой шкале.

На линейке внизу рисунка указывается точка, соответствующая степени выраженности оцениваемого субъективного признака, усреднённой за последние 3 суток.

Значения индекса могут варьировать в пределах от 0 (нет заболевания) до 103 (максимально тяжёлое течение атопического дерматита).

Атопический дерматит лёгкой степени тяжести соответствует значению SCORAD $<25$.

Атопический дерматит средней степени тяжести соответствует значению SCORAD от 25 до 50.

Тяжёлый атопический дерматит соответствует значению SCORAD >50. 
Приложение ГЗ. Классификация глюкокортикоидов, применяемых в дерматологии

\begin{tabular}{|l|c|}
\hline \multicolumn{1}{|c|}{$\begin{array}{c}\text { Международное название глюкокортикоидов, } \\
\text { применяемых в дерматологии }\end{array}$} & Концентрация \\
\hline \multicolumn{2}{|c|}{ Класс 1 (слабой активности) } \\
\hline Гидрокортизон** & $0,5 \% ; 1 \%$ \\
\hline Гидрокортизона ацетат & $0,5 \% ; 1 \%$ \\
\hline \multicolumn{2}{|c|}{ Класс 2 (умеренной активности) } \\
\hline Алклометазон & $0,05 \%$ \\
\hline Преднизолон** & $0,5 \%$ \\
\hline Флуоцинолон & $0,025 \%$ \\
\hline Триамцинолон & $0,025 \%$ \\
\hline \multicolumn{2}{|c|}{ Класс 3(сильной активности) } \\
\hline Гидрокортизона бутират & $0,1 \%$ \\
\hline Бетаметазон** & $0,05 \% ; 0,1 \%$ \\
\hline Метилпреднизолон & $0,1 \%$ \\
\hline Мометазон** & $0,1 \%$ \\
\hline Триамцинолон & $0,1 \%$ \\
\hline Флутиказон & $0,005 \% ; 0,05 \%$ \\
\hline & \\
\hline Клобетазол & $0,05 \%$ \\
\hline
\end{tabular}

\section{ОБ АВТOPAX}

Автор, ответственный за переписку:

Чикин Вадим Викторович, д.М.н..; адрес: Россия, 107076, Москва, ул. Короленко, д. 3, стр. 6; ORCID: http://orcid.org/0000-0002-9688-2727; eLibrary SPIN: 3385-4723; e-mail: chikin@cnikvi.ru

\section{Соавторы:}

Елисютина Ольга Гурьевна, д.М.Н., В.Н.С.; адрес: Россия, 115522, Москва, Каширское шоссе, д. 24; ORCID: https://orcid.org/0000-0002-4609-2591; eLibrary SPIN: 9567-1894; e-mail: el-olga@yandex.ru

Кубанов Алексей Алексеевич, д.М.Н., професссор, член-корреспондент РАН;

ORCID: https://orcid.org/0000-0002-7625-0503;

eLibrary SPIN: 8771-4990; e-mail: alex@cnikvi.ru

Намазова-Баранова Лейла Сеймуровна, д.М.Н., профрессор, академик РАН;

ORCID: https://orcid.org/0000-0002-2209-7531;

eLibrary SPIN: 1312-2147;

e-mail: leyla.s.namazova@gmail.com

Хаитов Рахим Мусаевич, Д.М.Н., профрессор, академик РАН;

ORCID: https://orcid.org/0000-0003-1829-0424; e-mail: rm.khaitov@nrcii.ru

\section{AUTHORS' INFO}

Corresponding author:

Vadim V. Chikin, MD, Dr. Sci. (Med.);

address: 3, b. 6, Korolenko str., Moscow, 107076, Russia;

ORCID: http://orcid.org/0000-0002-9688-2727;

eLibrary SPIN: 3385-4723; e-mail: chikin@cnikvi.ru

Co-authors:

Olga G. Elisyutina, MD, Dr. Sci. (Med.),

Senior Research Associate;

address: 24, Kashirskoyw shosse, Moscow, 115522, Russia;

ORCID: https://orcid.org/0000-0002-4609-2591;

eLibrary SPIN: 9567-1894; e-mail: el-olga@yandex.ru

Alexey A. Kubanov, MD, Dr. Sci. (Med.), Professor, Corresponding Member of the Russian Academy of Sciences; ORCID: https://orcid.org/0000-0002-7625-0503; eLibrary SPIN: 8771-4990; e-mail: alex@ cnikvi.ru

Leyla S. Namazova-Baranova, MD, Dr. Sci. (Med.), Professor, Academician of the Russian Academy of Sciences; ORCID:https://orcid.org/0000-0002-2209-7531; eLibrary SPIN: 1312-2147; e-mail: leyla.s.namazova@gmail.com

Rakhim M. Khaitov, MD, Dr. Sci. (Med.), Professor, Academician of the Russian Academy of Sciences; ORCID: https://orcid.org/0000-0003-1829-0424; e-mail: rm.khaitov@nrcii.ru 
Ильина Наталья Ивановна, д.м.н., профрессор; ORCID: https://orcid.org/0000-0002-3556-969X; eLibrary SPIN: 6715-5650; e-mail: instimmun@yandex.ru

Алексеева Анна Александровна, к.м.н.; ORCID: https://orcid.org/0000-0002-8023-2543; eLibrary SPIN: 7253-7970; e-mail: aleksaa06@yandex.ru

Амбарчян Эдуард Тигранович, К.М.Н.; ORCID: http:/orcid.org/0000-0002-8232-8936; eLibrary SPIN: 4878-5562; e-mail: edo_amb@mail.ru

\section{Артемьева Софья Иосифовна;}

ORCID: https://orcid.org/0000-0002-2793-8862; eLibrary SPIN: 2627-9842; e-mail: sofya.chern@gmail.com

\section{Аршинский Марк Иванович;}

ORCID: https://orcid.org/0000-0003-2952-9082; eLibrary SPIN: 1821-9471; e-mail: kkvd80@inbox.ru

Астафьева Наталья Григорьевна, д.М.Н., профессор; ORCID: https://orcid.org/0000-0002-7691-4584; eLibrary SPIN: 9941-7013; e-mail: astang@mail.ru

\section{Вишнева Елена Александровна, д.М.н.;} ORCID: https://orcid.org/0000-0001-7398-0562; eLibrary SPIN: 1109-2810; e-mail:vishneva.e@yandex.ru

Волнухин Владимир Анатольевич, д.м.н., профрессор; ORCID: https://orcid.org/0000-0002-8363-5188; eLibrary SPIN: 8206-2731; e-mail: vvoln@rambler.ru

Данилычева Инна Владимировна, К.M.н.; ORCID: http://orcid.org/0000-0002-8279-2173; eLibrary SPIN: 4547-3948; e-mail: ivdanilycheva@mail.ru

\section{Епишев Роман Владимирович, К.М.Н.;} ORCID: https://orcid.org/0000-0002-4107-4642; eLibrary SPIN: 5162-7846; e-mail: drepishev@gmail.com

Жестков Александр Викторович, д.М.Н., профрессор; ORCID htts://orcid.org/0000-0002-3960-830X; eLibrary SPIN: 2765-9617; e-mail: avzhestkov2015@yandex.ru

Жилова Марьяна Борисовна, д.м.н.;

ORCID: https://orcid.org/0000-0003-2545-2129;

eLibrary SPIN: 8930-4073; e-mail: zhilova@cnikvi.ru

Жукова Ольга Валентиновна, д.М.Н., профессор; ORCID: https://orcid.org/0000-0001-5723-6573; eLibrary SPIN: 8584-7564, e-mail: klinderma@inbox.ru

Заславский Денис Владимирович, д.м.н., профрессор; ORCID: https://orcid.org/0000-0001-5936-6232; elibrary SPIN: 5832-9510; e-mail:venerology@gmail.com

Знаменская Людмила Федоровна, д.м.н., ORCID: http://orcid.org/0000-0002-2553-0484; eLibrary SPIN: 9552-7850; e-mail: znaml@cnikvi.ru

Карамова Арфеня Эдуардовна, К.М.Н., ORCID: https://orcid.org/0000-0003-3805-8489; eLibrary SPIN 3604-6491; e-mail: karamova@cnikvi.ru
Natalya I. Ilyina, MD, Dr. Sci. (Med.), Professor; ORCID: https://orcid.org/0000-0002-3556-969X; eLibrary SPIN: 6715-5650; e-mail: instimmun@yandex.ru

Anna A. Alekseeva, MD, Cand. Sci. (Med.); ORCID: https://orcid.org/0000-0002-8023-2543; eLibrary SPIN: 7253-7970; e-mail: aleksaa06@yandex.ru

Eduard T. Ambarchian, MD, Cand. Sci. (Med.); ORCID: http:/orcid.org/0000-0002-8232-8936; eLibrary SPIN: 4878-5562; e-mail: edo_amb@mail.ru

\section{Sofya I. Artemyeva;}

ORCID: https://orcid.org/0000-0002-2793-8862;

eLibrary SPIN: 2627-9842; e-mail: sofya.chern@gmail.com

Mark I. Arshinskiy,

ORCID: https://orcid.org/0000-0003-2952-9082;

eLibrary SPIN: 1821-9471; e-mail: kkvd80@inbox.ru

Natalia G. Astafyeva, MD, Dr. Sci. (Med.), Professor; ORCID: https://orcid.org/0000-0002-7691-4584; eLibrary SPIN: 9941-7013; e-mail: astang@mail.ru

Elena A. Vishneva, MD, Dr. Sci. (Med); ORCID: https://orcid.org/0000-0001-7398-0562; eLibrary SPIN: 1109-2810; e-mail:vishneva.e@yandex.ru

Vladimir A. Volnukhin, MD, Dr. Sci (Med), Professor; ORCID: https://orcid.org/0000-0002-8363-5188; eLibrary SPIN: 8206-2731; e-mail: vvoln@rambler.ru

Inna V. Danilycheva, MD, Cand. Sci. (Med.); ORCID: http://orcid.org/0000-0002-8279-2173; eLibrary SPIN: 4547-3948; e-mail: ivdanilycheva@mail.ru

Roman V. Epishev, MD, Cand. Sci. (Med.); ORCID: https://orcid.org/0000-0002-4107-4642; eLibrary SPIN: 5162-7846; e-mail: drepishev@gmail.com

Aleksandr V. Zhestkov, MD, Dr. Sci. (Med.), Professor; ORCID htts://orcid.org/0000-0002-3960-830X; eLibrary SPIN: 2765-9617; e-mail: avzhestkov2015@yandex.ru

Maryana B. Zhilova, MD, Dr. Sci. (Med.);

ORCID: https://orcid.org/0000-0003-2545-2129;

eLibrary SPIN: 8930-4073; e-mail: zhilova@cnikvi.ru

Olga V. Zhukova, MD, Dr. Sci. (Med.), Professor; ORCID: https://orcid.org/0000-0001-5723-6573; eLibrary SPIN: 8584-7564, e-mail: klinderma@inbox.ru

Denis V. Zaslavsky, MD, Dr. Sci. (Med.), Professor; ORCID: https://orcid.org/0000-0001-5936-6232; elibrary SPIN: 5832-9510; e-mail:venerology@gmail.com

Lyudmila F. Znamenskaya, MD, Dr. Sci. (Med.); ORCID: http://orcid.org/0000-0002-2553-0484; eLibrary SPIN: 9552-7850; e-mail: znaml@cnikvi.ru

Arfenya E. Karamova, MD, Cand. Sci. (Med.); ORCID: https://orcid.org/0000-0003-3805-8489; eLibrary SPIN 3604-6491; e-mail: karamova@cnikvi.ru 
Короткий Николай Гаврилович, д.М.Н., профессор; ORCID: https://orcid.org/0000-0002-0913-000X; eLibrary SPIN: 7319-7942; e-mail: kng40@mail.ru

Кохан Муза Михайловна, д.М.Н., профессор; ORCID:https://orcid.org/0000-0001-6353-6644; eLibrary SPIN: 3470-9306; e-mail: mkokhan@yandex.ru

Круглова Лариса Сергеевна, д.М.н., профессор; ORCID: https://orcid.org/0000-0002-5044-5265; eLibrary SPIN: 1107-4372; e-mail: kruglovals@mail.ru

Кунгуров Николай Васильевич, д.М.Н., профессор; ORCID: https//ORCID.org/0000-0002-4134-047X; eLibrary SPIN: 3903-2425; e-mail: N.kungurov@gmail.com

Левина Юлия Григорьевна, к.М.н.; ORCID: https://orcid.org/0000-0002-2460-7718; eLibrary SPIN: 4626-2800; e-mail: julia.levina@mail.ru

Львов Андрей Николаевич, д.м.Н., профессор; ORCID: https://orcid.org/0000-0002-3875-4030; eLibrary SPIN: 1053-3290; e-mail: alvov@mail.ru

Материкин Александр Игоревич, к.М.Н., ORCID: https://orcid.org/0000-0002-6034-8231; eLibrary SPIN: 5935-8090; e-mail: al_m86@bk.ru

Мишина Олеся Сергеевна, К.М.н.; ORCID: https://orcid.org/0000-0002-6415-4338; e-mail: olesya.mishina@mail.ru

Монахов Константин Николаевич, д.М.н., профессор; ORCID: https://orcid.org/0000-0002-8211-1665; eLibrary SPIN: 1837-2098, e-mail: knmonakhov@gmail.com

Мурашкин Николай Нколаевич, д.м.н.;

ORCID: http:/orcid.org/0000-0003-2252-8570;

eLibrary SPIN: 5906-9724; e-mail: m_nn2001@mail.ru

Ненашева Наталья Михайловна, д.М.Н., профрессор; ORCID: http://orcid.org/0000-0002-3162-2510; eLibrary SPIN: 3363-6170; e-mail: 1444031@gmail.com

Пампура Александр Николаевич, д.М.Н., профессор; ORCID: https://orcid.org/0000-0001-5039-8473; eLibrary SPIN: 9722-7961; e-mail: apampura1@mail.ru

Плахова Ксения Ильинична, д.м.н.;

ORCID: https://orcid.org/0000-0003-4169-4128; eLibrary SPIN 7634-5521; e-mail: plahova@cnikvi.ru

Потекаев Николай Николаевич, д.М.Н., профессор; ORCID: https://orcid.org/0000-0002-9578-5490; eLibrary SPIN: 8862-5688; e-mail: klinderma@mail.ru

Притуло Ольга Александровна, д.м.н., профрессор; ORCID: http://orcid.org/0000-0001-6515-1924; eLibrary SPIN: 2988-8463; e-mail: 55550256@mail.ru

Разнатовский Константин Игоревич, д.м.н., профрессор; ORCID: https://orcid.org/0000-0003-1022-7463; eLibrary SPIN: 4587-2393; e-mail: konstantan.r@bk.ru
Nikolay G. Korotky, MD, Dr. Sci (Med.), Professor; ORCID: https://orcid.org/0000-0002-0913-000X; eLibrary SPIN: 7319-7942; e-mail: kng40@mail.ru

Muza M. Kokhan, MD, Dr. Sci (Med.), Professor; ORCID:https://orcid.org/0000-0001-6353-6644; eLibrary SPIN: 3470-9306; e-mail: mkokhan@yandex.ru

Larisa S. Kruglova, MD, Dr. Sci. (Med.), Professor; ORCID: https://orcid.org/0000-0002-5044-5265; eLibrary SPIN: 1107-4372; e-mail: kruglovals@mail.ru

Nikolay V. Kungurov, MD, Dr. Sci. (Med.), Professor; ORCID: https//ORCID.org/0000-0002-4134-047X; eLibrary SPIN: 3903-2425; e-mail: N.kungurov@gmail.com

Julia G. Levina, MD, Cand. Sci. (Med.); ORCID: https://orcid.org/0000-0002-2460-7718; eLibrary SPIN: 4626-2800; e-mail: julia.levina@mail.ru

Andrey N. Lvov, MD, Dr. Sci. (Med.), Professor; ORCID: https://orcid.org/0000-0002-3875-4030; eLibrary SPIN: 1053-3290; e-mail: alvov@mail.ru

Alexander I. Materikin, MD, Cand. Sci. (Med.); ORCID: https://orcid.org/0000-0002-6034-8231; eLibrary SPIN: 5935-8090; e-mail: al_m86@bk.ru

Olesya S. Mishina, MD, Cand. Sci. (Med.); ORCID: https://orcid.org/0000-0002-6415-4338; e-mail:olesya.mishina@mail.ru

Konstantin N. Monakhov, MD, Dr. Sci. (Med.), Professor; ORCID: https://orcid.org/0000-0002-8211-1665;

eLibrary SPIN: 1837-2098, e-mail: knmonakhov@gmail.com

Nikolay N. Murashkin, MD, Dr. Sci. (Med.);

ORCID: http:/orcid.org/0000-0003-2252-8570;

eLibrary SPIN: 5906-9724; e-mail: m_nn2001@mail.ru

Natalia M. Nenasheva, MD, Dr. Sci. (Med.), Professor; ORCID: http://orcid.org/0000-0002-3162-2510; eLibrary SPIN: 3363-6170; e-mail: 1444031@gmail.com

Alexander N. Pampura, MD, Dr. Sci. (Med.), Professor; ORCID: https://orcid.org/0000-0001-5039-8473; eLibrary SPIN: 9722-7961; e-mail: apampura1@mail.ru

Xenia I. Plakhova, MD, Dr. Sci. (Med.);

ORCID: https://orcid.org/0000-0003-4169-4128; eLibrary SPIN 7634-5521; e-mail: plahova@cnikvi.ru

Nikolay N. Potekaev, MD, Dr. Sci. (Med.), Professor; ORCID: https://orcid.org/0000-0002-9578-5490; eLibrary SPIN: 8862-5688; e-mail: klinderma@mail.ru

Olga A. Prytulo, MD, Dr. Sci. (Med.), Professor; ORCID: http://orcid.org/0000-0001-6515-1924 eLibrary SPIN: 2988-8463; e-mail: 55550256@mail.ru

Konstantin I. Raznatovskiy, MD, Dr. Sci. (Med.), Professor; ORCID: https://orcid.org/0000-0003-1022-7463; eLibrary SPIN: 4587-2393; e-mail: konstantan.r@bk.ru 
Сапунцова Светлана Геннадьевна, К.М.Н., доцент; ORCID: https://orcid.org/0000-0001-9231-2391; eLibrary SPIN: 1875-7155;

e-mail: ssfesmu@yandex.ru

Селимзянова Лилия Робертовна, к.М.Н.; ORCID:https://orcid.org/0000-0002-3678-7939; eLibrary SPIN: 5508-1689; e-mail: lilysir@mail.ru

Скороходкина Олеся Валерьевна, д.м.н., профрессор; ORCID: https://orcid.org/0000-0001-5793-5753; eLibrary SPIN: 8649-6138; e-mail:olesya-27@rambler.ru

Феденко Елена Сергеевна, д.М.н., профессор; ORCID: https://orcid.org/0000-0003-3358-5087; eLibrary SPIN: 5012-7242; e-mail: efedks@gmail.com

Фомина Дарья Сергеевна, К.м.Н., доцент; ORCID: https://orcid.org/0000-0002-5083-6637; eLibrary SPIN: 3023-4538; e-mail: daria_fomina@mail.ru

Фриго Наталия Владиславовна, д.м.н.; ORCID: https://orcid.org/0000-0001-6231-971X; eLibrary SPIN: 7009-9991; e-mail: frigo2013@yandex.ru

\section{Фролова Зоя Вадимировна;}

ORCID: https://orcid.org/0000-0002-2633-1452; eLibrary SPIN: 9490-7107, e-mail: kkvd80@inbox.ru

Хаитов Муса Рахимович, д.М.Н., професссор, член-корреспондент РАН; ORCID: https://orcid.org/0000-0003-4961-9640; eLibrary SPIN: 3199-9803; e-mail: mr.khaitov@nrcii.ru
Svetlana G. Sapuntsova, MD, Cand. Sci. (Med.), Associate Professor;

ORCID: https://orcid.org/0000-0001-9231-2391; eLibrary SPIN: 1875-7155; e-mail: ssfesmu@yandex.ru

Liliia R. Selimzianova, MD, Cand. Sci. (Med.); ORCID:https://orcid.org/0000-0002-3678-7939; eLibrary SPIN: 5508-1689; e-mail: lilysir@mail.ru

Olesya V. Skorokhodkina, MD, Dr. Sci. (Med.), Professor; ORCID: https://orcid.org/0000-0001-5793-5753; eLibrary SPIN: 8649-6138; e-mail:olesya-27@rambler.ru

Elena S. Fedenko, MD, Dr. Sci. (Med.), Professor; ORCID: https://orcid.org/0000-0003-3358-5087; eLibrary SPIN: 5012-7242; e-mail: efedks@gmail.com

Daria S. Fomina, MD, Associate Professor;

ORCID: https://orcid.org/0000-0002-5083-6637; eLibrary SPIN: 3023-4538; e-mail: daria_fomina@mail.ru

Nataliya V. Frigo, MD, Dr. Sci. (Med);

ORCID: https://orcid.org/0000-0001-6231-971X; eLibrary SPIN: 7009-9991; e-mail: frigo2013@yandex.ru

\section{Zoya V. Frolova;}

ORCID: https://orcid.org/0000-0002-2633-1452;

eLibrary SPIN: 9490-7107, e-mail: kkvd80@inbox.ru

Musa R. Khaitov, MD, Dr. Sci. (Med.), Professor, Corresponding Member of the Russian Academy of Sciences; ORCID: https://orcid.org/0000-0003-4961-9640; eLibrary SPIN: 3199-9803; e-mail: mr.khaitov@nrcii.ru 